\title{
Air Toxics Provisions of the Clean Air Act: Potential Impacts on Energy
}

Environmental Assessment and Information Sciences Division Argonne National Laboratory

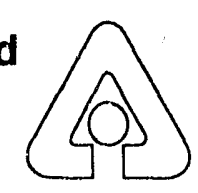

Operated by The University of Chicago, under Contract W-31-109-Eng-38, for the

United States Department of Energy 


\section{Argonne National Laboratory}

Argonne National Laboratory, with facilities in the states of Illinois and Idaho, is owned by the United States govemment, and operated by the University of Chicago under the provisions of a contract with the Department of Energy.

This technical memo is a product of Argonne's Environmental Assessment and Information Sciences (EAIS) Division. For information on the division's scientific and engineering activities, contact:

Director, Environmental Assessment and

Information Sciences Division

Argonne National Laboratory

Argonne, Illinois 60439-4815

Telephone (708) 252-3759

Presented in this technical memo are preliminary results of ongoing work or work that is more limited in scope and depth than that described in formal reports issued by the EAIS Division.

\section{Disclaimer}

This report was prepared as an account of work sponsored by an agency of the United States Govemment. Neither the United States Government nor any agency thereof, nor any of their employees, makes any warranty, express or implied, or assumes any legal liability or responsibility for the accuracy, completeness, or usefulness of any information, apparatus, product, or process disclosed, or represents that its use would not infringe privately owned rights. Reference herein to any specific commercial product, process, or service by trade name, trademark, manufacturer, or otherwise, dous not necessarily constitute or imply its endorsement, recommendation, or favoring by the United States Govemment or any agency thereof. The views and opinions of authors expressed herein do not necessarily state or reflect those of the United States Govemment or any agency thereof.

Available to DOE and DOE contractors from the Office of Scientific and Technical Information, P.O. Box 62 , Oak Ridge, TN 37831; prices available from (615) 576-8401, FTS 626-8401.

Available to tive public from the National Technical Information Service, U S. Department of Commerce, 5285 Port Royal Road, Springfield, VA 22161. 


\section{Air Toxics Provisions of the Clean Air Act: Potential Impacts on Energy}

by H.A. Hootman and J.E. Vernet*

Policy and Economic Analysis Group,

Environmental Assessment and Information Sciences Division,

Argonne National Laboratory, 9700 South Cass Avenue, Argonne, Illinois 60439

November 1991

Work sponsored by United States Department of Energy,

Office of the Deputy Under Secretary for Policy, Planning and Analysis,

Office of Environmental Analysis

"Vernet is affiliated with the sponsoring office. 


\section{CONTENTS}

ACKNOWLEDGMENTS $\ldots \ldots \ldots \ldots \ldots \ldots \ldots \ldots \ldots \ldots \ldots \ldots \ldots$ viii

NOMENCLATURE $\ldots \ldots \ldots \ldots \ldots \ldots \ldots \ldots \ldots \ldots \ldots \ldots \ldots \ldots \ldots$

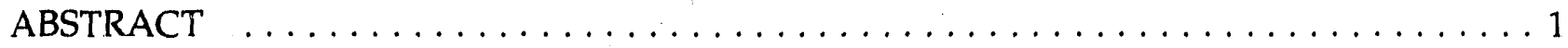

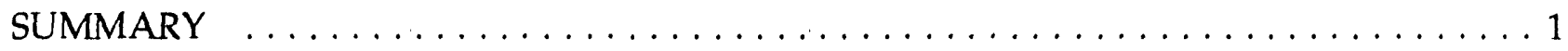

1 INTRODUCTION $\ldots \ldots \ldots \ldots \ldots \ldots \ldots \ldots \ldots \ldots \ldots \ldots \ldots \ldots \ldots$

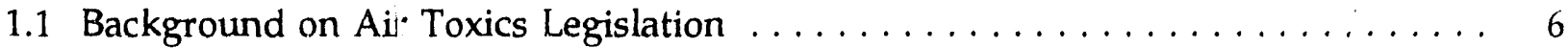

1.2 Comparison of Prsposed Legislation on Air Toxics $\ldots \ldots \ldots \ldots \ldots$

1.3 Energy-Related Suurces Identified in the EFA Draft Source Category List . . . . . 8

1.4 Energy-Related Sources of High-Risk Hazardous Air Pollutants . . . . . . . . . 17

2 NEAR-TERM IMPLEMENTATION OF AIR TOXICS REGULATIONS . . . . . . . . 22

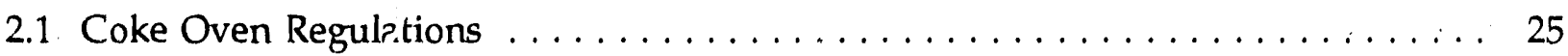

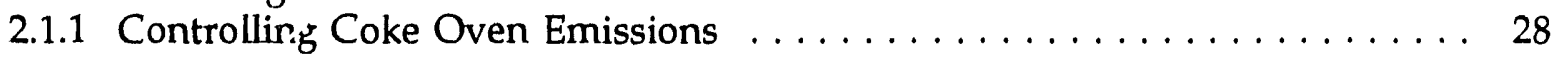

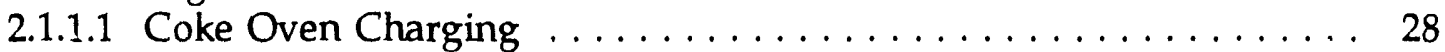

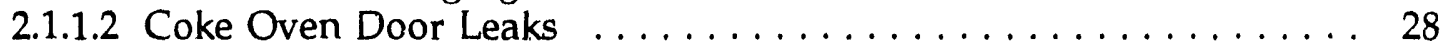

2.1.1.3 Topside Leaks . . . . . . . . . . . . . . . . . . . . . 29

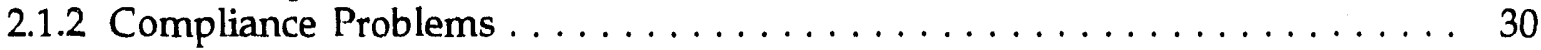

2.1.3 Economic Position of the Coke Industry $\ldots \ldots \ldots \ldots \ldots \ldots \ldots \ldots \ldots \ldots$

2.2 Chromium from Industrial Cooling Towers $\ldots \ldots \ldots \ldots \ldots \ldots \ldots \ldots \ldots \ldots$

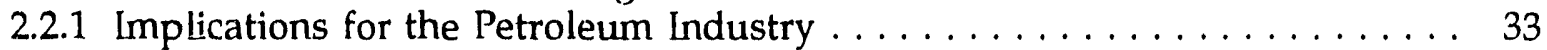

2.2.2 Alternatives to Chromate-Based Water Treatment . . . . . . . . . . . 36

2.2.3 Interaction of Potential Chromium Electroplating and

Cooling Tower Regulations ....................... 39

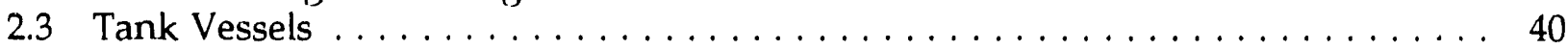

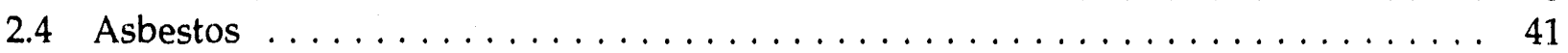

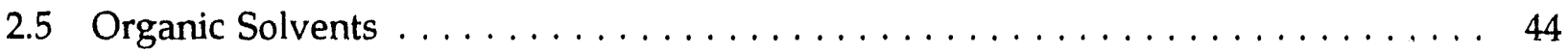

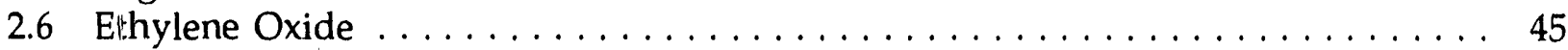

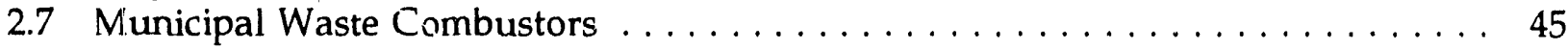

2.7.1 Title III Provisions Pertaining to Municipal Waste Combustors . . . . . . . . 47

2.7.2 Status of Municipal Waste Combustor Rulemaking . . . . . . . . . . . 48

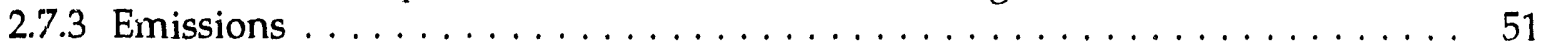

3 IMPLICATIONS OF AIR TOXICS REGULATIONS FOR

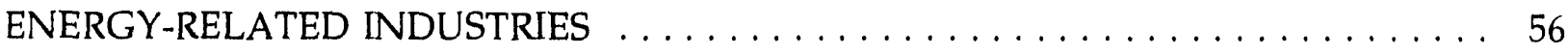

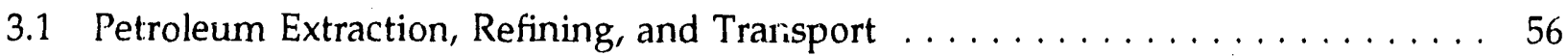

3.1.1 Title III Provisions Pertaining to the Petroleum Industry . . . . . . . . . . 59

3.1.2 Hazardous Air Pollutant Emissions from the Petroleum Industry . . . . . . 60

3.1.3 Mobile Source Provisions as They Affect Petroleum Refining . . . . . . . . 61

3.1.3.1 Reformulated Gasoline and Oxygenated Gasoline Requirements . . . 62

3.1.3.2 Mobile-Source-Related Air Toxics . . . . . . . . . . . . . . . 63 


\section{CONTENTS (Cont'd)}

3.1.3.3 Clean Fuel Vehicles ......................... 63

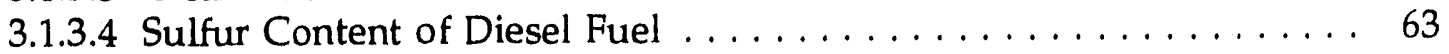

3.2 Coal Mining, Preparation, and Distribution .................... 64

3.3 Natural Gas Extraction, Preparation, and Distribution $\ldots \ldots \ldots \ldots \ldots \ldots \ldots 66$

3.4 Electric Utilities ................................. 66

3.4 .1 Fossil Fuel Variability $\ldots \ldots \ldots \ldots \ldots \ldots \ldots \ldots \ldots \ldots \ldots \ldots$

3.4.2 Hazardous Air Pollutant Emissions from Utilities . . . . . . . . . . . 69

3.4.2.1. Emissions of Hydrogen Chloride $\ldots \ldots \ldots \ldots \ldots \ldots \ldots \ldots . \ldots \ldots$

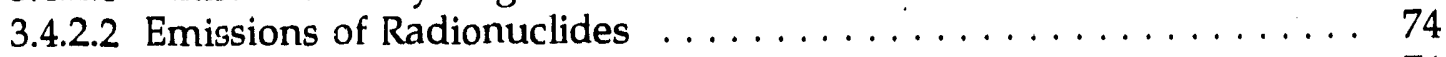

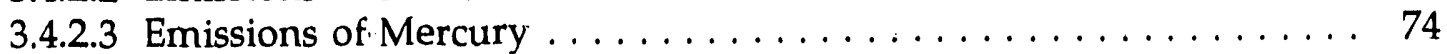

3.5 Uranium Processing and Production $\ldots \ldots \ldots \ldots \ldots \ldots \ldots \ldots \ldots \ldots \ldots$

3.5.1 Radionuclide Emissions from Uranium Production and Processing . . . . . 76

3.5.2 Radionuclide Control Techniques for Uranium Production . . . . . . . . 79

4 OVERVIEW AND ASSESSMENT OF AIR TOXICS DATABASES $\ldots \ldots \ldots \ldots \ldots$.

4.1 Toxic Release Inventory $\ldots \ldots \ldots \ldots \ldots \ldots \ldots \ldots \ldots \ldots \ldots \ldots \ldots$

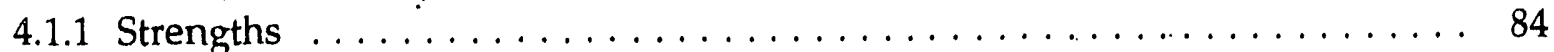

4.1 .2 Limitations ............................. 84

4.1 .3 Status and Technical Capabilities . . . . . . . . . . . . . . . 86

4.2 Power Plant Integrated Systems: Chemical Emissions Studies . . . . . . . . . . 86

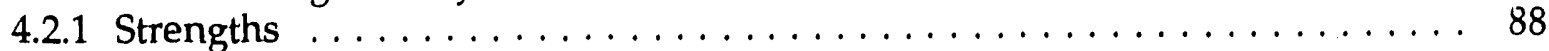

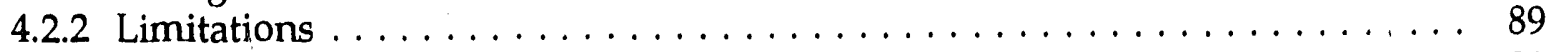

4.2.3 Status and Technical Capabilities . . . . . . . . . . . . . . . . . 89

4.3 The 1985 NAPAP Emissions Inventory $\ldots \ldots \ldots \ldots \ldots \ldots \ldots \ldots \ldots \ldots \ldots . \ldots \ldots$

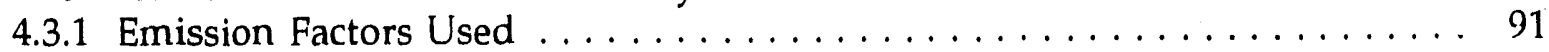

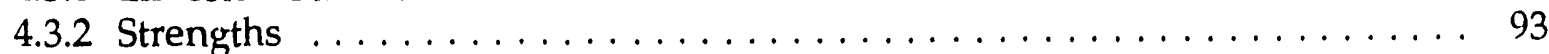

4.3 .3 Limitations ............................... 93

4.3.4 Status and Technical Capabilities . . . . . . . . . . . . . . . . . . 94

4.4 Particulate Matter Species Manual $\ldots \ldots \ldots \ldots \ldots \ldots \ldots \ldots \ldots \ldots . \ldots \ldots . \ldots \ldots$

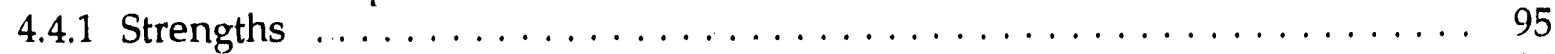

4.4 .2 Limitations ............................. 96

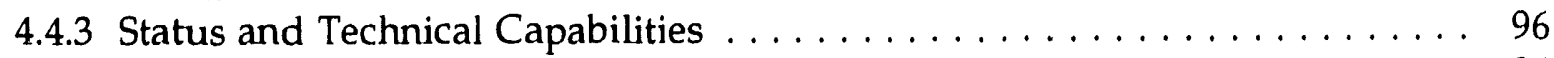

4.5 Toxics Emission Inventory Database $\ldots \ldots \ldots \ldots \ldots \ldots \ldots \ldots \ldots \ldots \ldots$

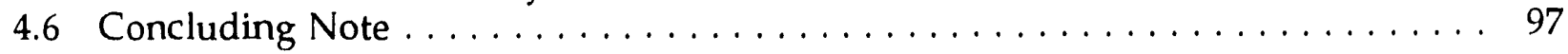

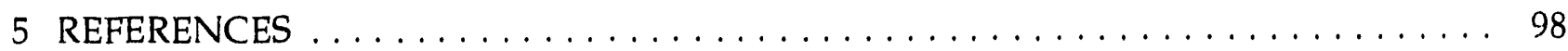

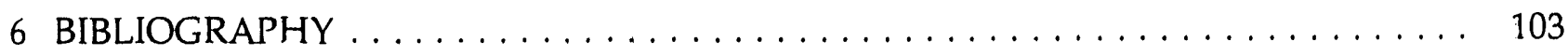

APPENDIX: Emission Control Technologies for Municipal Waste Combustors … . . 107 


\section{FIGURES}

1.1 Flowchart of Air Toxics Regulatory Procedures in 1990 Clean Air Act Amendments ................................ 7

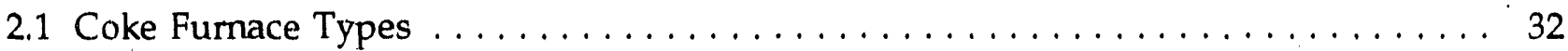

2.2 Pollution Abatement Expenditures and Corporate Profits for the Primary

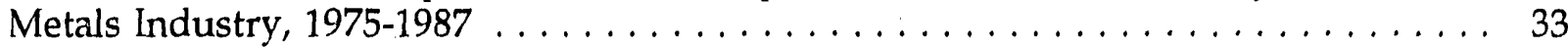

2.3 Distribution of Industrial Cooling Towers by Industry $\ldots \ldots \ldots \ldots \ldots \ldots \ldots$

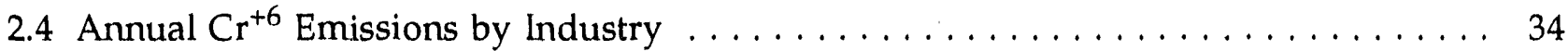

3.1 American Petroleum Institute's Estimates of the Total Cost of Complying with the Clean Air Act Amendments $\ldots \ldots \ldots \ldots \ldots \ldots \ldots \ldots \ldots \ldots \ldots \ldots$

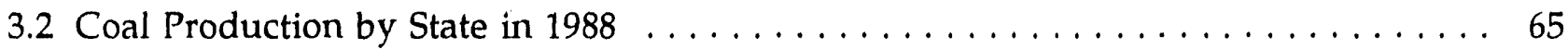

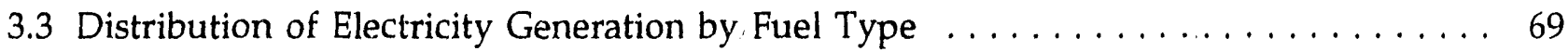

3.4 Net Generation by Energy Source $\ldots \ldots \ldots \ldots \ldots \ldots \ldots \ldots \ldots \ldots \ldots \ldots$

3.5 Mine Production of Uranium by State, $1968-1988 \ldots \ldots \ldots \ldots \ldots \ldots \ldots \ldots$

4.1 Top Ten Chemicals Emitted in 1987 according to TRI Database . . . . . . . . . . 83

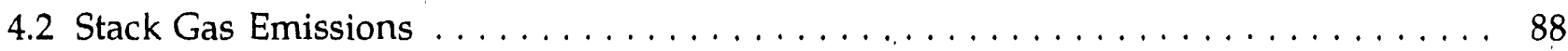

\section{TABLES}

1.1 Clean Air Act Amendments of 1990: A Merger of U.S. House and Senate Bills . . ... 9

1.2 Energy-Related Industries Identified in the EPA Draft Source Category List . . . . 14

1.3 Data Quality Ratings Assigned to Fuel Combustion Industry Groups . . . . . . . 18

1.4 High-Risk Pollutants and Corresponding Weighting Factors $\ldots \ldots \ldots \ldots \ldots \ldots$

2.1 Air Toxics Regulations Slated for the Near Term $\ldots \ldots \ldots \ldots \ldots \ldots \ldots \ldots$

2.2 Emissions Targeted in the EPA Voluntary Industrial Toxics Project . . . . . . . 26

2.3 Characterization of Industrial Cooling Towers $\ldots \ldots \ldots \ldots \ldots \ldots \ldots \ldots \ldots$

2.4 Costs and Cost Effectiveness of Improved Chromium Control . . . . . . . . . . 38 


\section{TABLES (Cont'd)}

2.5 Estimated Nationwide Annual VOC Emissions from Tank Vessels . . . . . . . . . . 41

2.6 Preliminary Tank Vessel Regulatory Alternatives

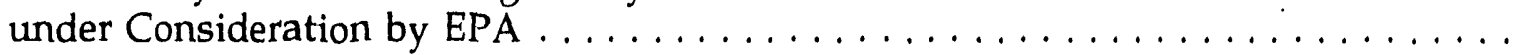

2.7 Comparison of Three Methods for Controlling VOC Emissions

from Tank Vessels

2.8 Effectiveness and Energy Requirements of Selected Control Technique Combinations for Organic Solvent Cleaners $\ldots \ldots \ldots \ldots \ldots \ldots \ldots$

2.9 Emission Standards for Municipal Waste Combustors Established under the Section 111 Rule . . . . . . . . . . . . . . . . . . . . . . . . . .

2.10 Emissions from Municipal Waste' Combustors According to Different

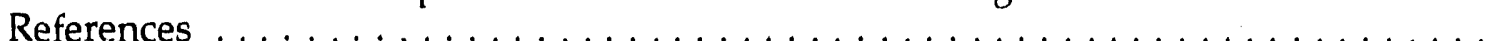

2.11 Design Considerations for Advanced Pollution Control Systems Being Retrofit on Municipal Solid-Waste Incinerators $\ldots \ldots \ldots \ldots \ldots \ldots \ldots \ldots$

3.1 Mean Concentrations of Trace Elements in U.S. Coals by Region . . . . . . . . . . 57

3.2 Ranges of Selected Pollutants in Oil $\ldots \ldots \ldots \ldots \ldots \ldots \ldots \ldots \ldots$

3.3 Hazardous Air Pollutants Released by Various Sectors

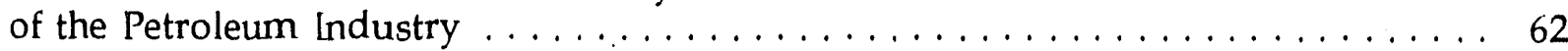

3.4 Potential Emissions from Coal Storage and Handling $\ldots \ldots \ldots \ldots \ldots \ldots$

3.5 Chemicals thai Can Be Emitted during Oil and Gas Extraction, Production,

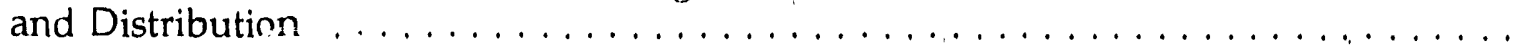

3.6 Ranges of Selected Pollutants in Coals . . . . . . . . . . . . . . . . . . . . . . 70

3.7 Hazardous Air Pollutants Emitted from Fossil-Fuel-Fired Utilities, by Fuel Type $\ldots \ldots \ldots \ldots \ldots \ldots \ldots \ldots \ldots \ldots \ldots \ldots \ldots \ldots$

3.8 Hazardous Air Pollutants in Fossil-Fuel-Fired Utility Emissions Identified by EPRI and EPA

3.9 Profile of 12 Hazardous Air Pollutants Emitted from the Ottumwa Generating Station

3.10 Radionuclide Emissions from Typical Coal-Fired Utilities and Corresponding Cancer Risks 


\section{TABLES (Cont'd)}

3.11 Estimated Distribution of the Fatal Cancer Risk from Uranium Mills

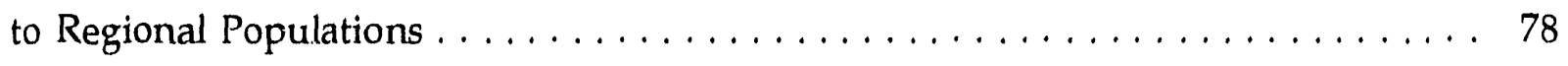

4.1 Characterization of Databases $\ldots \ldots \ldots \ldots \ldots \ldots \ldots \ldots \ldots \ldots \ldots \ldots, \ldots \ldots \ldots$

4.2 Ten Worst Emitting States according to TRI Database $\ldots \ldots \ldots \ldots \ldots \ldots \ldots$

4.3 Hydrogen Chloride and Hydrogen Fluoride Emission Factors $\ldots \ldots \ldots \ldots . . \ldots 2$ 


\section{ACKNOWLEDGMENTS}

The authors wish to thank Frank Stodolsky for his input on the effects of mobile source provisions on hazardous air pollutants from petroleum refining, David Streets for technical guidance and text improvements, and Marita Moniger for editorial input. The authors also wish to acknowledge the continued support of Ted Williams, in the U.S. Department of Energy's Office of Environmental Analysis, for analyses of the impacts of the Clean Air Act on energy development. 


\section{NOMENCLATURE}

\section{ABBREVIATIONS, ACRONYMS, AND CHEMICAL NAMES}

AE

AERAM

AHERA

AP

ASME

BACT

BDT

BSO

CAA

CAAA

CERCLA

CFC-113

$\mathrm{CO}$

$\mathrm{CO}_{2}$

COE

$\mathrm{Cr}^{+6}$

$\mathrm{CrO}_{4}$

DOE

DSI

DEHP

$E \& P$

$\mathrm{ECB}$

EEI

EIA

EPA

EO

EPRI

ESP

ETBE

FF

FID

FGD

FPA

FREDS

FSI

GACT

GC

GEP after enactment

Airborne Emissions Risk Assessment Model

Asbestos Hazard Emergency Response Act of 1986

American Petroleum Institute

American Society of Mechanical Engineers

best available $c_{1}$,ntrol technology

best demonstrated technology

benzene soluble organic

Clean Air Act

Clean Air Act Amendments

Comprehensive Environmental Response, Compensation, and Liability Act trichlorofluoroetharie carbon monoxide

carbon dioxide

coke oven emissions

hexavalent chromium

chromate

U.S. Department of Energy

duct sorbent injection

bis(2-ethylhexyl)phthalate

extraction and production

external combustion boiler

Edison Electric Institute

Energy Information Administration

U.S. Environmental Protection Agency

ethylene oxide

Electric Powis Research Institute

electrostatic precipitator

ethyl tertiary butyl etner

fabric filter

flame ionization detection

flue-gas desulfurization

Federal Power Act

Flexible Regional Ernissions Data System

furnace sorbent injection

generally achievable control technology

gas chromatograph

good engineering practice 


\begin{tabular}{|c|c|}
\hline $\begin{array}{l}\text { HAP } \\
\mathrm{HC} \\
\mathrm{HCl} \\
\mathrm{HDS} \\
\text { HEDE } \\
\text { HEFF } \\
\mathrm{HF} \\
\mathrm{Hg} \\
\mathrm{H}_{2} \mathrm{~S} \\
\mathrm{HVAC}\end{array}$ & $\begin{array}{l}\text { hazardous air pollutant } \\
\text { hydrocarbons } \\
\text { hydrogen chloride (hydrochloric acid) } \\
\text { hydrodesulfurization } \\
\text { high-efficiency drift eliminator } \\
\text { high-efficiency fabric filter } \\
\text { hydrogen fluoride } \\
\text { mercury } \\
\text { hydrogen sulfide } \\
\text { heating, ventilation, and air conditioning }\end{array}$ \\
\hline $\begin{array}{l}\text { ICE } \\
\text { ICT }\end{array}$ & $\begin{array}{l}\text { internal combustion engine } \\
\text { industrial cooling tower }\end{array}$ \\
\hline $\begin{array}{l}\text { LAER } \\
\text { LEDE }\end{array}$ & $\begin{array}{l}\text { lowest achievable emission rate } \\
\text { low-efficiency drift eliminator }\end{array}$ \\
\hline $\begin{array}{l}\text { MACT } \\
\text { MC } \\
\text { MDI } \\
\text { MDT } \\
\text { MEI } \\
\text { MS } \\
\text { MSW } \\
\text { MTBE } \\
\text { MWC } \\
\text { MWC II } \\
\text { MWC III }\end{array}$ & $\begin{array}{l}\text { maximum achievable control technology } \\
\text { methylene chloride } \\
\text { methylene diphenyl diisocyanate } \\
\text { maximum demonstrated temperature } \\
\text { maximally exposed individual } \\
\text { mass spectroscopy } \\
\text { municipal solid waste } \\
\text { methyl tertiary butyl ether } \\
\text { municipal waste combustor } \\
\text { rules for }>250 \text {-TPD MWCs due in November } 1991 \\
\text { rules for } \leq 250 \text {-TPD MWCs due in November } 1992\end{array}$ \\
\hline $\begin{array}{l}\text { NAAQS } \\
\text { NAPAP } \\
\text { NATICH } \\
\text { NAS } \\
\text { NASA } \\
\text { NECRMP } \\
\text { NEDS } \\
\text { NESHAP } \\
\mathrm{NH}_{3} \\
\mathrm{NIEHS} \\
\mathrm{NMHC}^{\text {NO }} \\
\text { NRC } \\
\text { NSPS } \\
\text { NTSB }\end{array}$ & $\begin{array}{l}\text { National Ambient Air Quality Standards } \\
\text { National Acid Precipitation Assessment Program } \\
\text { National Air Toxics Information Clearinghouse } \\
\text { National Academy of Sciences } \\
\text { National Aeronautics and Space Administration } \\
\text { Northeast Corridor Regional Modeling Project } \\
\text { National Emissions Data System } \\
\text { National Emission Standards for Hazardous Air Pollutants } \\
\text { ammonia } \\
\text { National Institute of Environmental Health Sciences } \\
\text { nonmethane hydrocarbons } \\
\text { nitrogen oxides } \\
\text { U.S. Nuclear Regulatory Commission } \\
\text { New Source Performance Standards } \\
\text { National Transportation Safety Board }\end{array}$ \\
\hline $\begin{array}{l}\text { O\&M } \\
\text { OPEC } \\
\text { OSHA } \\
\text { OTVC }\end{array}$ & $\begin{array}{l}\text { operation and maintenance } \\
\text { Organization of Petroleum Exporting Countries } \\
\text { Occupational Safety and Health Administration } \\
\text { open-top vapor cleaner }\end{array}$ \\
\hline
\end{tabular}




\begin{tabular}{|c|c|}
\hline PCE & perchloroethylene \\
\hline PISCES & Power Plant Integrated Systems: Chemical Emissions Studies \\
\hline PM & particulate matter \\
\hline POM & polycyclic organic matter \\
\hline PSD & prevention of significant deterioration \\
\hline RCRA & Resource Conservation and Recovery Act \\
\hline RDF & refuse-derived fuel \\
\hline Rvp & Reid vapor pressure \\
\hline SCC & source classification rode \\
\hline SIC & standard industrial classification \\
\hline SD & spray dryer \\
\hline SDA & spray dryer application \\
\hline SNCR & selective noncatalytic reduction \\
\hline $\mathrm{SO}_{2}$ & sulfur dioxide \\
\hline SOCMI & synthetic organic chemicals manufacturing industry \\
\hline TAME & tertiary amyl methyl ether \\
\hline TAP & toxic air pollutant \\
\hline TCA & 1,1,1-trichloroethane \\
\hline TCE & trichloroethylene \\
\hline Th & thorium \\
\hline $\mathrm{THC}$ & total hydrocarbons \\
\hline TRI & toxic release inventory \\
\hline TSCA & Toxic Substances Control Act \\
\hline TSP & total suspended particulates \\
\hline U & uranium \\
\hline USX & United States Steel Corp. \\
\hline V & vanadium \\
\hline VOC & volatile organie compound \\
\hline WESI & Wheelabrator Environmental Systems Inc. \\
\hline
\end{tabular}

UNITS OF MEASURE

$\begin{array}{ll}\text { bbl } & \text { barrel } \\ \mathrm{d} & \text { day } \\ \mathrm{dscm} & \begin{array}{l}\text { dry standard cubic meter } \\ \text { dscf }\end{array} \\ \mathrm{ft} & \text { foot } \\ \mathrm{ft}^{2} & \text { square foot } \\ \mathrm{g} & \text { gram } \\ \mathrm{GW} & \text { gigawatt }\end{array}$




\begin{tabular}{|c|c|}
\hline $\mathrm{h}$ & hour \\
\hline in. & inch \\
\hline $\mathrm{kg}$ & kilogram \\
\hline $\mathrm{kn}$ & kilometer \\
\hline $\mathrm{kWh}$ & kilowatt-hour \\
\hline $\mathrm{L}$ & liter \\
\hline lb & pound \\
\hline $\mathrm{m}$ & meter \\
\hline $\mathrm{m}^{3}$ & cubic meter \\
\hline $\mathrm{mCi}$ & millicurie \\
\hline $\mathrm{mg}$ & milligram \\
\hline $\mathrm{Mg}$ & megagram \\
\hline $\min$ & minute \\
\hline MW & megawatt \\
\hline MWe & megawatt electric \\
\hline ng & nanogram \\
\hline $\mathrm{nm}_{3}$ & nanometer \\
\hline $\mathrm{nm}^{3}$ & cubic nanometer \\
\hline ppm & parts per million \\
\hline ppmv & parts per million by volume \\
\hline psi & pounds per square inch \\
\hline psia & pounds per square inch absolute \\
\hline $\mathrm{t}$ & metric ton $(2200 \mathrm{lb})$ \\
\hline ton & short ton $(2000 \mathrm{lb})$ \\
\hline TPD & short tons per day \\
\hline TPY & short tons per year \\
\hline$\mu g$ & microgram \\
\hline vol. $\%$ & volume percent \\
\hline $\mathrm{yr}$ & ear \\
\hline
\end{tabular}




\title{
AIR TOXICS PROVISIONS OF THE CLEAN AIR ACT: POTENTIAL IMPACTS ON ENERGY
}

\author{
by
}

\author{
H.A. Hootman and J.E. Vernet
}

\begin{abstract}
This report provides an overview of the provisions of the Clean Air Act and its Amendments of 1990 that identify hazardous air pollutant (HAP) emissions and address their regulation by the U.S. Environmental Protection Agency (EPA). It defines the major energy sector sources of these HAPs that would be affected by the regulations. Attention is focused on regulations that would cover coke oven emissions; chromium emissions from industrial cooling towers and the electroplating process; HAP emissions from tank vessels, asbestosrelated activities, organic solvent use, and ethylene oxide sterilization; and emissions of air toxics from municipal waste combustors. The possible implications of Title III regulations for the coal, natural gas, petroleum, uranium, and electric utility industries are examined. The report discusses five major databases of HAP emissions: (1) TRI (EPA's Toxic Release Inventory); (2) PISCES (Power Plant Integrated Systems: Chemical Emissions Studies developed by the Elertric Power Research Institute); (3) 1985 Emissions Inventory on volatile organic. compounds (used for the National Acid Precipitation Assessment Program); (4) Particulate Matter Species Manual (EPA); and (5) Toxics Emission Inventory (National Aeronautics and Space Administration). It also offers information on emission control technologies for municipal waste combustors.
\end{abstract}

\section{SUMMARY}

This report provides an overview of prospective federal regulation of hazardous air pollutants (HAPs) emitted by energy sector sources, including a discussion of relevant statutory provisions and regulatory developments. Descriptions of significant energy-related source categories (industries, activities, processes, technologies, or other sources of HAP emissions) are presented, along with a discussion of data availability and emission control technologies. The report als;o describes major databases of HAP emissions.

\section{LEGISLATIVE AND REGULATORY BACKGROUND}

The Clean Air Act Amendments of 1990 (the Amendments; Public Law 101-549, November 15, 1990) comprise the first substantial revision to the U.S. air quality statute since 1977. Among the Amendments' comprehensive provisions is a total revamping of the federal regulatory program for HAPs. Title III of the Amendments designates 189 chemical substances 
as HAPs, and it requires emissions of these substances to be regulated by the U.S. Environmental Protection Agency (EPA). Under pre-1990 legislative authority, EPA had regulated the emissions of only eight of these substances from only selected source categories.

Title III of the Amendments also provides a regulatory framework for control of a list of specified substances deemed by Congress to be hazardous to human health or the environment when released to the ambient air. This list is subject to regulatory revision by the EPA. Control of these emissions is to be accomplished through a two-phase program. In th: first phase, sources will be required to comply with technology-based control requirements set according to industrial category. In the second phase, an evaluation of the risk remaining from major HAP emission sources after they have complied with the technology standards will be done; it may result in the subsequent imposition of stricter emission limitations if the residual risk is unacceptably high.

In addition to addressing general emission control requirements for major sources of HAPs, Title $\pi$ addresses area sources of HAPs. It also requires EPA to develop a program to prevent and control accidental releases to the air of extremely hazardous substances. Municipal waste combustors, coke ovens, and electric utility steam generating units are afforded special treatment under Title III as well.

\section{REGULATION OF EMISSION SOURCE CATEGORIES UNDER TITLE III}

The report provides detailed information on certain HAP emission source categories, for which EPA regulations under Title III are scheduled for publication in the early 1990s (either under category-specific statutory deadlines or because EPA began regulatory development work before the Amendments were passed). The sources are coke ovens, dry-cleaning, industrial cooling towers, tank vessels, asbestos-related activities, organic solvents, ethylene dioxide sterilization, and municipal waste combustion. Because studies of these categories had been done before the Amendments were passed, better data were available for these categories than for many other source categories.

Projecting the potential energy and economic impacts that near-term regulation of HAPS from these categories could have is a complex task. For example, the interaction of two Title III requirements for controlling chromium compound emissions - from industrial cooling towers and from chromium electroplating - could result in refineries both eliminating the use of chromate to reduce corrosion in towers and assuming increased costs for replacing corrosionresistant parts. The interaction of other Clean Air Act legislative provisions on energy-related industries is illustrated by the following example. The required national regulation of unspeciated volatile organic compound (VOC) emissions from tank vessels, such as those used in petroleum and petroleum product transport, is projected to cost more than $\$ 700$ million annually. A subsequent review of the estimated 60 types of HAPs that are VOCs that may be emitted even after general VOC control is achieved could result in additional regulation of this source category under Title III.

*In December 1991, just before the printing of this report, the number changed to 188 as a result of Public Law 102-187, a technical amendment to the Clean Air Act, which deletes hydrogen sulfide from the list to correct an inadvertent clerical error. The text of this report reflects the original listing of 189 substances. 
The gaps in data on HAP emissions from much of the energy production and use sector categories, together with the wide variability in the types and amounts of trace elements in fossil fuels (which may result in H,AP emissions upon combustion), make projecting the impact of Title III on these sources difficult. For example, the constituents of coal, even when the coal is from mines within the same region, can vary by an order of magnitude.

The potential for interaction and overlap among various provisions in the Act was specifically recognized by the U.S. Congress in Title II. An example is the title's treatment of the electric utility industry, which has been estimated to emit up to 47 different HAPs. Although estimates of the quantities of HAPs emitted by a utility boiler indicate that only a few individual HAPs may be emitted in threshold amounts, chlorine emissions alone could exceed the threshold, thus necessitating the regulation of all the other HAPs emitted from this source category. Differing criteria for the threshold level for radionuclides could have the same effect.

In recognition of the impact of other provisions of the statute (such as the Title IV program for acid rain control) on the utility sector, the Amendments direct the EPA to study the HAP emissions remaining after all other control programs have been implemented and to regulate these remaining HAP emissions as appropriate and necessary. Although initial estimates of the annual cost of the possible regulation of HAPs from utilities range from $\$ 0.43$ to $\$ 11$ billion, whether this category will be regulated under Title III is highly uncertain. In addition to requiring the EPA to conduct a general electric utility study, Title III requires the EPA to study mercury emissions from the utility sector and other sources, mercury control technology, and the environmental effects of mercury emissions.

Among the other industries in the energy sector that are facing HAP regulation, the petroleum industry faces the greatest potential for regulation under the Amendments, under both the HAP provisions and the Title I and II provisions designed to control VOC and limit carbon monoxide emissions. Many petroleum industry HAPs are VOCs that might have to be limited in order to meet ambient ozone standards, depending on the geographic location of the emission source. During legislative deliberations, the industry estimated that the cost of compliance with the Amendments could approach $\$ 15$ million. The petroleum industry is estimated to release up to 47 different HAPs from various processes within its many sectors, although most of the data are based on a small number of source tests. An industry group began a major effort to enhance the quality of available data on HAP emissions from the petroleum sector, and EPA is required by the Amendments to study emissions of HAPs from motor vehicles.

\section{DATABASES ON HAZARDOUS AIR POLLUTANTS}

The report discusses the capabilities of five national databases to provide data on toxic air emissions. EPA's Toxic Release Inventory (TRI) was developed from annual self-reporting by almost 20,000 entities, which was mandated under 1986 amendments to the Superfund law. Although it is a comprehensive source of HAP data for releases of the 328 TRI chemicals, it covers only the manufacturing sector. The agriculture, mining, and electric utility industries are not covered. In addition, the reportable releases are those to any medin they are not limited to

air releases. The vastness of the inventory may provide a better cross section of pollution sources and the variances within industrial categories than other databases, but its self-reporting nature poses some quality assurance concerns. 
The Electric Power Research Institute database - Power Plant Integrated Systems: Chemical Emissions Studies (PISCES) - is now nearing completion of its first phase. It will offer comprehensive data collected from 1972 to 1988 on the speciated emissions from operating coal-, oil-, and gas-fired electricity generating units - both conventional and advanced systems. A field monitoring project, begun in May 1990, will fill data gaps and validate a computerized systems model to track the pathways of chemical substances and quantify emissions. Additional model development is underway to link risk assessment with the database. While PISCES appears promising, until the database and system are published, its methodological limitations are unknown.

The 1985 Emissions Inventory for the National Acid Precipitation Assessment Program, the National Aeronautics and Space Administration's database on the off-gassing of materials, and the EPA Particulate Matter Species Manual all offer some usefulness in HAP analysis but are limited primarily in that they are designed for other purposes. 


\section{INTRODUCTION}

Prior to the 1990 enactment of the Amendments, the Clean Air Act (CAA; 42 USC 7401) had not been amended for 13 years. Title III of the new Clean Air Act Amendments (CAAA; 104 STAT 2531) will institute vast changes in the way hazardous air pollutants (HAPs) are regulated. The new Title III requires the regulation of 189 HAPs. The U.S. Environmental Protection Agency (EPA) is required to promulgate rules for all major sources of any of these HAPs. According to the new Title III, any source emitting 10 tons per year (TPY) of one HAP or 25 TPY of a combination of HAPs will be considered "major." In contrast to the original National Emission Standards for Hazardous Air Pollutants (NESHAP), designed to protect public health to "an ample margin of safety," the new air toxics title, in its first phase, will regulate any source emitting HAPs in excess of the 10/25-TPY threshold levels, regardless of health risks. Furthermore, the accidental release section of Title III may affect energy-sector industries that emit any of the pollutants deemed "extremely hazardous." (These pollutants are not yet designated.)

Some experts believe that although the air toxics title (II) is one of the most costly titles of the clean air legislation, it could also provide great benefits to the U.S. public. However, other experts do not believe the potential benefits are great enough to justify the cost. The range of opinions regarding the potential effectiveness of Title III reflects, to some extent, the vastly divergent estimates of compliance costs that have been reported, ranging from lower-end estimates of $\$ 5$ billion to upper-end estimates of $\$ 62$ billion. (This upper-end estimate is based on compliance with both the early-phase technology-based standards and with the health-based, residual risk standards as proposed in the original Senate bill, S. 1630.) Variance among estimates depends on the assumptions used in calculating costs, and acceptance of any one of these cost estimates must therefore be premised by an understanding of these assumptions. For this reason, the qualitative aspects of potential responses to HAP legislation are explored in this report, both in terms of identifying which energy-related industries will be.affected as well as the options available to them for complying with potential regulations.

First, this report briefly discusses the legislative history of air toxics and summarizes the current Title III of the CAAA. Next, EPA's draft list of 766 source categories to potentially be regulated under Title III (EPA 1990a) is reviewed, and energy-related sources included in the list are identified. The report then identifies the source categories currently scheduled for regulation and discusses them in greater detail. Finally, the report surveys available HAP information. Major HAP databases are described in terms of their level of detail (i.e., chemical species, source types, and emission rates). In addition, the strengths and weaknesses of each database are discussed. (These discussions fluctuate in length and detail because of the different stages of development and the varying amounts of information on each available to the public.) Consistencies and inconsistencies among the databases are highlighted.

\footnotetext{
*In December 1991, just before the printing of this report, the number changed to 188 as a result of Public Law 102-187, a technical amendment to the Clean Air Act, which deletes hydrogen sulfide from the list to correct an inadvertent clerical error. The text of this report reflects the original listing of 189 substances.
} 


\subsection{BACKGROUND ON AIR TOXICS LEGISLATION}

Under the CAA of 1970, the criginal Section 112 called for the EPA to establish air toxics standards that would provide "an ample margin of safety to protect public health." This Section 112 is now widely regarded as an "abysmal failure" (Eckart 1990). EPA's inability to regulate more than eight chemicals during the ensuing 20-year period after the CAA's enactment has been attributed to the encumbering procedures that were involved in setting standards; EPA was required to develop a health-based justification (i.e., demonstration or reasonable anticipation of mortality or serious illness), publish a formal listing notice for each pollutant to be regulated, and publish within 180 days a proposed NESHAP for the listed pollutant. (The eight regulated substances were mercury, beryllium, asbestos, vinyl chloride, benzene, radionuclides, coke oven emissions, and inorganic arsenic.) In contrast to this stagnant federal air toxics program, autonomous state programs regulated a combined total of 708 different HAPs, thus demonstrating the potential magnitude of the air toxics issue.

The new approach adopted in Title II of the 1990 CAAA attempts to strengthen air toxics legislation. An often-cited problem with the original air toxics provisions was the administrative paralysis that resulted from the disagreement over how to ensure "an ample murgin of safety," particularly for pollutants with no known safe exposure threshold. The landmark vinyl chloride decision clearly underscored EPA's dilemma in prioritizing factors such as technology feasibility, economic impacts, and health assessments in the promulgation of air toxics standards. In 1987, the Washington, D.C., circuit court ruled that EPA had acted improperly in withdrawing a proposed revision to the vinyl chloride standards because EPA had factored cost and technology feasibility problems into this decision (NRDC $v$. EPA, 824 F.2d 1146 [1987]). This ruling set the stage for the current air toxics title, which circumvents EPA's dilemma by separating technology-based standards from those based on public health considerations, as shown in Figure 1.1.

Title III of the CAAA of 1990, in completely revising Section 112 of the Clean Air Act, sets a new framework for federal regulation of HAPs. This framework begins with the initial legislative identification of 189 substances as hazardous. Specific provisions detail the basis for adding or deleting substances from this list. Categories of stationary sources of listed substances in threshold amounts will have technology-based standards set in the first phase of the program. These standards under Section 112(d) are to be based on maximum achievable control technology (MACT) for each category.

During the subsequent phase, for each source category under Section 112(f), EPA's authority for further regulation reverts to health-based considerations. This section requires that EPA, after consultation with the Surgeon General, must report to Congress on the public health risks remaining (i.e., residual risks) from sources subject to regulation under the first phase of regulation. Residual risk standards will be required only if Congress fails to act on the recommendations in this report, which is due six years after enactment (AE).

Title III also establishes a Risk Assessment and Management Commission to investigate and report on the policy implications and appropriate uses of risk assessment and risk management in regulatory programs under various federal laws. (This report is due four years AE.) EPA may also adopt recommendations by the National Acaderny of Sciences (NAS), to be contained in a third report that reviews the risk assessment methodology used by the EPA to determine carcinogenic risks associated with exposure to HAPs. 


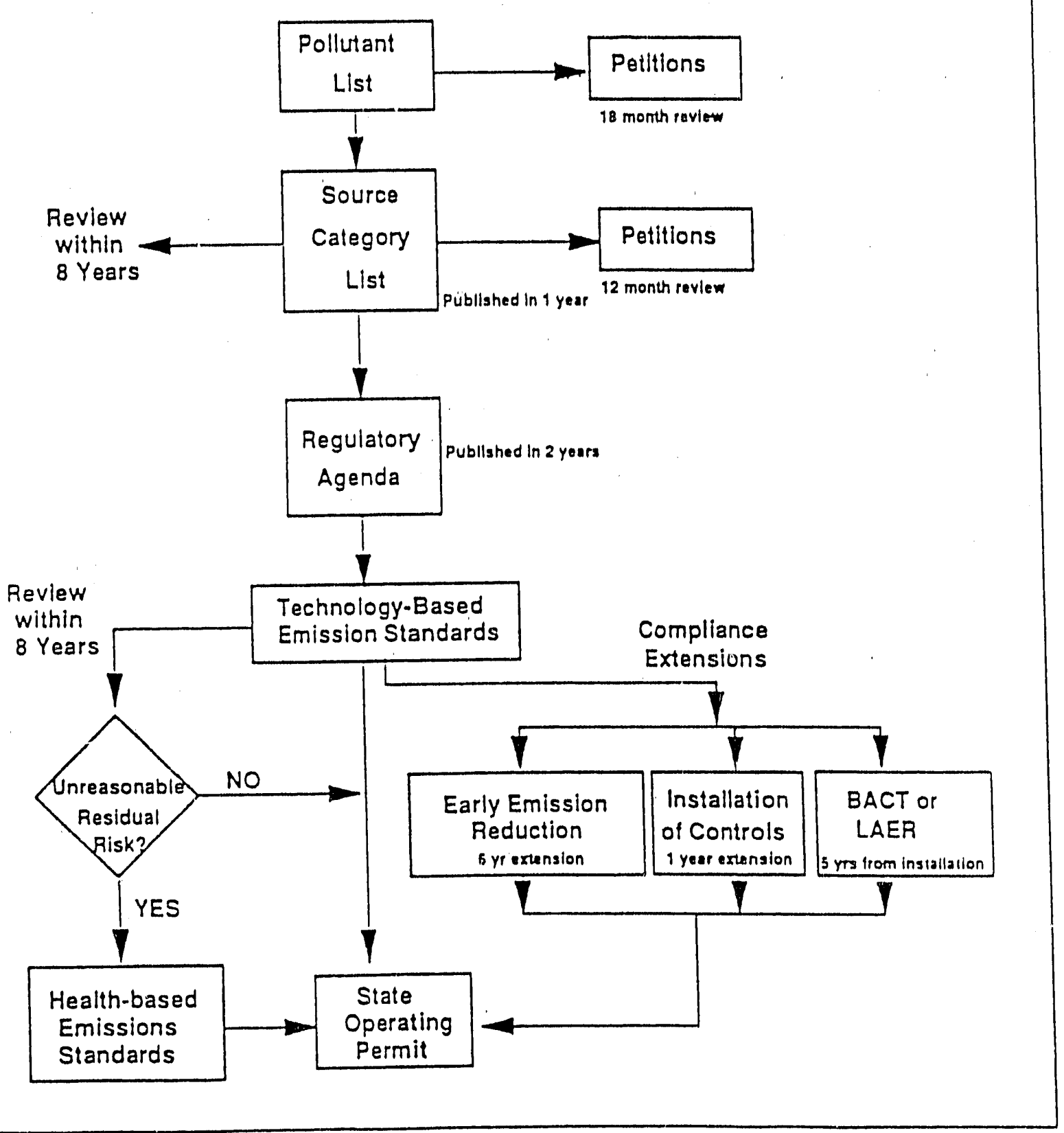

FIGURE 1.1 Flowchart of Air Toxics Regulatory Procedures in 1990 Clean Air Act Amendments (Source: NATICH Newsletter 1991)

While some statutory guidance is provided in defining an "ample margin of safety" for carcinogens (a lifetime cancer risk of more than one in a million is deemed unacceptable), there remains a sufficient amount of ambiguity in phase two of the air toxics title to cause confusion in the future and perhaps even hinder implementation. The stipulated "bright line" of one in a million in the CAAA is helpful only if risk analysis methods are agreed upon. Risk analysis, however, remains a field of much debate in the scientific community. In addition, this "bright line" limit is not to be applied to any of the noncancer health risks, thus allowing differences in the interpretation of an ample margin of safety as it pertains to other health effects. Although the statute does not require that a risk level be established before requiring MACT, the source may conduct a risk assessment in an effort to obtain an alternative emissions limitation. 
Critics of the technology-based approach claim that it weighs technology costs too heavily and deemphasizes health risks in determining which control measures to implement. Furthermore, answers to controversial questions, such as how to measure public exposure to chemicals and how to assess their associated health risks, are postponed rather than answered in the CAAA of 1990. Nevertheless, proponents of the new air toxics title contend that the technology-based approach contained in the CAAA at least provides a starting point from which to reduce emissions while the health-based standards continue to be debated.

\subsection{COMPARISON OF PROPOSED LEGISLATION ON AIR TOXICS}

The U.S. Senate and House both passed comprehensive clean air bills in 1990. While the House and Senate air toxics provisions were structurally similar, specific details varied, as shown in Table 1.1. The general structure of these bills resembled legislation introduced by President Bush the previous year. Conference committee negotiations reconciled differences between the House and Senate versions and yielded a compromise bill on October 22, 1990. The President signed the CAA Conference Committee bill (S. 1630) into law on November 8, 1990, and this legislation is described in the third column of Table 1.1.

The CAAA of 1990 is basically a hybrid of two bills passed during the 101st Congress. The Amendments were, to a great extent, fashioned after the amended version of S. 1630 that the Senate passed or April 3, 1990, and they also incorporated parts of the House bill, which was heavily based on a previous bill, H.R. 3030.

\subsection{ENERGY-RELATED SOURCES IDENTIFIED IN THE EPA DRAFT SOURCE CATEGORY LIST}

The CAAA of 1990 requires EPA to list both "major source" and "area source" catagories. A major source is defined as any stationary source of air pollution (including all emission points and units located within a contiguous area and unde $i$ common control) that emits, in the aggregate, 10 TPY or more of a single HAP or 25 TPY or more of any combination of HAPs. An area source is defined as any stationary source of HAPs that is not a major source (EPA 1990a). In other words, an area source is a stationary source that emits any of the 189 chemicals in any amount less than the major source threshold levels.

The draft source category list is currently under review; the final initial list is due in November 1991. EPA will be required to promulgate MACT standards for the categories in the final list on a phased schedule over the period that extends from 2 to 10 years after enactment. The first draft list of December 1990 (EPA 1990a) included 766 source categories, consisting of 18 broad industrial groups. Of these broad industrial groups, those that are directly related to energy include fuel combustion, petroleum refineries, petroleum and gasoline production and marketing, and radionuclide emitters. However, the majority of the source categories (440 of 766) fell within the synthetic organic chemicals manufacturing industry (SOCMI). The draft list also included many other broad industrial groups, which are perhaps indirectly related to energy insofar as they consume energy, but which are not within the scope of this report. These other broad industry groups included minerals processing, surface coating processing, metallurgical industry, and a miscellaneous group composed of sources such as pulp and paper production, asphalt roof manufacturing, dry cleaning, cold cleaning, fabric dyeing, and solvent extraction processes. 


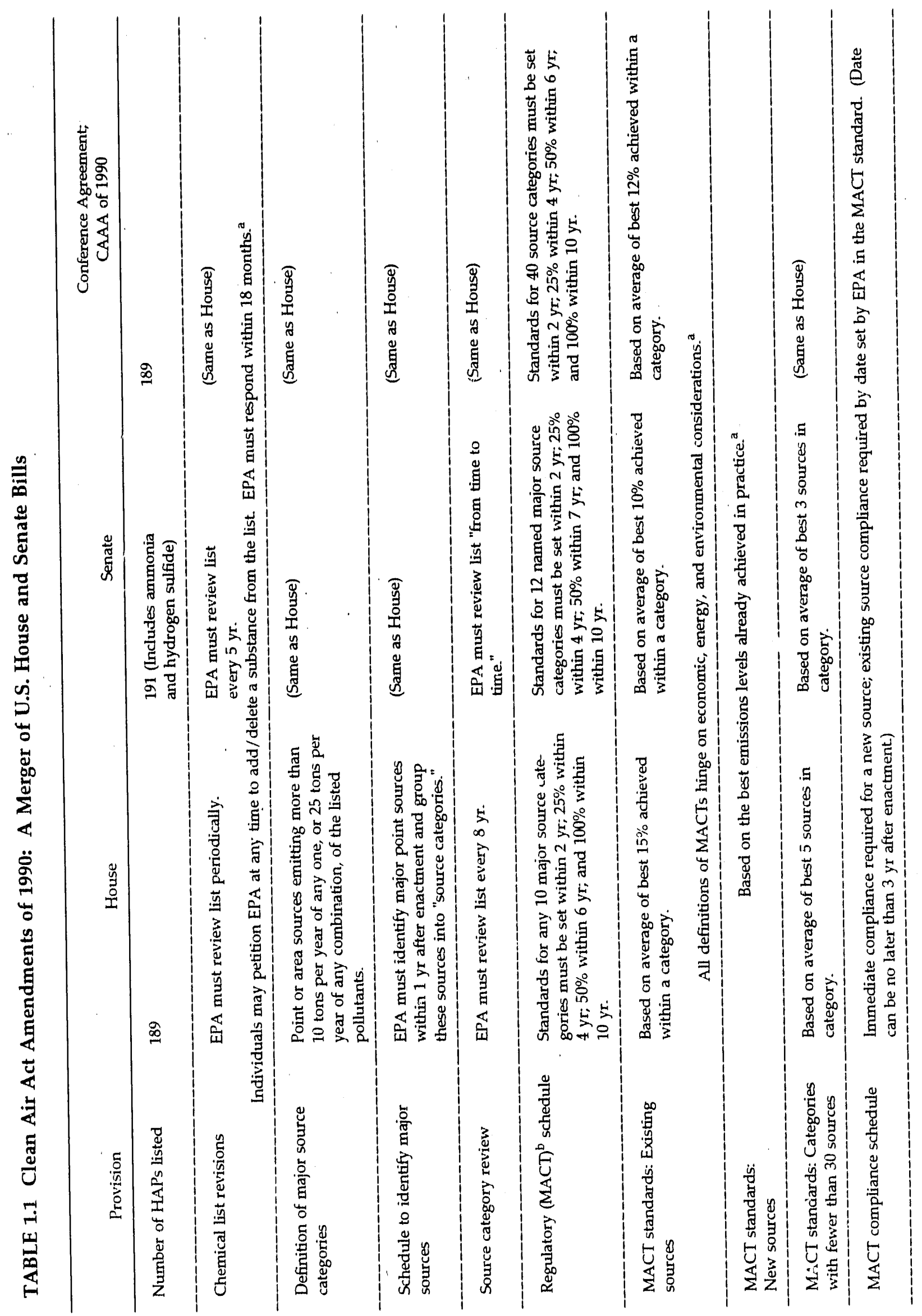




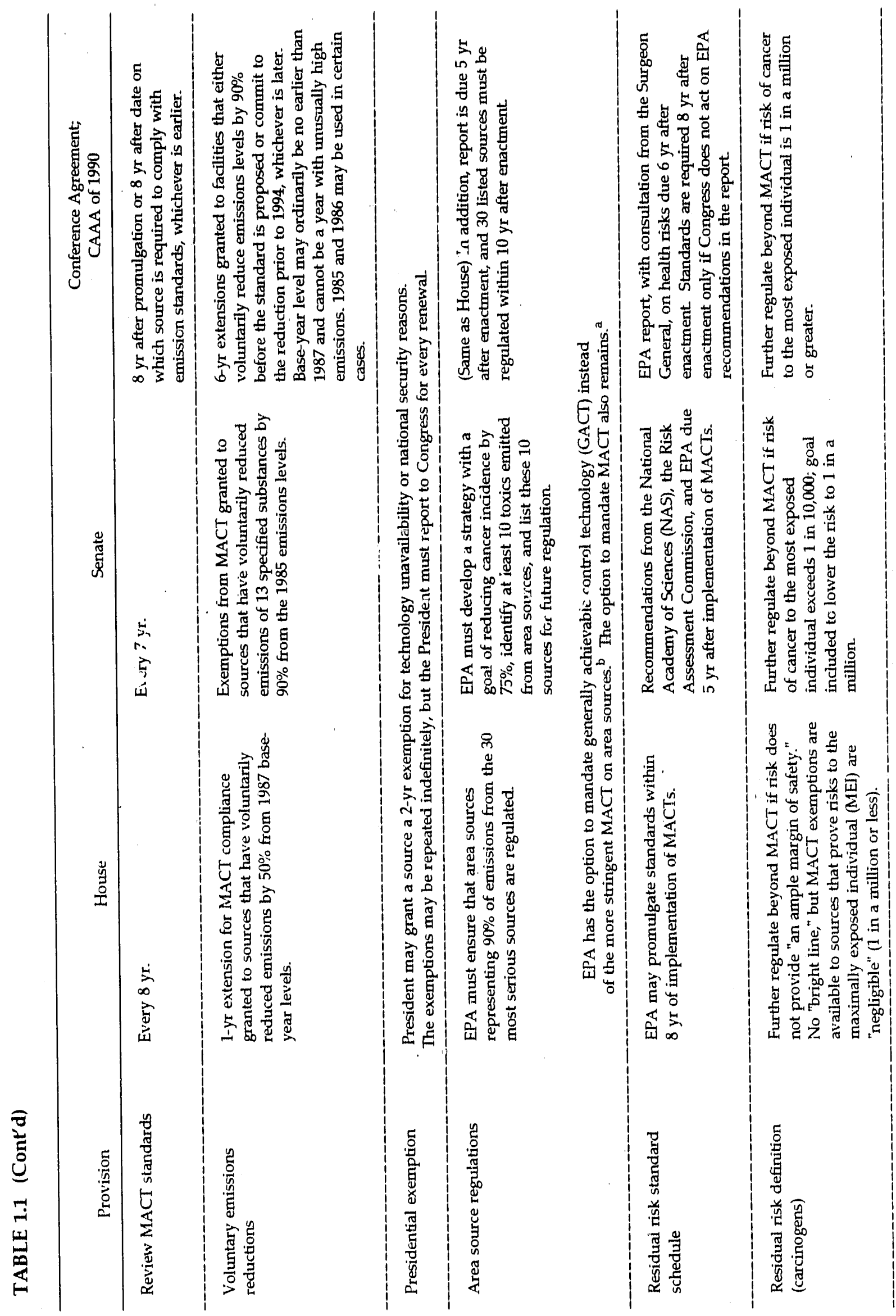




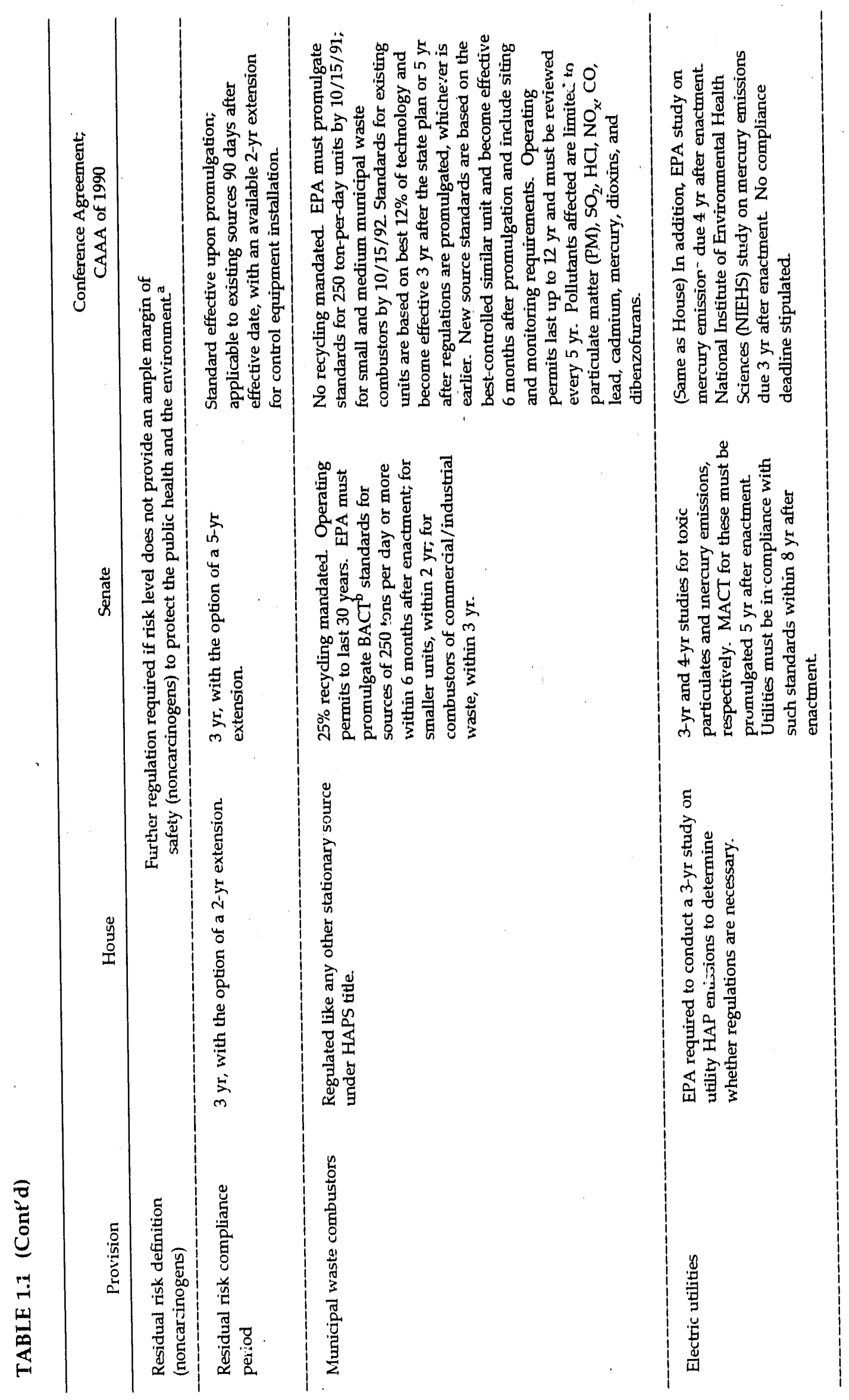




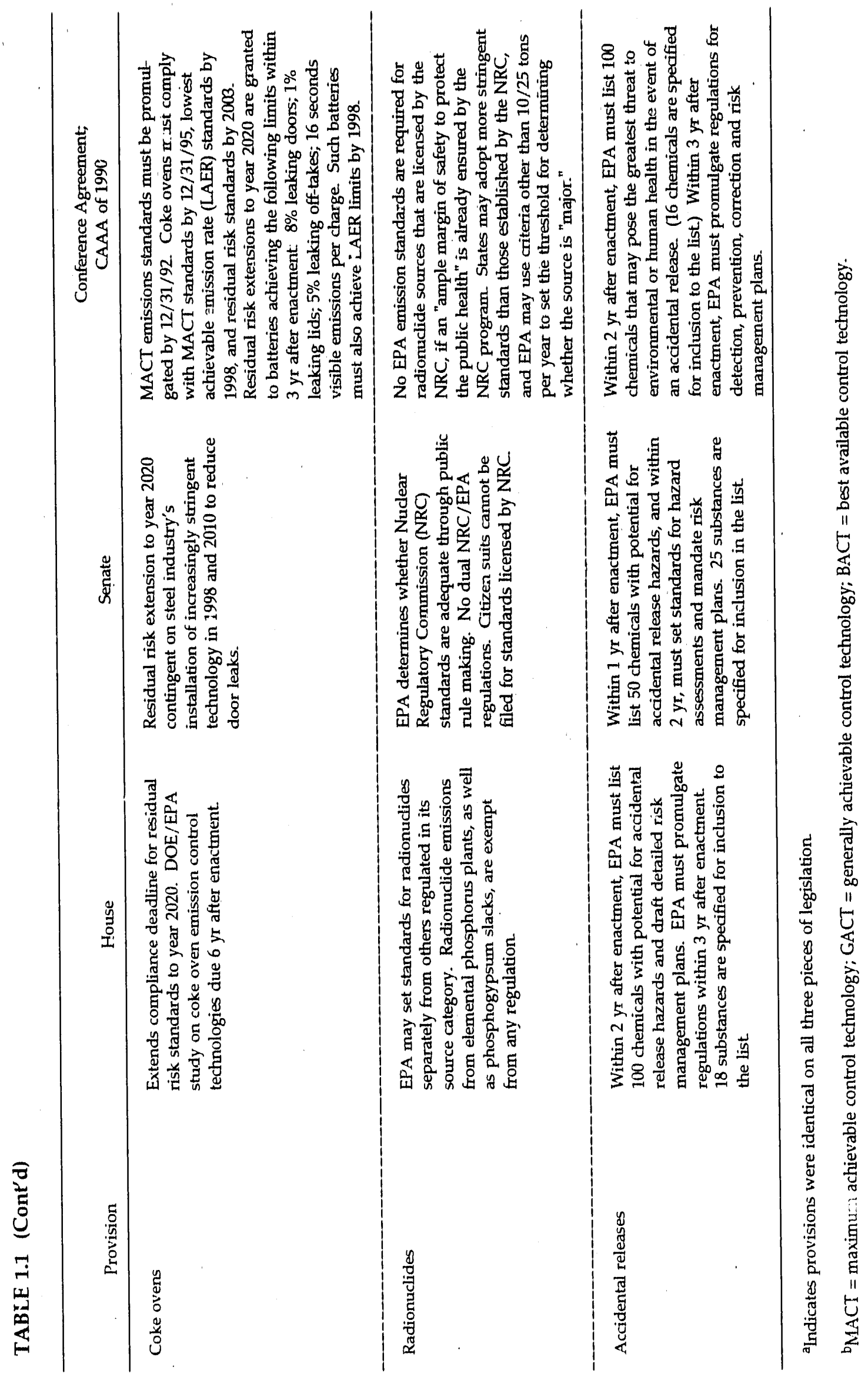


More recently (June 21, 1991), EPA published another draft list of source categories, Preliminary Draft List of Categories and Subcategories under Section 112 of the Clean Air Act (EPA 1991b). The following categories that were included in the December 1990 list were omitted from the June 1991 list:

- Radionuclide emitters,

- Solid waste incineration categories that are also subject to regulation under Section 129 (i.e., municipal waste combustors, medical waste incinerators, and general industrial solid waste incineration), and

- Utility boilers with more than $25 \mathrm{MW}$ of electrical output.

The omission of these categories from the June 1991 list does not necessarily preclude them from being included in the final list that is scheduled for November 1991. In fact, the utility category is being seriously considered for inclusion in the final list (see EPA 1991b). Other energy-related categories still included in the June 1991 list are petroleum industry process heaters, oil and gas steam generation, residential wood combustion (both fireplaces and woodstoves), asbestos spraying and insulation, petroleum refining, oil and gas production, gasoline/petroleum storage, petroleum marketing, manganese fuel additives, natural gas storage/transmission, and oil shale retorting.

Industries included in the draft list of source categories that are directly related to energy are included in Table 1.2, along with the HAPs they are thought to emit. EPA has also provided rankings for the data used to compile the draft list, ranging from best (A) to worst (D). As shown in Table 1.2, the data quality can vary from chemical to chemical within a source category. None of the information for energy-related industries is rated above $B$, and much of it is rated $C$ or below. Data rated $C$ are defined as being based on a small number of tests using analytical techniques and are considered "reasonably representative of the total population." A $D$ rating indicates that the data rely on either a single source studied using analytical techniques or rely on more than one source studied using engineering calculations. (EPA's definition of D ratings fails to indicate how representative of the total population the $D$ data are.) An $E$ rating indicates the data are based on engineering judgment and/or have no documentation and are therefore not considered representative of the total nopulation.

EPA's draft source category list is currently under review and will likely undergo much development. Major criticisms of the draft list have included the following:

- Major and area sources are not distinguished from one another, even though standards for area sources are permitted to be less stringent.

- Amounts of pollution released are not indicated.

- Specific facility sizes are not indicated (although they are estimated in limited cases). 


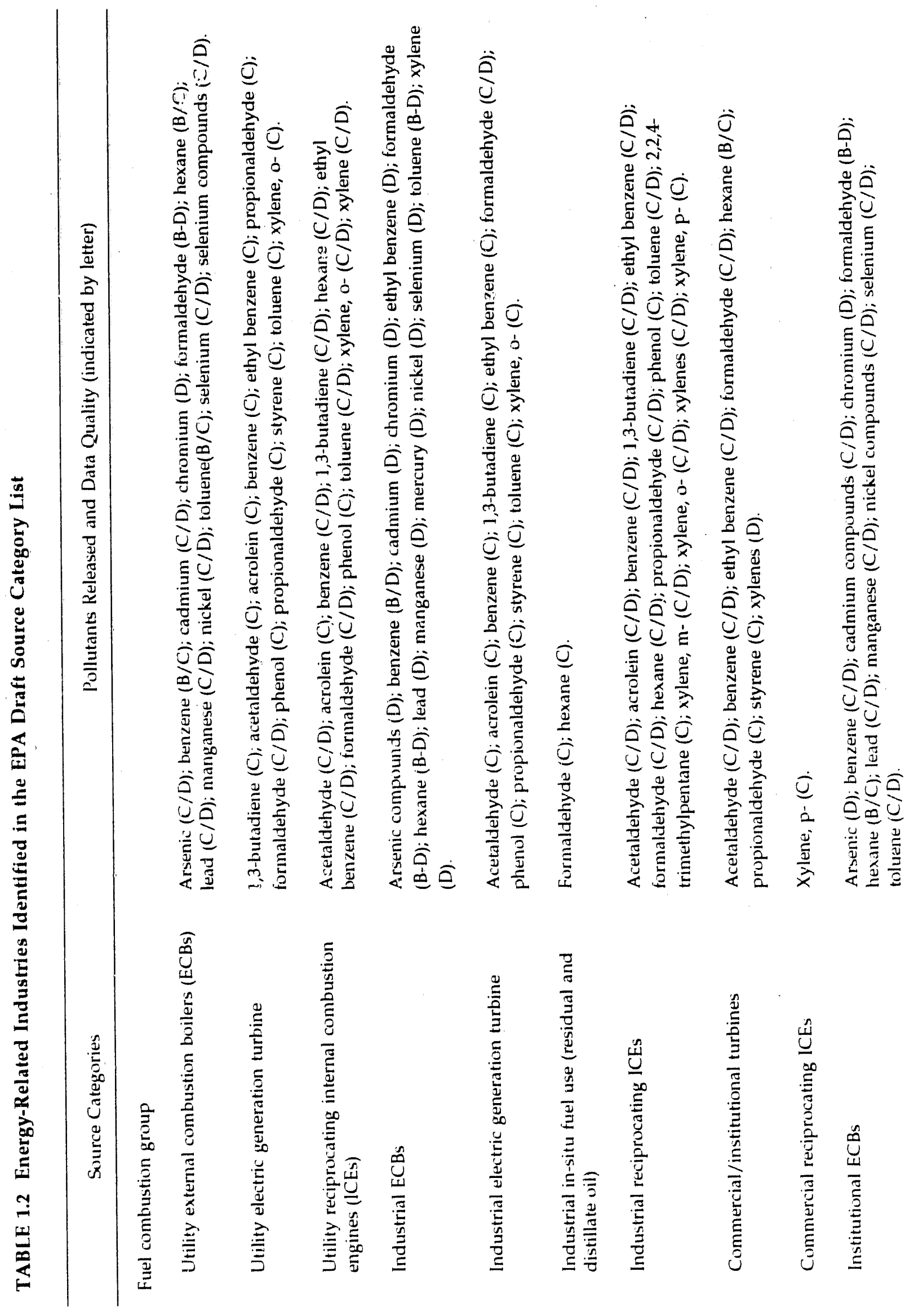




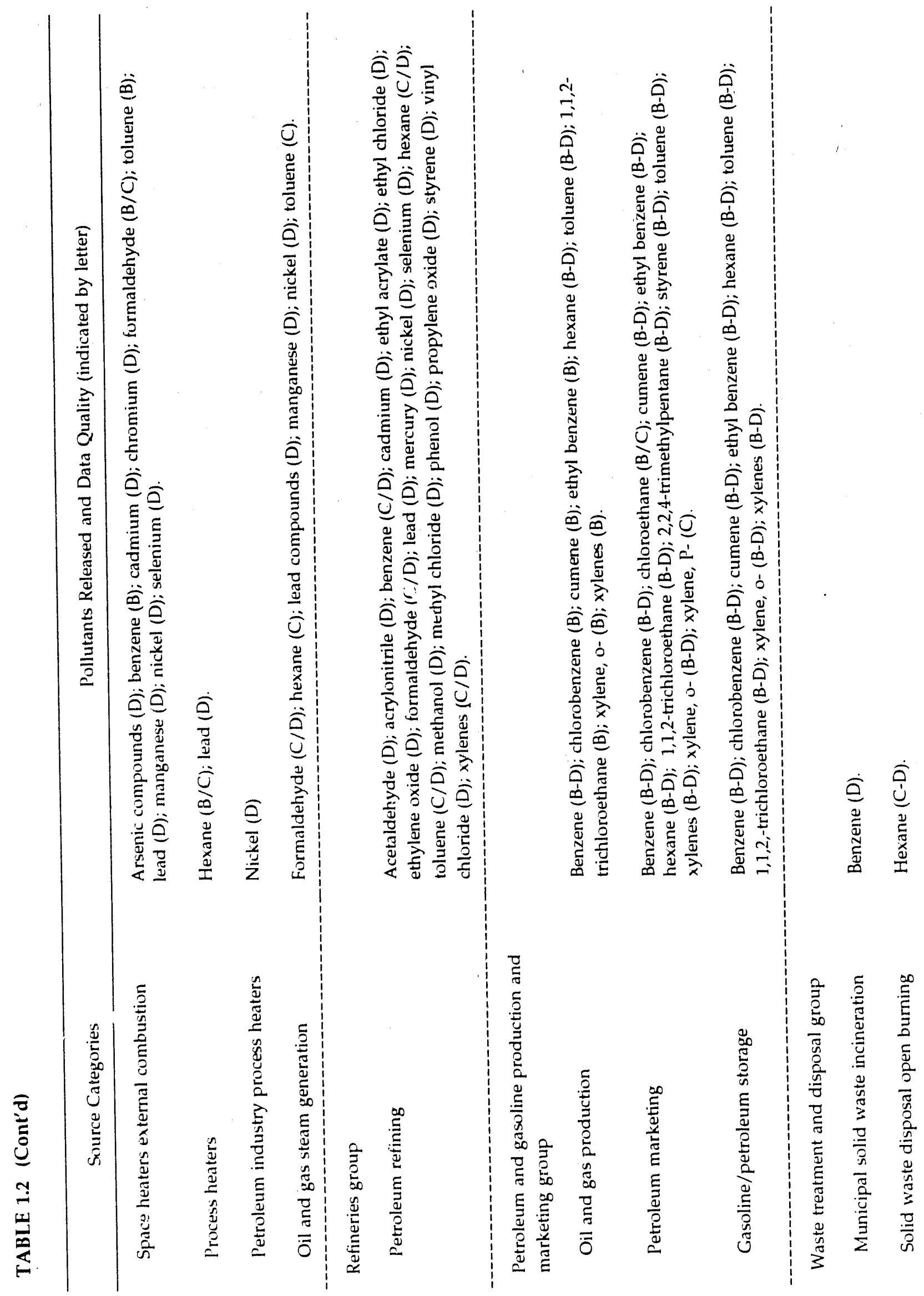




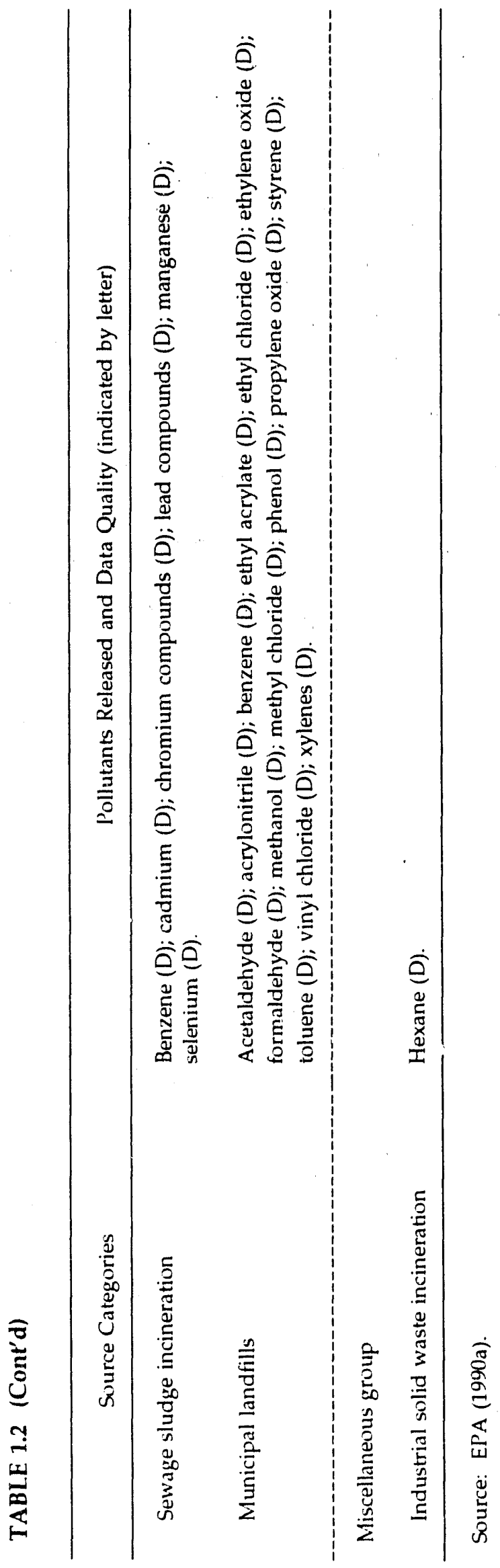


- In no event does the rating quality for utility, industrial, or institutional coal boilers of any type for any pollutant exceed the level of $\mathrm{C}$ - a level indicating that the data can be considered only reasonably representative of the total population.

The last point was emphasized in U.S. Department of Energy (DOE) comments, which stated that ". . . this level of data quality does not provide a sufficient basis for listing the category under Section 112, in light of the regulatory burdens which follow. . ." (Stuntz 1991). Despite DOE's suggestion that "additional data accumulation above the ' $D$ ' level is necessary for the responsible identification of that source on the source category list," the time constraints that EPA is faced with under Title III make the likelihood of gathering more data minimal at best.

Table 1.3 summarizes the data quality ratings that EPA assigned to industries directly related to energy. EPA based the decision to include sources in the draft list on the data rated here. A range of ratings is provided when ranks vary among data for different pollutants or for different processes within an industry.

- Across all sectors, data on oil combustion range from B to D.

- Similarly, data on natural gas combustion also range between B and D.

- Data on coal combustion, however, are consistently ranked D across all sectors.

Upon examination of trends within sectors, one finds that data for the industry and commercial/institutional sectors range between $\mathrm{B}$ and $\mathrm{D}$, while data for the utility sector never exceed a $C$ rating.

Other energy-related industries included in the draft source category involve energy

production. Data ratings referring to oil and gasoline production range from $B$ to $D$. Data referring to petroleum refining (i.e., fluid catalytic converter, process drains, pipeline valves, pump seals without controls and blind charging) are rated either $C$ or $D$. Data for petroleum marketing (including gasoline station tanks, bulk terminals, and plants) and gasoline/petroleum storage tanks are ranked between $B$ and $D$.

\subsection{ENERGY-RELATED SOURCES OF HIGH-RISK HAZARDOUS AIR POLLUTANTS}

A source that tries to qualify for a MACT' compliance extension with its subsequent alternative emission limitation by achieving early emission reductions may be limited in including reductions of high-risk pollutants in pollutant offsets. The new Section 112 (i)(5)(E) of the CAA stipulates that the offsetting limitation applies to pollutants for which a "high risk for adverse public health effects may be associated with exposure to small quantities, including but not limited to chlorinated dioxins and furans" (see Table 1.4). Therefore, sources whose total emissions are composed of a large proportion of pollutants deemed high risk could be prevented from qualifying for a MACT compliance extension and alternative emission limitation. The treatment of high-risk HAPs will prove important to energy-related industries that emit these 


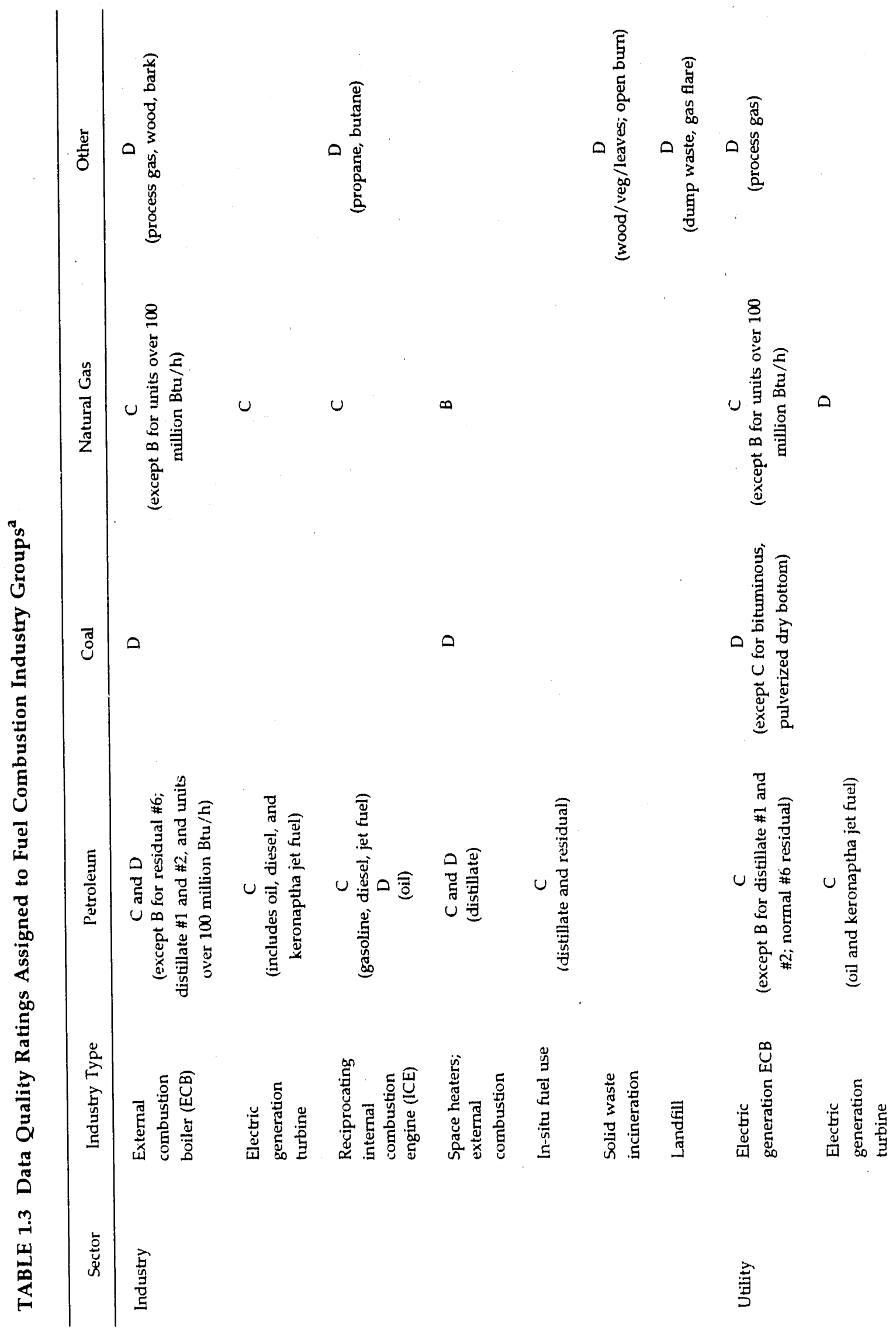




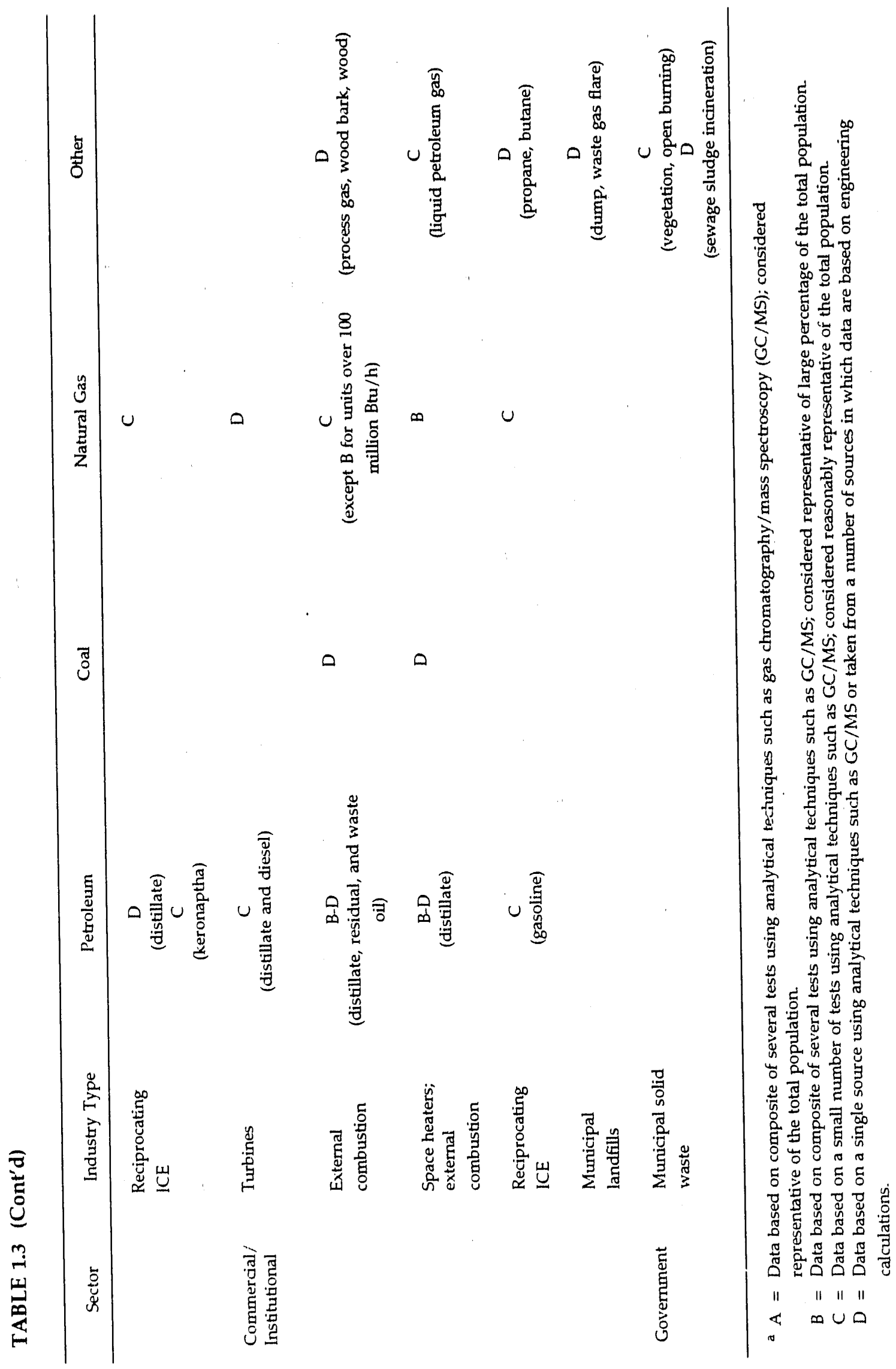


TABLE 1.4 High-Risk Pollutants and Corresponding Weighting Factors

\begin{tabular}{lr}
\hline \multicolumn{1}{c}{ Pollutant } & $\begin{array}{r}\text { Weighting } \\
\text { Factor }^{\mathrm{a}}\end{array}$ \\
\hline Carcinogens & \\
2,3,7,8-Tetrachlorodibenzo-p-dioxin & 100,000 \\
Benzidene & 1,000 \\
Bis(chloromethyl)ether & 1,000 \\
Asbestos & 100 \\
Chromium compounds & 100 \\
Hydrazine & 100 \\
Arsenic compounds (inorganic including arsine) & 100 \\
Chloromethyl methyl ether & 10 \\
Cadmium compounds & 10 \\
Heptachlor & 10 \\
Beryllium compounds & 10 \\
Acrylamide & 10 \\
Coke oven emissions & 10 \\
Hexachlorobenzene & 10 \\
Chlordane & 10 \\
Dichloroethyl ether (bis(2-chloroethyl)ether] & 10 \\
1,3-Butadiene & 10 \\
Benzotrichloride & 10 \\
Ethylene dibromide (dibromoethane) & 10 \\
Ethylene oxide & 10 \\
Vinyl chloride & 10 \\
Acrylonitrile & 10 \\
1,1,2,2-Tetrachloroethane & 10 \\
Vinylidene chloride (1,1-dichloroethylene) & 10 \\
Benzene & 10 \\
1,2-Propylenimine (2-methyl aziridine) & 10 \\
Noncarcinogens & 10 \\
2,4-Toluene diisocyanate & 10 \\
Acrolein & 10 \\
Acrylic acid & 10 \\
Chloroprene & 10 \\
Dibenzofurans & 10 \\
Mercury compounds & \\
Methyl isocyanate & 10 \\
Methylene diphenyl diisocyanate (MDI) & \\
Phosgene & 10 \\
\hline
\end{tabular}

${ }^{a}$ HAPs not on the risk list have a weighting factor of 1 .

Source: EPA (1991a). 
pollutants and are subsequently discouraged from participating in the early reduction program. On the basis of EPA's December 1990 draft source category list, energy-related industries may be affected by EPA's final definition of high-risk pollutants.

Originally, EPA had planned to prohibit offsets of high-risk pollutants with other listed HAPs. Because several high-risk pollutants (e.g., arsenic, chromium, and dioxin) can be emitted in trace amounts for which $90 \%$ reductions are extremely difficult, EPA established a system of indexing pollutants (see Table 1.4). In this system, offsets of higher-risk pollutants with lowerrisk (less toxic) pollutants would be permitted, based on relative toxicity. Where a measure of relative toxicity has been established, greater reductions of lower-risk pollutant emissions would be needed to offset emissions of higher-risk pollutants. The indexed offsetting system is based on estimates of the carcinogenic potency of the carcinogens on the HAP list (EPA 1991a). While comparable measures of relative toxicity of the listed noncarcinogens are not currently available, EPA has employed the carcinogen indexing system to obtain rough weightings for the high-risk noncarcinogens (EPA 1991a). The proposed system is expected to evolve as more appropriate indexes become available and are added. 


\section{NEAR-TERM IMPLEMENTATION OF AIR TOXICS REGULATIONS}

The June 21 Preliminary Draft List of Categories and Subcategories under Section 112 of the Clean Air Act (EPA 1991b) indicates the sources for which MACT regulations are likely to be promulgated over the next 10 years. The energy-related industrial groups identiffed in this list include fuel combustion, petroleum refineries, and petroleum and gasoline production and marketing. The question of how soon each of these categorles will be regulated within the allotted 10-year time frame remains uncertain.

Given the short time frame in which EPA must promulgate the first phase of MACT regulations - within two years for at least 40 source categories - EPA will necessarily rely heavily on the NESHAP standards that are already under development to meet near-term promulgation deadlines. Table 2.1 lists the stationary source categories currently under NESHAP regulatory development as identified in EPA's regulatory agenda.

Very few of the rules to be promulgated in the near term will affect energy-related industries directly. At most, the majority of the rules listed in Table 2.1 might affect energy consumption by affecting industries that are energy intensive and by requiring control technologies that require more energy. However, such repercussions relate to energy industries only indirectly, and individual industries would require further in-depth study. The industries that could be recipients of direct energy-related impacts resulting from the promulgation of the aforementioned "early-phase" rules are as follows (ranging from the most direct to less direct):

- Coke ovens: Direct impacts will result since the emissions from this industry are essentially the result of processing coal. Additionally, the energyintensive steel industry, which relies on coke, could continue to undergo energy consumption changes.

- Tank vessels: Rules to control volatile organic compound (VOC) emissions will affect the petroleum industry, whose resources and products (i.e., crude oil and gasoline) are transported via tank vessels.

- Industrial cooling towers (ICTs): Prohibition of the use of hexavalent chromium in ICTs could affect both energy producers and major energy users, since a large percentage of the petroleum industry uses ICTs, as do certain energy-intensive industries such as primary metals and glass producers.

- Asbestos: Indirect impacts on energy consumption in the longer term could result if the cost of insulating material were to rise, which would result in a subsequent drop in its use and lower energy efficiency.

- Gasoline marketing: Potential rules might affect the perroleum industry by requiring changes either in the formulation of gasoline or at the pump. 


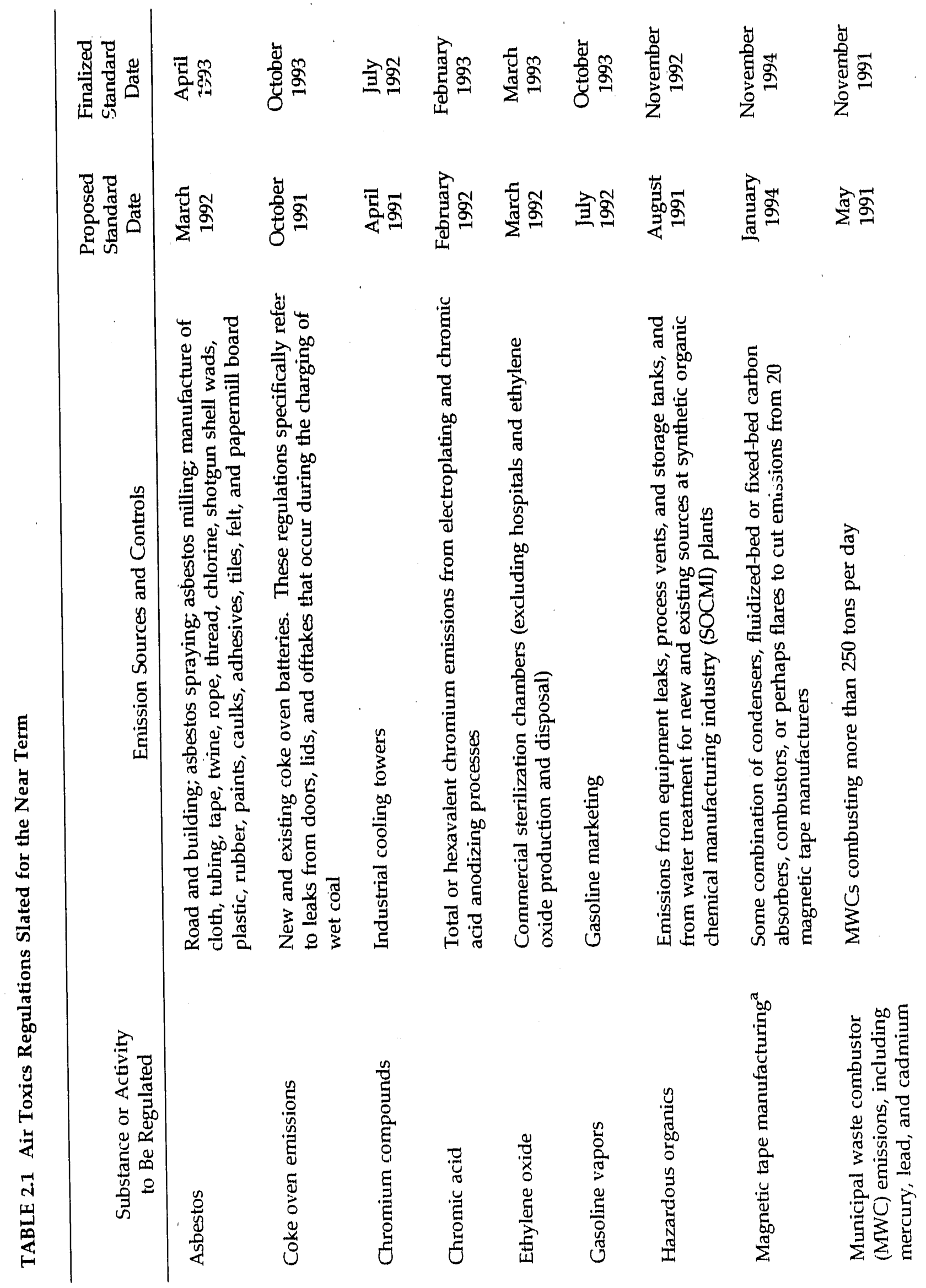




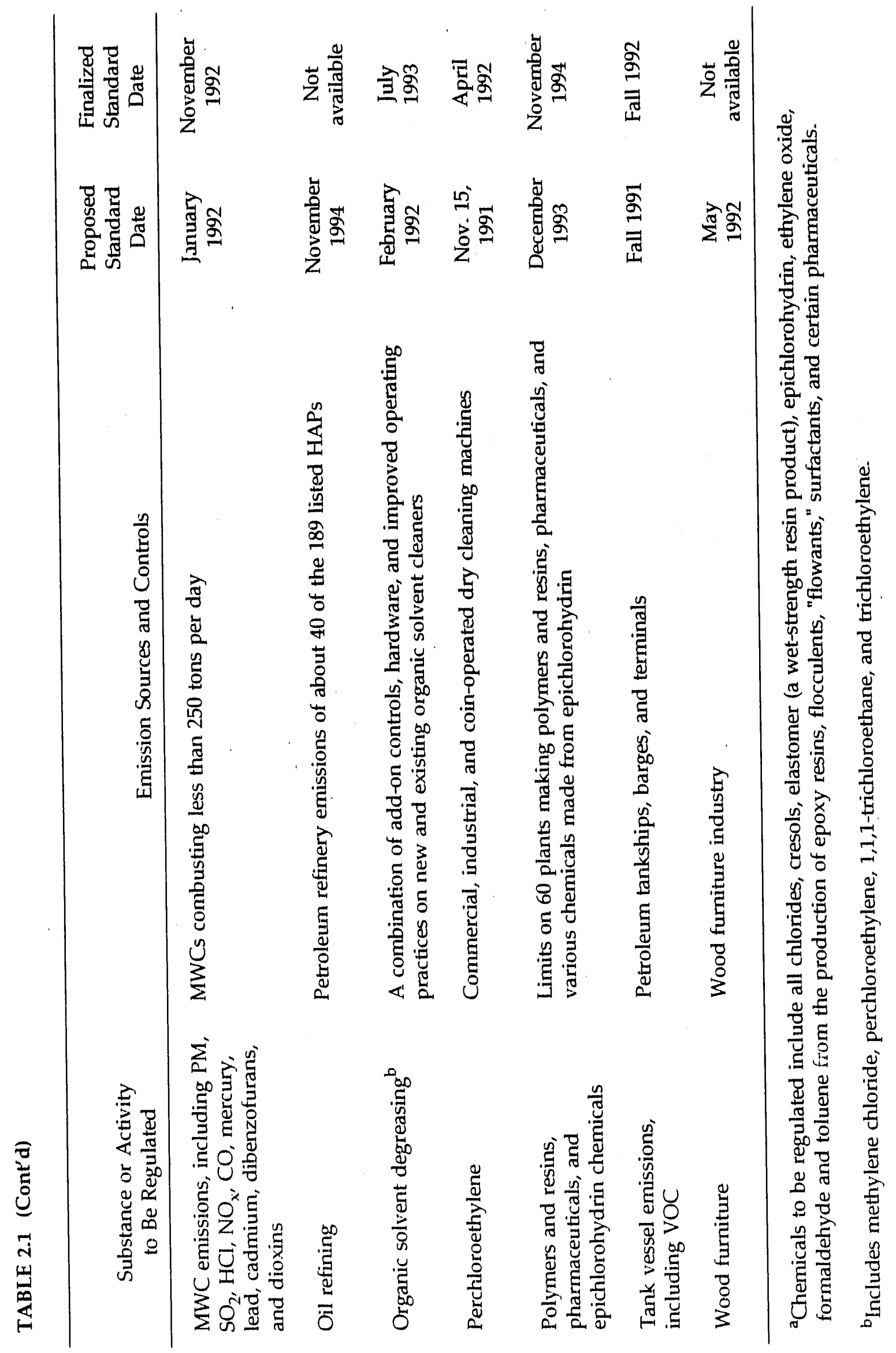


- Organic solvents: Relatively indirect and very limited impacts related to the potential for substituting the regulated solvents with petroleum-based distillates could result. A potential for increased energy consumption exists as a result of the implementation of emission control technology.

- Ethylene oxide: Indirect and minimal impacts could result from possible increased energy consumption d te to the operation of control equipment, transportation of captured residuals, or process substitution (i.e:, radiation sterilization).

Potential impacts on energy industries resulting from the remainder of the scheduled rules would be indirect, most likely in the form of energy consumption changes. More significant and direct impacts on energy-related industries are likely to occur in the later phases of Title $I I I$ regulation rather than in the earlier phases.

In addition to the chemicals listed for regulation in Title III of the CAAA, EPA has released a primary list of 17 chemicals to be targeted for major near-term reductions through a voluntary cooperative program with industry, the "Industrial Toxics Project" (see Table 2.2). The goal is to reduce the releases of these chemicals, named by EPA as the "worst toxics," from all media (not just air) by $30 \%$ in 1992 and $50 \%$ in 1995. EPA sent letters to the top 600 companies reporting releases of benzene, cadmium and compounds, carbon tetrachloride, chloroform, chromium and compounds, cyanide and compounds, dibenzofurans, dichloromethane, nickel and compounds, perchloroethylene, toluene, trichloroethylene, and xylene. All of these chemicals are included in the list of HAPs in Title III, with the exception of 1,1,1-trichloroethane (1,1,2-trichloroethane is listed). These firms were asked to make written commitments by May 15, 1991. About 200 companies have expressed interest. Others may have been discouraged by uncertainties surrounding the issue of how sources would be later credited for these voluntary emission reductions in the context of complying with CAAA requirements.

\subsection{COKE OVEN REGULATIONS}

The production of coke involves heating bituminous coal in the absence of air. Volatile gas is released as the coal is heated and softened. The coal then resolidifies as shiny, hard, black coke. Coke oven emissions (COEs) contain over 10,000 compounds as gases, vapors, and respirable particulate matter (PM). The most critical component, in terms of public health concerns, is benzene. Most attention to coke oven emissions has focused on the toxic effects of the benzene soluble organic (BSO) portion of PM, because this fraction cuntains polycyclic organic matter (POM), which includes compounds that are known animal carcinogens. Beryllium and arsenic are also emitted from coke ovens and are considered human carcinogens. In addition, there is concern over the potential health risks caused by long-term exposure to trace metals (e.g., cadmium, chromium, lead, and nickel) and gases (e.g., hydrogen sulfide, carbon monoxide, nitric oxide, and sulfur desiccant) contained in the COEs (EPA 1987). Controls on coke ovens would directly affect energy production and might also indirectly affect energyconsuming industries. 


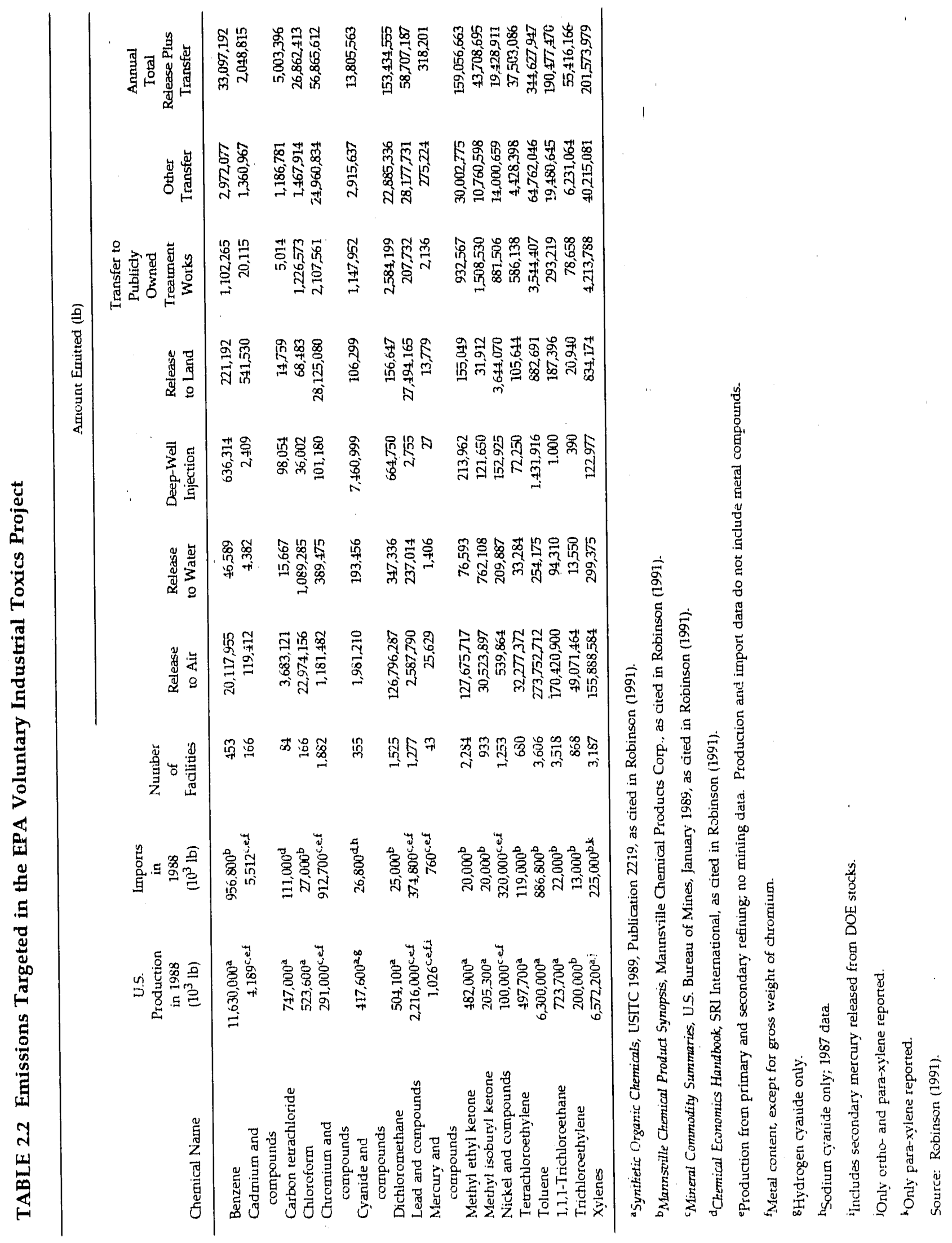


In the past, coke oven standards for occupational exposure were established in response to studies by industrial health specialists who found working conditions at the top of coke oven batteries to be injurious to the health of workers. Oven workers with five years of experience or more tended to have higher incidences of cancer of the respiratory system. Thus, coke oven emissions were regulated under the U.S. Occupational Safety and Health Administration (OSHA) to improve safety in the work environment. It is uncertain whether risks to the general public, which the CAAA is designed to protect, are similar to those of exposed workers. It is generally agreed, however, that coke liberates a large amount of organic chemicals as by-products and that without emission control technology, coke plants have the potential to be serious polluters of air (Shobert 1987). More recently, regulatory schedules for coke ovens have been established in the CAAA of 1990.

The CAAA of 1990 provide specific regulatory requirements for coke oven emissions that depart from those generally required for other source categories. In essence, the variation for coke ovens allows additional time for compliance and allows sources to elect to forego initial compliance with MACT through early compliance with residual risk standards.

First, by December 1992, EPA is to promulgate MACT standards for existing coke batteries, with compliance required by 1998 . While the generally required residual risk review of the MACT standards applies, any residual risk standard has an extended compliance date of the year 2020. If a source elects before 1998 to comply with the residual risk standards by 2003, however, it does not need to initially comply with the MACT. If a source elects by 1998 to replace an existing battery as its MACT compliance method, the replacement battery is eligible for the residual risk compliance extension to the year 2020.

The latter-phase health-based standards are of greater concern to the coke oven industry than the first-phase regulations, which mostly call for operation and maintenance (O\&M) changes. Industry experts have estimated that setting limits on cancer risks downwind of coke ovens would shut down nearly all of the nation's 40 plants, eventually halting steel production. These concerns, however, have been somewhat aneliorated because of Congress's decision to grant coke ovens that cut their emissions to meet MACT levels by 1998 a waiver until 2020 for the residual risk requirements. Although the nation's largest coke plant, with 800 ovens, is one of its cleanest coke plants (after having reduced its emissions 95\% in the last decade), it ranks as a top cancer risk because of its size and proximity to residents, with odds of 1 in 55 for the most exposed individual (based on an EPA calculation that United States Steel Corp. [USX] disputes).

Title III additionally mandates a joint EPA and U.S. Department of Energy (DOE) project that involves a coke oven emission study and a federal financial assistance program. Together, DOE and EPA are directed to assess emission control technologies associated with the range of coke oven operation and battery designs, identifying the technologies that can significantly reduce emissions of HAPs. Title III also appropriated $\$ 5$ million for each year from 1992 through 1997 for EPA/DOE to reward grants of up to $50 \%$ of costs to persons proposing to install and operate coke oven emission control technologies. DOE must report annually on the practicable and economically viable control technologies for coke oven production facilities. 


\subsubsection{Controlling Coke Oven Emissions}

Originally, coke was made by filling the passageways in a mound of coal with wood and then igniting the wood to create a carbonized mound of coke. This process was inefficient, unpredictable, and pollutive. The "beehive" cokı: oven later emerged in the mid-19th century to produce better-quality coke. When the by-products of coke ovens (e.g., ammonia) became especially valuable during World War I, new by-product ovens gained popularity (Shobert 1987). Today, between 15 and 100 ovens are grouped together in a battery. Gas is burned between adjacent flue chambers to yield the heat that is necessary for carbonizing the coal inside the ovens. Emissions are released at many different points during coke production. After leaving the combustion chamber, for example, the burned charging gas enters the atmosphere. Emission sources within the coke production process can be divided into three groups:

1. Dust emissions from the initial transport and preparation of coal,

2. Emissions of dust, gases, and tar that contain vapors that occur during coking (charging of the coke oven, the coking process itself, coke pushing, and quenching and heating of coke ovens), and

3. Dust emissions caused by the transport and screening of coke.

Regulations proposed by EPA in 1987 focused on the second of these groups and are limited to visible releases that result from coke oven charging, door leaks, and topside leaks on wet-coal-charged batteries. EPA reports on COEs do not suggest regulations that mandate new additional equipment with substantial capital investments.

\subsubsection{Coke Oven Charging}

Factors influencing emissions from charging include charging equipment (e.g., pressure fluctuations, process time needed, and gap sizes around the drop sleeves), operating conditions, coal type, and blending practices.

- Aspiration of air into the by-products system from points where pollution gases and smoke are otherwise emitted can reduce emissions from charging (EPA 1987).

- Suction devices with a downstream scrubber can purify the charging gases in the top charging operation.

- Operating procedures can play the most important role in the successful control of charging emissions (EPA 1987).

\subsubsection{Coke Oven Door Leaks}

Emissions released from doors are dependent on the duration of the coking cycle and the size of the gap between the seal and the opening. Regardless of concern about pollution, inward leakages of air adversely affect efficiency. The coke oven door minimizes heat loss, 
prevents gas loss, holds the coal mass in the oven during charging, and allows the operator to level the coal charge in the oven. Hydrogen and methane are major constituents of gases released from coke oven doors. Techniques to control COEs from doors can be grouped into four categories:

1. Oven door seal technology consists of three types of seals used to prevent releases of pollutants from gaps between the door and the door jamb: metal-to-metal, resilient soft, and hand-luted. Most doors have self-sealing, metal-to-metal jambs, wherein the gaps are plugged by condensing tar that escapes with the coke oven gas. The same hardened tar that serves to seal gaps in metal-to-metal doors can also exacerbate the formation of problematic gaps through which significant amounts of gas are emitted. Metal-to-metal seals therefore depend on operation and maintenance (O\&M) procedures such as seal adjustment and door handling. Other door seals employ hand luting, where a luting mixture of clay, coke breeze, and water is troweled into the opening between the metal door frame and the jamb. The water eventually dries and the gap is sealed. This technique can be less costly to maintain than self-sealing doors and can offer maximum emission reductions if properly applied, in conjunction with adequate inspection and reluting.

2. Pressure and differential devices either permit gas from the bottom of the oven to escape to the collecting main or put external pressure on the seal through the use of steam or inert gases to reduce or reverse the pressure differential caused by defects in the door seal.

3. Collection hoods and sheds over doors collect leaking gases and particulates through a suction hood with a wet electrostatic precipitator (ESP) and may incur significant capital and operating costs. Generation of solid waste and tar from emissions recovery, disruption of recovery due to cross winds, and a tendency to relax leak detection efforts are other problems.

4. O\&M procedures have been given emphasis by EPA with respect to their potential for being improved to reduce COEs, because they are the ". . . least expensive, most effective, and justifiably on many occasions the best practical means of controlling the pollution" (EPA 1987). O\&M improvements require the training of coke oven workers in very specific cleaning procedures and proper work conditions (e.g., sufficient lighting and sufficient staff with training to detect leaks). Management improvements are also necessary to better motivate oven workers, whose full cooperation and awareness is crucial.

\subsubsection{Topside Leaks}

Topside leak rates of POMs can range from an average of $0.002 \mathrm{~kg} / \mathrm{h}$ for small leaks to $0.013 \mathrm{~kg} / \mathrm{h}$ for larger leaks. Emission rates for lids and offtakes depend on worker practice in applying luting mixtures, pressure fluctuations, and gap size (i.e., improperly seated or distorted lids and broken seals) of the emission point. Pressure fluctuations encourage the unseating of lids and standpipes and must therefore be minimized. In this regard, the training of personnel is again cruciai in minimizing leaks. 
The emphasis of coke oven regulations in the United States (compared with those regulations that rely on advanced technologies in Japan and West Germany) is on proper maintenance. EPA has concluded that many existing coke ovens could reduce emissions by increasing the number of personnel on duty who monitor leaks (especially during the night shifts, when maintenance and environmental controls tend to be relaxed) without making many major technological modifications. Coke oven MACT regulations would therefore result in higher operating costs rather than large capital expenditures.

\subsubsection{Compliance Problems}

COEs are highly variable and not easily measured. Emissions escape from many different pieces of equipment, and leaks can change in size and location over time. The tar component of coke oven emissions also condenses on measurement equipment, causing erroneous results. For these reasons, the proposed regulations addressed only visible emissions that are estimated (in term of duration) by operators. However, visible emission readings represent only the total time that emissions occur and do not account for differences in the density of emissions, the mass emission rate, or the number of emission points (EPA 1987).

Several factors make compliance with COE standards difficult. It is extremely difficult to bring the emission sources together in controlling different simultaneous emission types. The alignment of bricks in old ba' : ries shifts to create unpredictable problems. Furthermore, battery conditions, worker attitude, and training vary at each location (EPA 1987). An array of many different strategies may be required, since the construction of coke ovens has traditionally lacked standardization.

\subsubsection{Economic Position of the Coke Industry}

Except for the ore itself, coke is the most important raw material in the iron and steel industry (Shobert 1987). Controls on coke ovens, therefore, would directly affect energy production and might also indirectly affect energy-consuming industries. In $1984,92 \%$ of coke plants were owned by or affiliated with iron- and steel-producing companies that consumed coke in their own blast furnaces. Historically, the eight largest steel producers have been responsible for approximately $75 \%$ of coke production (EPA 1987). The remaining independent coke plants were typically owned by chemical or coal firms. Any impacts on coke production will therefore also affect the steel industry (Shobert 1987). The reverse is also true; the steel industry is in a period of transition and the changes will likely affect the coal industry. Furthermore, coke plants depend primarily on coal from West Virginia, Kentucky, Pennsylvania, and Virginia, so any impacts felt by the coke industry will therefore be concentrated in these states (EPA 1987).

It is uncertain, amid the ailing financial conditions of the steel industry and the development of new technologies, whether new coke plants would be built even in the absence of additional environmental regulation. In 1975, there were 62 operating by-product coke plants (consisting of 231 batteries). By 1984, there were only 43 by-product plants (consisting of 134 batteries, and only 36 of these were actually operating). U.S. coke production decreased $56 \%$ between 1976 and 1983. Production levels have been erratic since 1983 but have generally remained low in comparison to levels in the 1970s. Historically, nonregulatory factors have been associated with declines in demand for coal in coking. 
- Innovation in blast furnace practices between 1950 and 1970 reduced the amount of coke needed to produce equal amounts of iron by almost $38 \%$.

- Increased use of fuel supplements (coke oven gas, fuel oil, tar and pitch, natural gas, blast furnace gas, and oxygen) in the past 20 years caused the amount of coal used per ton of pig iron produced (the coke rate) to decrease (EPA 1987).

- The use of higher metallic content ores also caused declines in the coke rate.

- Electric arc furnaces, which do not require coke, are becoming increasingly important in the steel industry as labor-saving technology is implemented more often.

- Increases in efficiency decreased the coke rate for furnaces; in 1983, an average of only $540 \mathrm{~kg}$ of coke was required to produce $1 \mathrm{Mg}$ of pig iron, compared with $860 \mathrm{~kg}$ in 1956 (EPA 1987).

- Because of a decrease in the domestic demand for steel, an increase in competition from foreign steel producers, and a subsequent reduction in coke production, coal consumption at coke plants declined steadily from 1979 to 1983 (EIA 1987).

- More reliance is being placed on the reuse of steel scrap, and substitutes are increasingly replacing the final products (iron and steel) to which coke is an input.

- The U.S. share of world coke production decreased from $36 \%$ in 1950 to $14.1 \%$ in 1979 . Coke imports nearly tripled between 1986 to 1987 , from 329,000 to 922,000 tons, and exports were cut in half, from 1 million tons to nearly 574,000 tons (EIA 1987).

On the other hand, some technology changes increase the demand for coke. While the use of electric arc furnaces has more than tripled between 1960 and 1982, the use of basic oxygen furnaces has increased more than 18-fold, as shown in Figure 2.1. The basic oxygen process requires a relatively large amount of coke (Shobert 1987).

Demand for coal in coking hinges on demands for iron and steel products, which are, in turn, sensitive to the performance of the overall economy. Regardless of pollution regulations, since 1950 coke consumption has fluctuated with cycles in aggregate demand. In 1978, two factors were attributed to the lack of adequate coke production in the United States. First, a coal miners strike caused the drawing down of stocks of coke when they should have been increasing; second, there were some premature closings because of EPA regulation of some coke ovens that normally would have been replaced before they were closed (EPA 1987).

Trends in expenditures in the steel industry also suggest that the financial problems of the steel industry have not been inextricably linked to pollution abatement. Pollution abatement capital expenditures as a percentage of net capital expenditures peaked at $25.6 \%$ in 1979 , and by 

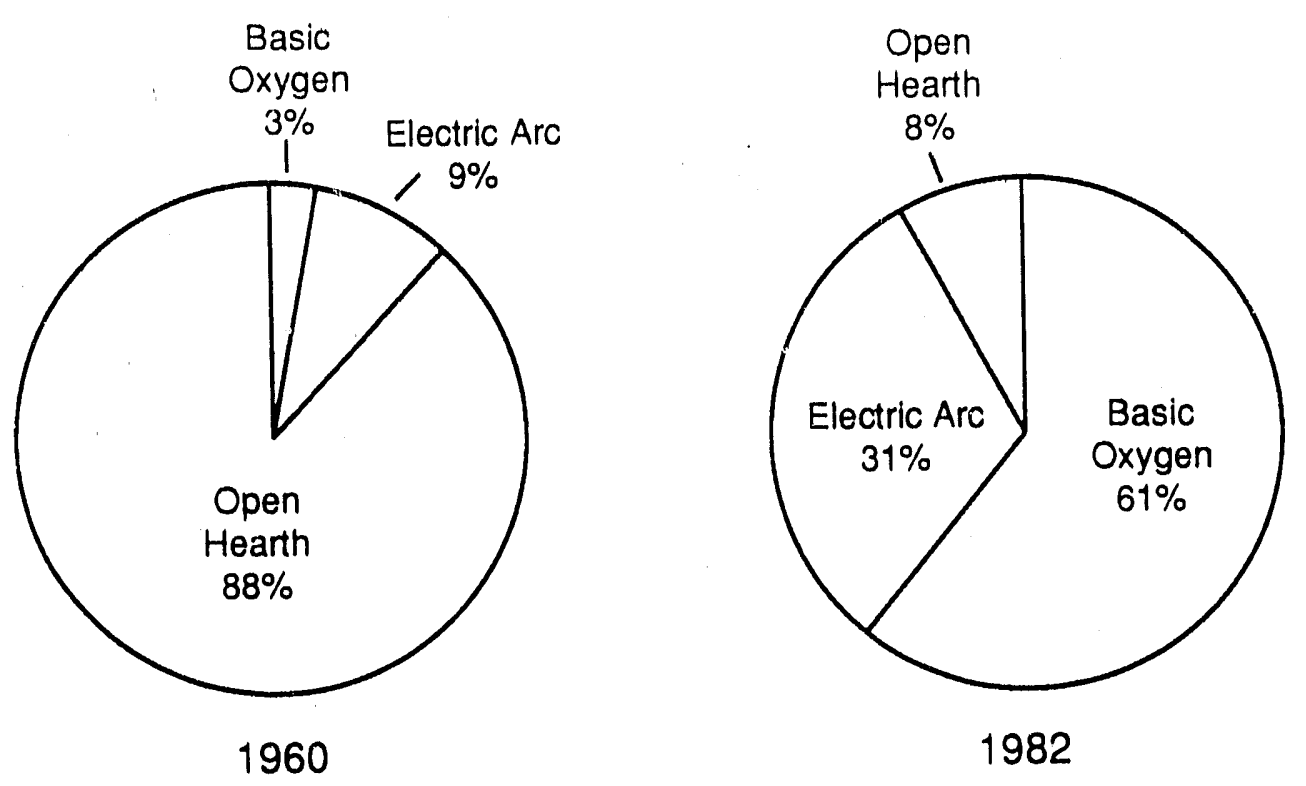

FIGURE 2.1 Coke Furnace Types

1982, this share had decreased by more than half. The decline in pollution abatement expenditures coincided with huge financial losses in the steel industry totaling $\$ 3.6$ billion in 1983. Figure 2.2 demonstrates that the costs of air pollution equipment incurred by blast furnaces and steel works do not appear to have affected the corporate profits of the primary metals industry - at least not immediately. However, these costs do not account for any controls installed at old plants.

\subsection{CHROMIUM FROM INDUSTRIAL COOLING TOWERS}

Hexavalent chromium $\left(\mathrm{Cr}^{+6}\right)$ has typically been added to cooling water to prevent corrosion, control the rate of scaling and fouling, and control the growth of microorganisms in these systems. However, as water containing hexavalent chromium falls through the cooling tower, some droplets are carried away in the air stream and released into the ambient air (NATICH Newsletter 1990b). Hexavalent chromium has been designated by EPA as a known human carcinogen. In addition, studies on the transfer of chromium from cooling tower operations to surrounding vegetation have also been conducted.

The use of hexavalent chromium in commercial comfort cooling towers, such as those dedicated to heating and cooling commercial space in office buildings, has been prohibited by EPA since 1990 (40 CFR 749) under the authority of the Toxic Substances Control Act. Use of hexavalent chromium in other types of cooling systems, such as ICTs and closed cooling systems, remains permissible. The cooling towers now under consideration for Title III regulation are those used to cool industrial processes (i.e., reducing the heat load returned to surface streams by evaporating the waste heat into the atmosphere). While systems devoted exclusively to heating, ventilation, and air conditioning (HVAC) may be exempted from a Title III rule, a HVAC system integrated with industrial processes might be covered. 


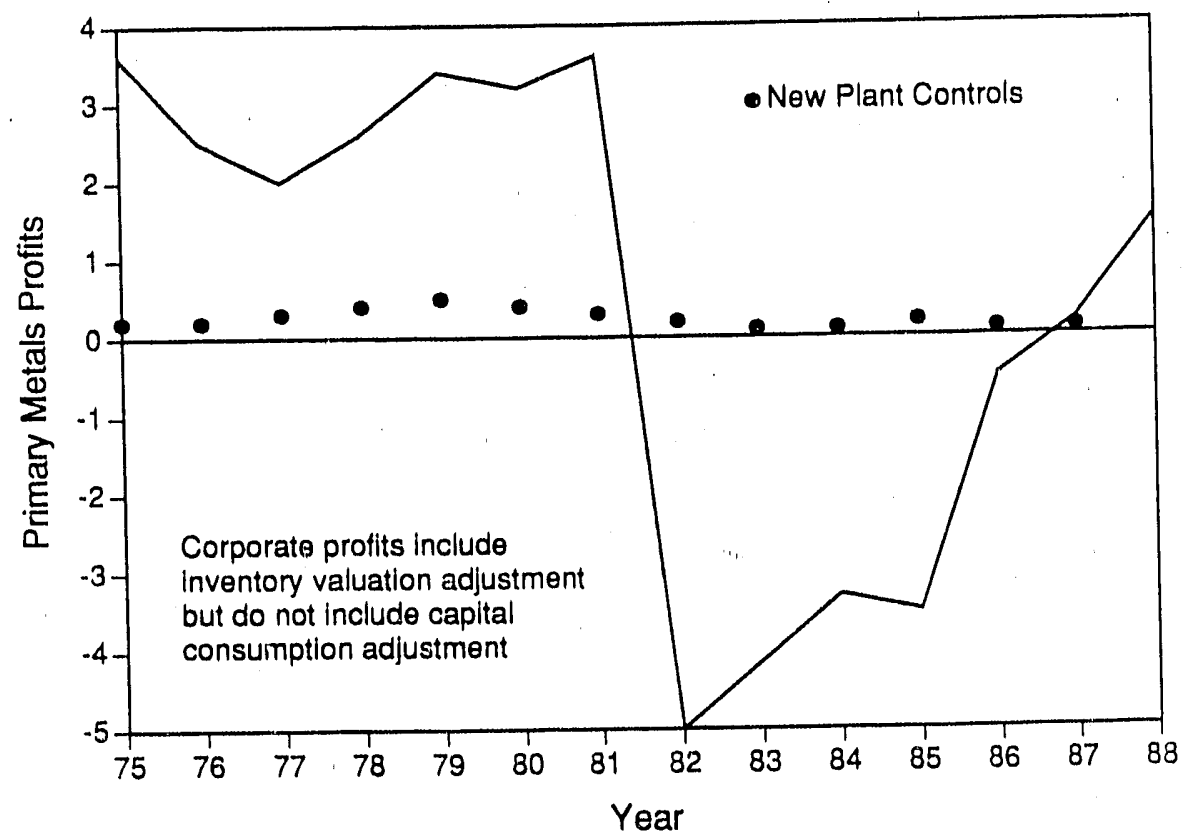

FIGURE 2.2 Pollution Abatement Expenditures and Corporate Profits for the Primary Metals Industry, 1975-1987 (Source: U.S. Department of Commerce 1988)

\subsubsection{Implications for the Petroleum Industry}

The regulation of ICTs could affect both energy producers and major energy users. Petroleum refineries could be among the industries that are most severely affected by possible chromium rules. Energy-intensive industries, such as the primary metals and glass manufacturers, also use ICTs. The distribution of ICTs that use chromium-based water treatment chemicals is shown in Figure 2.3.

Petroleum refining accounts for the second largest number of cooling towers using chromate $\left(\mathrm{CrO}_{4}{ }^{\prime}\right)$, ranking far behind chemical manufacturing, which is responsible for over twothirds of the total number of the cooling towers using chromate (see Figure 2.4). However, a far greater percentage of all petroleum refining facilities operate ICTs. It is estimated that there are 189 operating petroleum refineries with $680 \mathrm{ICTs}$, and $70 \%$ of these ICTs use chromate-based water treatment systems. Furthermore, in terms of annual hexavalent chromium emissions, the petroleum industry does not rank far behind the chemical industry (see Figure 2.4). Although the petroleum industry is responsible for less than one-fifth of the total number of ICTs, it is responsible for $37.5 \%$ of the hexavaleni chromium emitted per year. The discrepancy between the number of ICTs using chromate in a given industry and the subsequent chromate emissions results from the following:

- The varying recirculation rates in ICTs among different industries, as shown in Table 2.3. The more times the cooling water containing $\mathrm{CrO}_{4}=$ is circulated, the more opportunities $\mathrm{Cr}^{+6}$ has to escape into the atmosphere. ICTs used by petroleum refineries generally have relatively high recirculation rates. 


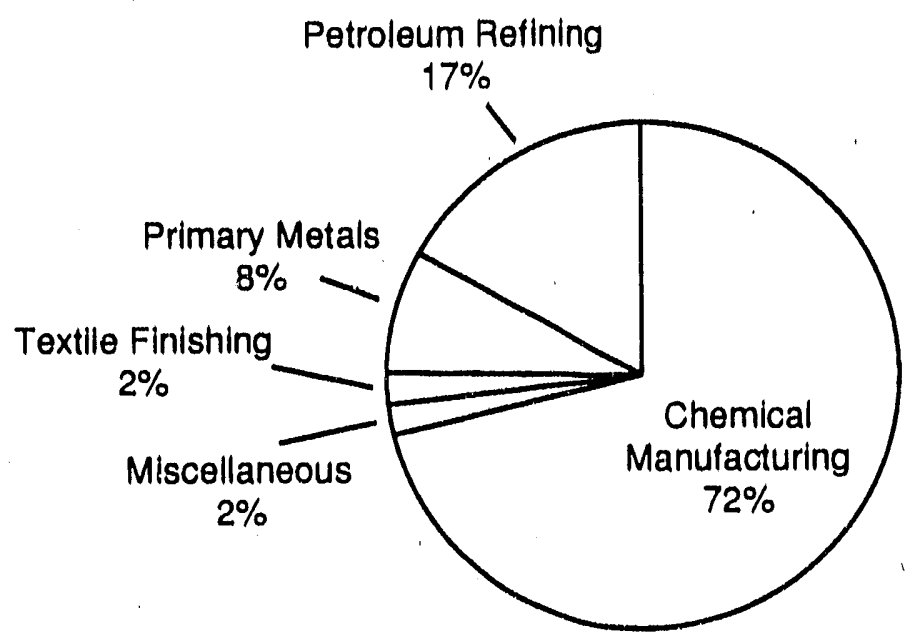

Total Number of ICTs $=2,855$

FIGURE 2.3 Distribution of Industrial Cooling Towers by Industry (Source: Table 5-13 in EPA 1988)

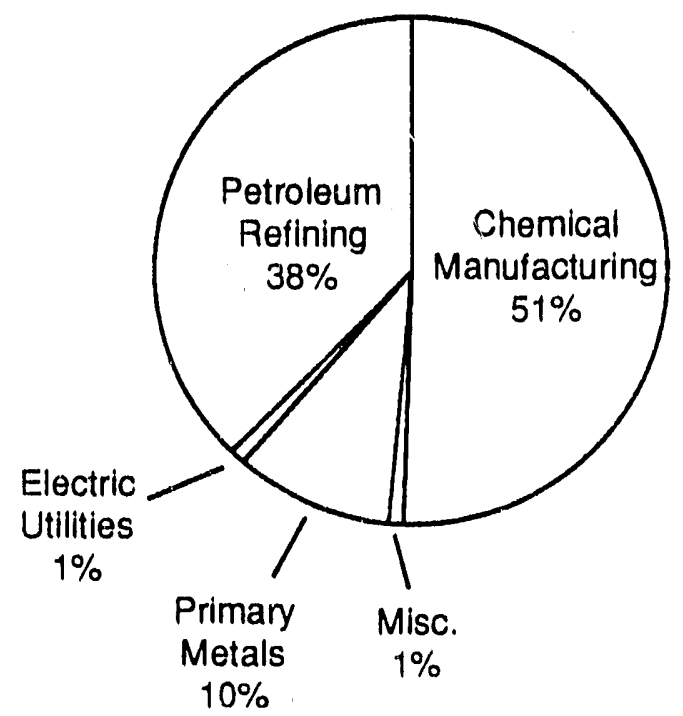

Total Annual Chromium Emissions: 93.48 tons

FIGURE 2.4 Annual $\mathrm{Cr}^{+6}$ Emissions by Industry (Source: Table 5-13 in EPA 1988) 


\begin{tabular}{|c|c|c|c|c|c|}
\hline Industry & $\begin{array}{l}\text { No, of } \\
\text { Plants }\end{array}$ & $\begin{array}{l}\text { No. of } \\
\text { Towers per } \\
\text { Plant }\end{array}$ & $\begin{array}{c}\text { Share of } \\
\text { Towers } \\
\text { Using } \\
\mathrm{CrO}_{4} \\
(\%)\end{array}$ & $\begin{array}{c}\text { Range of } \\
\text { Average } \\
\text { Recirculation } \\
\text { (gal/min/tower) }\end{array}$ & $\begin{array}{c}\text { Share of Towers } \\
\text { at Specific } \\
\text { Recirculation Rates } \\
\text { (\% at gal } / \mathrm{min} / \text { lower) }\end{array}$ \\
\hline $\begin{array}{l}\text { Chemical } \\
\text { manufacturing }\end{array}$ & 1,820 & 2.8 & 40 & $5,230-104,810$ & $\begin{array}{l}50 \text { at } 1,(000) \\
24 \text { at } 5,000 \\
16 \text { at } 15,500 \\
10 \text { at } 42,000\end{array}$ \\
\hline Glass & 146 & 0.4 & 5 & 2,230 & 100 at 2,230 \\
\hline $\begin{array}{l}\text { Petroleum } \\
\text { refinery }\end{array}$ & 189 & 3.6 & 70 & $1,06()-41,280$ & $\begin{array}{l}39 \text { at } 5,000 \\
29 \text { at } 15,000 \\
29 \text { at } 15,500 \\
3 \text { at } 105,000\end{array}$ \\
\hline $\begin{array}{l}\text { Primary } \\
\text { metal }\end{array}$ & 243 & 4.6 & 20) & $990-105,630$ & $\begin{array}{l}33 \text { at } 1,(0) 0 \\
29 \text { at } 5,(000) \\
31 \text { at } 15,500 \\
7 \text { at } 105,000\end{array}$ \\
\hline $\begin{array}{l}\text { Tire and } \\
\text { rubber }\end{array}$ & 99 & 2.7 & 15 & 2,000 & 100 at 2,000 \\
\hline $\begin{array}{l}\text { Textile and } \\
\text { finishing }\end{array}$ & 424 & 2.4 & 5 & 1,260 & $100)$ at 1,260 \\
\hline
\end{tabular}

Source: Based on information provided in EPA (1988).

- The amount of time that fans are running. In descending order, the average percentage of time that fans in ICTs are running are as follows: $90 \%$ in utilities; $87.3 \%$ in petroleum refining; $78.8 \%$ in the primary metals industry; $72.2 \%$ in chemical manufacturing; $65.5 \%$ in tire and rubber production; $58 \%$ in glass production; and $47 \%$ in textile finishing.

This type of discrepancy is not as large in the other energy-related industries; utilities account for $2 \%$ of all cooling towers using chromate (only two utilities with three cooling towers each are reported to use chromium-based cooling towers) and similarly account for only $1.1 \%$ of the annual $\mathrm{Cr}^{+6}$ emissions.

The number of ICTs per industry using chromates does not necessarily indicate the degree to which an industry as a whole will be affected by ICT regulations. Also important is the share of an industry that uses chromate in its ICTs, as shown in Table 2.3. Although the chemical industry is responsible for the largest share of all ICTs using chromate, a larger percentage of all petroleum refiners than chemical manufacturers would be affected by regulations. There is an average of 3.6 towers at each petroleum site, compared with 2.8 towers 
at each chemical production site. Moreover, $70 \%$ of all the towers at petroleum refineries use chromate-based water treatment. Regulations would also probably have less severe effects on the primary metal industry, because only a fifth of this industry uses chromium-dependent cooling towers. Similarly, $15 \%$ of the tire and rubber industry uses the chromate water treatment system, and an estimated 5\% of the ICT's in the glass production and textlle finishing industries are chromate based. The petroleum industry would likely be one of the industries most severely affected by the proposed regulation of chromium from ICTs.

\subsubsection{Alternatives to Chromate-Based Water Treatment}

Chromate may be removed to varying degrees from water treatment systems. Chromate concentrations in recirculating cooling water can be limited and used in combination with substitutes or can be completely supplanted by substitutes. These alternatives will be chosen by industries on the basis of how well they can mimic the anti-scalant, anti-fouling, and anticorrosive properties of chromate as well as on the basis of their costs. In addition to these alternatives, ICTs can also be retrofitted with high-efficiency drift eliminators (HEDEs). Many new factors come into play and gain importance when lower concentrations of chromate are used:

- Heat exchanger tube life under low chromate treatment has been reported to decrease by $25 \%$ from that under high chromate treatment (EPA 1988).

- Substitutes for chromate must limit cathodic reactions, to act as a dispersant and to prevent excessive scaling, fouling, and corrosion.

- Low chromate systems are very sensitive to water quality (i.e., $\mathrm{pH}$, alkalinity, hardness, and conductivity) and operating conditions. Maintenance requirements at low chromate ICTs are as rigorous as those for nonchromate programs, because water temperature, flow rate, inhibitor concentration, contaminants, and feed rates must be closely monitored.

All that is true of low chromate programs is doubly true for nonchromate programs; maintenance and monitoring are crucial. In fact, the use of some substitutes requires such closely monitored conditions that in many instances, automatic control of $\mathrm{pH}$, blowdown, and inhibitor feed are strongly recommended, although not essential. In nonchromate programs, chromate is completely replaced by combinations of cathodic inhibitors, anodic inhibitors, antiscalants, and dispersants. Typical nonchromate formulations are based on phosphates, molybdate, and organics (e.g., modified lignins, tannins, polyamines, phosphonides, phosphonium compounds, and heterocyclic nitrogen compounds), for which monitoring and control are critical. These substances are generally more costly than chromate, and the total amounts needed are greater (EPA 1988). Consumption of biocides, for example, can be greater in organic-based systems than in chromate-based systems.

Different formulations of substitutes have different advantages and problems. Microbiological control may be more difficult where phosphates are substituted since phosphates are also nutrients. On the other hand, the primary advantage of using phosphates over chromate is that phosphates do not react with reducing agents (contaminants) in the recirculation of water and thus do not lose their effectiveness in contaminated water. Thus, there is a complex set of requirements that the substitutes of chromate must satisfy. 
The results from low-chromate and nonchromate ICT demonstrations are mixed. Lowchromate programs (4-6 parts per million or pprn). have yielded acceptable results in some cases:

- Chevron and Shell oil refineries are successfully operating such programs.

- The Basin Electric Company facility is also successfully operating a lowchromate program.

Demonstrations have not always been successful in industrial applications (EPA 1988). Failures of some low-chromium programs $(2-4 \mathrm{ppm})$ at oil refineries were a result of process leaks into recirculating water.

Nonchromate programs, too, are not without problems, and tests show mixed results:

- The Basin Electric Company reported that corrosion significantly worsened under a nonchromate prograin (EPA 1988).

- Most responses from petroleum refineries and steel industries indicated that treatment costs, process debits, fouling, and corrosion rates increase when chromate programs are switched to nonchromate programs (EPA 1988).

- A Chevron oil refinery was unsuccessful because used boiler blowdown containing water with orthophosphate (high alkalinity and high $\mathrm{pH}$ ) was used as makeup water. The program was successful when municipal'water (which had less silica and was not as hard) was used.

- An Amoco refinery indicated that corrosion rates are equal to or less than those achieved by chromate when treatment is well controlled.

In some cases, fouling became so severe that the nonchromate program could not be continued. In addition to maintenance practices that vary drastically, the effectiveness of nonchromium treatment also appears to depend on the materials used for the condenser and coder bundles. Certain materials such as stainless steel and admiralty brass are naturally less corrosive. However, carbon steel is the predominant material used to make heat exchangers, and it has a higher corrosion rate. The designs of ICTs vary and can influence the scale of corrosion. Tubes in typical heat exchangers in petroleum refineries are 20 feet; those in the textile and finishing industries are 8 feet, on average. Thus, a larger area in the refinery ICTs may be vulnerable to corrosion and in need of replacement.

On the basis of these examples, three factors appear to be important in deciding the suitability of implementing nonchromate programs:

1. Maintenance and monitoring capabilities,

2. Design of ICTs and the materials that are exposed to substitutes, and

3. Accessibility to high-quality water. 
Drift eliminators were originally used to alleviate the nuisance deposition of water drift and its dissolved solids on nearby buildings or automobiles (EPA 1988). Drift ellminator blades are configured to force directional changes in the alr flow such that the momentum of the water droplets causes them to collect on the blade surfaces. The impaction of droplets on drift eliminator surfaces reduces the concentration of drift from the exit air of cooling towers. Most of the drift eliminators currently used on ICTs are low-efficiency drift eliminators (LEDEs). The retrofitting of these facilities with HEDEs has demonstrated reductions of hexavalent chromium emissions by $66-88 \%$ (EPA 1988). The performance of drift eliminators depends on proper Installation and maintenance practices. Perlodic inspections are required to ensure that drift eliminators fit tightly around structural members and to detect leaks from the distribution deck plank and thus ensure there are no leaks that permit the bypass of drift eliminators.

Table 2.4 is included to demonstrate the relationships between costs of various methods to control chromium emissions. Costs estimates vary dramatically depending on i' estimator, but the general relationships between methods probably do not vary. Retrofitting ICT's with HEDEs was found to be the least costly and the most cost-effective method of reducing chromium emissions (EPA 1988). It is likely that regulation of chromium emissions from ICTs would to some extent be based on these findings and would require emissions to be reduced to levels achievable with HEDEs. What is true in general also appears to be true for the petroleum industry; implementation of HEDEs is indeed the most cost-effective way to reduce chromium in the petroleum industry.

TABLE 2.4 Costs and Cost Effectiveness of Improved Chromium Control

\begin{tabular}{|c|c|c|c|}
\hline Control Option & $\begin{array}{c}\mathrm{Cr}^{+6} \text { Emission } \\
\text { Reduction } \\
(\%)\end{array}$ & $\begin{array}{l}\text { Annualized Cost } \\
(\text { million } \$)\end{array}$ & $\begin{array}{l}\text { Cost Effectiveness } \\
(\$ / \mathrm{Mg})\end{array}$ \\
\hline \multicolumn{4}{|l|}{ Low-chromate program } \\
\hline Average (all industries) & 54 & 26 & 571,000 \\
\hline Petroleum industry & - & $y$ & $524,(0)(0)$ \\
\hline Electric utilities & - & - & - \\
\hline \multicolumn{4}{|l|}{ Nonchromate program } \\
\hline Average (all iridustries) & 100 & 73.2 & 865,000 \\
\hline Petroleum industry & - & 25.5 & $8(12,60)$ \\
\hline Electric utilities & - & 1.3 & $1,315,8(0)$ \\
\hline \multicolumn{4}{|l|}{ Retrofit with HEDE } \\
\hline Average (all industries) & 67 & 13.7 & $241,(00)$ \\
\hline Petroleum industry & - & 4.2 & 198,200 \\
\hline Electric utilities & - & 0.2 & 790,300 \\
\hline \multicolumn{4}{|l|}{ Low-chromate and HEDE } \\
\hline Average (all industries) & 82 & 39.7 & $554,()(1)$ \\
\hline Petroleum industry & - & 13.2 & $489,50()$ \\
\hline Eléctric utilities & - & 0.2 & $79(0,300$ \\
\hline
\end{tabular}

Source: Based on information provided in EPA (1988). 
The utility industry, however, is unique. Costs to reduce chromlum emissions do not rise proportionately with larger emission reductions. For exarriple, an $83 \%$ emission reduction costs $n 0$ more than a $66 \%$ emission reduction. The implementaticn of a low-chromium trealinent program does not add to the costs of installing HEDEs, because uttlities have admiralty brass heat exchangers instead of the more corrosive carbon steel heat exchangers that are predominantly used in other industrles. The high costs for other industries result from the need for corrosion inthibitors to protect the heat exchanger from the effects of reduchng chromate, and these are not needed by utilities.

\subsubsection{Interaction of Potential Chromium Electroplating and Cooling Tower Regulations}

Chromium electroplating is better defined as a process than as an industry (EPA 1988). Although some electroplating firms specialize in electroplating operations, with ancillary operations such as polishing and grinding, slightly more than half of all electroplating is done. by firms that have an electroplating operation as one stage of production within a larger manufacturing operation (captive electroplating). The producers of electroplated goods serve an extremely diversiffed market. Five product groups for which chromium electroplating is an important component include plumbing materials, hand tools, automobile parts, industrial rollers, and hydraulic cylinders. The purposes of electroplating range from decorative (t.e., the common chrome-plated consumer goods) to practical industrial applications (e.g." inhibiting chemical corrosion or physical abrasion). Lndirect impacts on energy-related industries could result from the latter of these two types. Cylinders and rollers used in industrial processes are often electroplated with chromium. The regulation of hard-chromium plating would likely increase the cost of electroplated parts incurred by a number of energy-intensive industries. In addition, the regulation of chromium electroplating also has a direct impact on energy production. Hydraulic cylinders, which are used by the nuclear and mining industries and in oil drilling, are treated with hard-chromium plating.

The regulation of electroplating could also clash with potential regulations on ICTs and could compound strains on petroleum refiners trying to comply with both regulations concurrently. By requiring the removal of chromate along with its anti-corrosive properties from recirculating water in cooling towers, ICT regulations could increase corrosion rates or necessitate the use of expensive anti-corrosive materials in cooling towers. Just as chromate is used in recirculation water to minimize corrosion, so too are electroplated parts used to minimize corrosion. The petroleum and chemical industries rely on electroplated components such as blow-out preventers, chokes, pumps, compressors, tubing, vessels, packers, various valves, and heat exchange equipment. Heat exchange equipment is also used in cooling towers. If both regulations were to be finalized, petroleum refiners would be faced with adding expensive anti-corrosive substances in cooling towers to replace chromate and finding alternatives to the hard-chromium plating of parts. Electroless nickel is a potential substitute for hard chromium but is significantly more expensive (EPA 1988). Therefore, substitution for hardchromium electroplating appear's very unltkely because comparably priced hard-chromium substitutes are not available (EPA 1988). 


\subsection{TANK VESSELS}

Regulatory authority for controlling emissions from tank vessels (or tankers), which may carry energy products such as gasoline or crude oil, is provided under both Title I and Title III of the CAAA of 1990. As a precursor to ozone, VOC emissions are regulated under Title 1, Provisions for Attainment and Mainterlance of National Ambient Air Quality Standards. VOC emissions released from tank vessels encompass 250 different compounds, of which 60 are on the CAAA list of 189 HAPs.

Although these vessels are used to transport many different commodities, those used in the transport of gasoline and crude oil each account, for $47.2 \%$ of the total VOC emissions from vessels. State regulations of 141 tanker terminals cover more than half of the nationwide emissions from this category of sources; vessel rules have been proposed or promulgated in Alaska, Louisiana, New Jersey, Pennsylvania, and parts of California.

Development of CAA regulations is currently underway. EPA will first make a decision on the control of VOC emissions under the specific requirements for these sources in new Section 183 of the CAA, with subsequent review of the rule's adequacy under the HAPs requirements. Although a separate rule under Title III may be necessary to comply with the requirements for MACT, similar considerations under each provision must be given to the costs and energy impacts of the control requirements.

EPA is developing tank vessel rules on the basis of emissions data provided by 1,800 terminals (see Table 2.5). The data indicate that 60 of the 189 listed HAPs are emitted from tank vessels, although the quantity of each emitted chemical is unknown. The regulatory alternatives under consideration by EPA are shown in Table 2.6. One of the critical questions in developing tank vessel rules revolves around whether to mandate a percent emissions reduction or set a mass emission limit based on gallon: loaded. Critics of regulations based on percent reduction contend that two different operators can generate drastically different quantities of VOC emissions, despite loading the same product and volume (Hodges 1991). Loading temperatures and pressures affect the concentration of hydrocarbons, making a standard based on percent reduction problematic. Others, however, have pointed out that requiring a percent emission reduction was more appropriate than imposing limits based on mass emission rate regulations, since the rules must apply to different situations.

EPA will likely base tank vessel standards to control VOC emissions on one the following three control candidates: (1) flares, with a control efficiency of $98 \%$; (2) carbon bed adsorption, with a control efficiency of $95 \%$; or (3) incineration, with a control efficiency of $98 \%$. In a discussion among EPA, state regulators, and technology experts (vendors) at the National Air Pollution Control Techniques Advisory Committee Conference, held in Research Triangle Park, North Carolina, on January 31, 1991, pros and cons were noted (although not described as such) for each of the potential control methods (see Table 2.7). In addition, technologies for energy recovery (i.e., those that route the flue gas through a turbine) are possible, but they are unlikely because marine vessel loading is a batch process and piping costs would be high (Markwordt 1991). 
TABLE 2.5 Estimated Nationwide Annual VOC Emissions from Tank Vessels

\begin{tabular}{lcccc}
\hline & $\begin{array}{c}\text { No. of } \\
\text { Terminals } \\
\text { Loading } \\
\text { Designated } \\
\text { Commodity }\end{array}$ & $\begin{array}{c}\text { Total } \\
\text { National } \\
\text { Throughput } \\
\left(10^{6} \text { bbl/yr }\right)\end{array}$ & $\begin{array}{c}\text { Annual } \\
\text { Emissions } \\
\text { Estimate } \\
(\mathrm{Mg} / \mathrm{yr})\end{array}$ & $\begin{array}{c}\text { Total } \\
\text { Emissions } \\
(\%)\end{array}$ \\
\hline Gasuline & 580 & 657 & 37,300 & 47.2 \\
Crude oil & 397 & 1,312 & 37,400 & 47.2 \\
Jet fuel & 232 & 112 & 2,030 & 2.57 \\
Naphtha, solvents & 227 & 73 & 1,010 & 1.28 \\
Alcohols & 226 & 49 & 978 & 1.24 \\
l'oluene & 176 & 17 & 238 & 0.30 \\
Distillate fuel & 791 & 515 & 95 & 0.12 \\
Chemicals & 658 & 286 & 27 & 0.03 \\
Other & 403 & 59 & 6 & 0.01 \\
Kerosene & 114 & 14 & 3 & 0.004 \\
Total & Not & 3,094 & 79,100 & 100 \\
& applicable & & & \\
\hline
\end{tabular}

Source: Markwordt (1991).

\subsection{ASBESTOS}

Asbestos has been used in insulating materials in buildings since 1926. Although the amount of energy saved from using such insulatory materials has not been estimated, it may be fairly significant whell compared with the absence of insulatory materials. The energy-related questions surrounding the general regulation of asbestos involve the costs of substitutes: (1) How do the costs of substitutes compare with the costs of asbestos-containing insulatory materials? (2) If the costs of substitutes are higher, will they discourage the application of materials to conserve energy?

There are existing (pre-1990 Amendments) CAA NESHAP regulations on asbestos emissions from various sources, including asbestos mills, manufacturing, roadways, demolition and reconstruction, spraying, insulation, and some disposal sites (see 40 CFR, Part 61, Subpart M). These are still in effect. The near-term implementation of Title III for some sources of asbestos would be based on the regulatory development for the revision of the existing NESHAP.

Asbestos is also regulated under a broad set of regulations, including several rules set by OSHA; the Asbestos Hazard Emergency Response Act of 1986 (AHERA); the Resource, Conservation and Recovery Act (RCRA); the Toxic Substances Control Act (TSCA); and the Comprehensive Environmental Response, Compensation, and Liability Act (CERCLA). Air toxics rules that deal with asbestos were designed to control the release of asbestos fibers to the outdoor air. Ironically, such releases increased as a result of other regulations that mandated the removal of asbestos to control indoor air pollution but did not enforce the proper disposal 


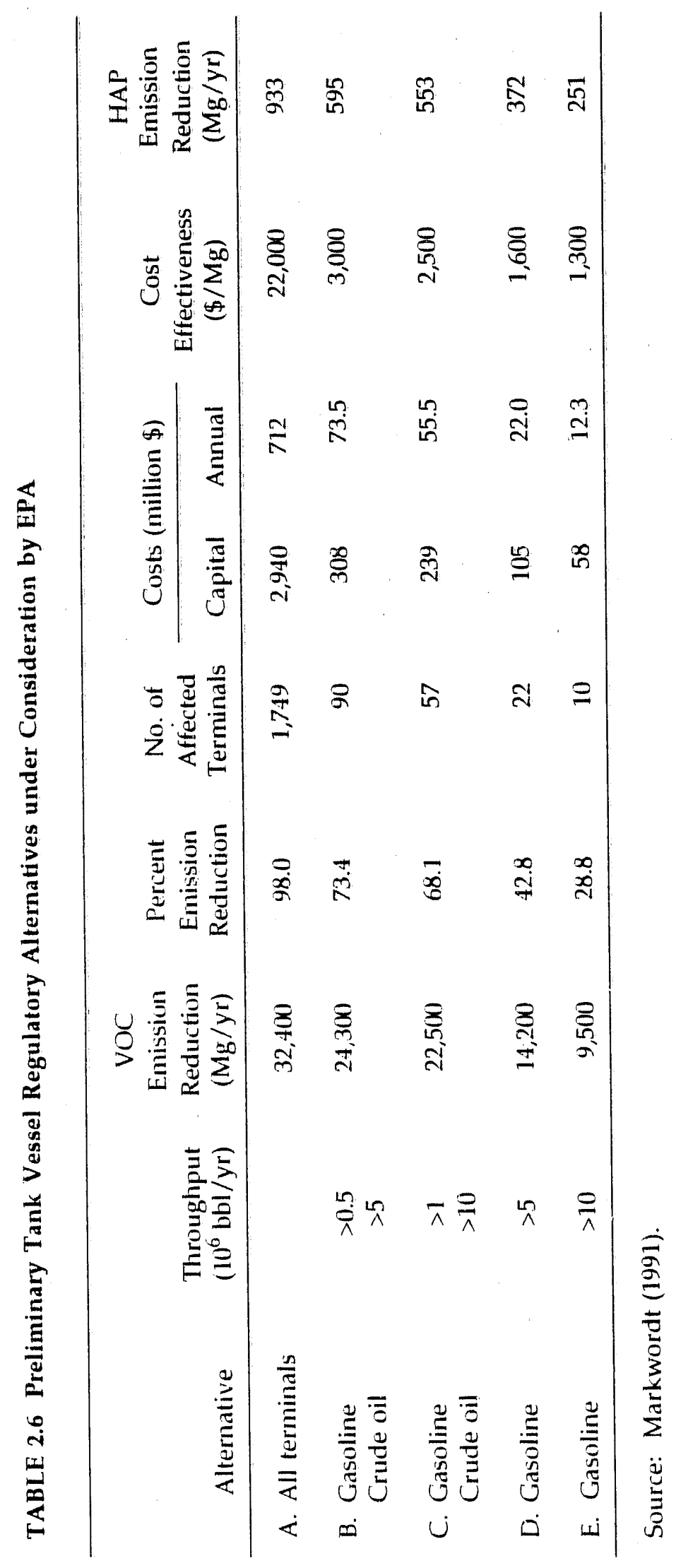


TABLE 2.7 Comparison of Three Methods for Controlling VOC Emissions from Tank Vessels

\begin{tabular}{|c|c|c|}
\hline $\begin{array}{l}\text { VOC Emission } \\
\text { Control Method }\end{array}$ & Positive Features & Negative Features \\
\hline Carbon bed adsorption & $\begin{array}{l}\text { Carbon adsorption can recover } \\
\text { valuable resources. } \\
\text { Carbon adsorption may be the } \\
\text { preferred technology in some } \\
\text { states (e.g., New Jersey). } \\
\text { Carbon adsorption that is } \\
\text { currently used achieves an } \\
\text { emission rate of } 2 \text { mg per liter. }\end{array}$ & $\begin{array}{l}\text { It is uncertain how adsorption } \\
\text { would perform on a wide } \\
\text { range of chemical substances, } \\
\text { since some substances can } \\
\text { poison the carbon bed. It is } \\
\text { widely acknowledged that } \\
\text { designing a carbon adsorber to } \\
\text { control multiple compounds } \\
\text { adds to the complexity and the } \\
\text { cost of the system. Terminals } \\
\text { that load several different } \\
\text { commodities would find } \\
\text { carbon adsorption difficult to } \\
\text { use. }\end{array}$ \\
\hline Incineration & $\begin{array}{l}\text { Incineration can handle } \\
\text { multiple commodities with } \\
\text { different chemical species } \\
\text { (Markwordt 1991a). } \\
\text { More cost data on incineration } \\
\text { than on any other control } \\
\text { methods are available to EPA. }\end{array}$ & $\begin{array}{l}\text { The products of incomplete } \\
\text { combustion from incineration } \\
\text { are undesirable (i.e., } \mathrm{CO}, \mathrm{NO}_{\mathrm{x}} \\
\text { and } \mathrm{CO}_{2} \text { ). }\end{array}$ \\
\hline Open-flame flare"s & $\begin{array}{l}\text { Minimal capital investment is } \\
\text { needed to purchase open- } \\
\text { flame flares. }\end{array}$ & $\begin{array}{l}\text { EPA's efficiency rating for } \\
\text { open-fleme flares is based on } \\
\text { very limited testing; the same } \\
\text { company that conducted the } \\
\text { testing stated that the real-life } \\
\text { application of this method has } \\
\text { not consistently achieved such } \\
\text { high levels of efficiency ( } 98 \% \text { ). } \\
\text { Tests were done with pilot- } \\
\text { plant-size equipment under } \\
\text { controlled conditions, with } \\
\text { engineers and technicians } \\
\text { operating the equipment. } \\
\text { Safety is decreased due to the } \\
\text { continuous ignition source. } \\
\text { Flaring prohibits the collection } \\
\text { of trade-off pollutants (e.g., } \\
\text { CO and NO } O_{x} \text { ), whose recovery } \\
\text { can provide a valuable } \\
\text { resource. }\end{array}$ \\
\hline
\end{tabular}


TABLE 2.7 (Cont'd)

\begin{tabular}{|c|c|c|}
\hline $\begin{array}{l}\text { VOC Emission } \\
\text { Control Method }\end{array}$ & Positive Features & Negative Features \\
\hline Open flame (Cont'd) & & $\begin{array}{l}\text { To achieve reduced emission } \\
\text { rates, temperature, time, and } \\
\text { mixing controls must be } \\
\text { employed with combustion } \\
\text { devices. This is not possible } \\
\text { with open-flame flares (as } \\
\text { opposed to enclosed com- } \\
\text { bustors) (Hodges 1991). }\end{array}$ \\
\hline & & $\begin{array}{l}\text { Unlike vapor recovery systems } \\
\text { and enclosed incineration } \\
\text { systems, direct emission } \\
\text { testing from open-flame flares } \\
\text { cannot be done accurately, } \\
\text { thus limiting the ability to } \\
\text { monitor emissions (Hodges } \\
\text { 1991). }\end{array}$ \\
\hline
\end{tabular}

of asbestos. The air toxics rules pertaining to asbestos probably do not add much weight to the already lengthy list of regulations that provide disincentives to using asbestos-containing materials.

\subsection{ORGANIC SOLVENTS}

Halogenated solvents are widely used to clean or condition the surfaces of metal parts, electronic components, and other nomporous substrates. They can dissolve many common residues from manufacturing processes, are relatively nonflammable, and can effectively clean even very small and intricate parts. The five industries that use the largest quantities of halogenated solvents for cleaning are furniture and fixtures (Standard Industrial Classification [SIC] 25), fabricated metals (SIC 34), electric and electronic equipment (SIC 37), transportation equipment (SIC 37), and miscellaneous manufacturing (SIC 39) industries. Nonmanufacturing industries such as railroad, bus, aircraft, and truck maintenance, automobile dealers, and service stations also use organic solvent cleaners. The five commonly used halogenated solvents include methylene chloride (MC), trichloroethylene (TCE), perchloroethylene (PCE), trichlorofluoroethane (CFC-113), and 1,1,1-trichloroethane (TCA). Except for TCA, these solvents are on the current list of HAPs. In some cases, new solvents and blends that do not contain any of the five halogenated solvents, such as water-based cleaners, can replace existing solvent systems. However, water solvents may require relatively high energy use and may generate large wastewater streams.

Energy repercussions of regulating these solvents would involve their substitution by petroleum-based distillates in a very limited number of circumstances and the potential increase in consumption of energy with the implementation of emission control technology. The 
electricity needed to power emission control devices used in solvent-based cleaning processes is noted in Table 2.8. The two types of halogenated solvent-based cleaning processes, open-top vapor cleaners (OTVCs) and in-line cleaners, can implement different combinations of emission controls. The possible combinations of control technologies depend on operating schedules and specific techniques in use. The emission reductions achievable with various control combinations are $30-90 \%$. Hoists are always included in the emission control scenarios, albeit with different speed capacities. The scenario that achieves the greatest emission reductions based on these data combines implementation of hoists with an enclosed design and a sump cooling system. Cooling systems help to condense solvent vapors and prevent their release after being heated during the cleaning system.

\subsection{ETHYLENE OXIDE}

EPA is in the process of developing the regulation for ethylene oxide (EO), which is used as a sterilant for heat- or moisture-sensitive materials and as a fumigant to control microorganisms or insects. EO is used in the production of medical equipment (e.g., syringes and surgical gloves), spices, cosmetics, and pharmaceutical products. Libraries and museums use it to fumigate books and historical items. Beehives are even fumigated with EO to control diseases to bees. It is used at more than 200 commercial sterilization facilities in the United States and at approximately 7,000 hospitals (for which NESHAP rules have not been proposed).

It is expected that the regulation of $\mathrm{EO}$ will have virtually no energy-related impact. At most, the impact would be indirect and probably minimal. If control technologies were installed, they might require slightly more energy than previously used. The transport of the by-products might then also require some amount of energy. Radiation sterilization, which is currently used for about half of the products sterilized in the United States, could serve as a substitute for use of EO and may consume more energy. The operating costs associated with these controls and substitutes, however, would be minuscule compared with labor, installation, and capital costs associated with reducing $E O$ emissions. The cost of energy would also be very small when compared with other control equipment operating costs such as catalyst and filter replacements for scrubbers.

\subsection{MUNICIPAL WASTE COMBUSTORS}

Municipal waste combustors (MWCs) make up one of the categories affected under the solid waste combustion section of Title III, and waste-to-energy facilities currently produce about $0.2 \%$ of the nation's energy (Rathje 1991). MWCs usually produce energy as exportable electric power at the rate of 550 kilowatt-hours ( $\mathrm{kWh}$ ) per ton of trash (Sussman 1991). The economic benefits associated with waste-to-energy plants are twofold: waste-to-energy plants make "cash from trash" at the tipping floor, where communities pay $\$ 20-50$ per ton to dump their garbage, and the turbine generators fueled by the trash produce salable electricity (Rathje 1991). An estimated 128 of the MWCs nationwide are waste-to-energy plants, and 19 waste-to-energy plants are under construction (Rathje 1991). 
TABLE 2.8 Effectiveness and Energy Requirements of Selected Control Technique Combinations for Organic Solvent Cleaners

\begin{tabular}{|c|c|c|}
\hline $\begin{array}{l}\text { Control Technique } \\
\text { Combination }\end{array}$ & $\begin{array}{l}\text { Range of Achievable } \\
\text { Emission Reduction } \\
(\%)^{\mathrm{a}}\end{array}$ & $\begin{array}{c}\text { Annual } \\
\text { Electricity } \\
\text { Requirement } \\
(\mathrm{kWh})^{\mathrm{b}}\end{array}$ \\
\hline \multicolumn{3}{|l|}{ Open-top vapor cleaners (OTVCs) } \\
\hline $\begin{array}{l}\text { Hoist }(11 \mathrm{ft} / \mathrm{min}) \\
\text { Automated cover }\end{array}$ & $30-60$ & $783-1,343$ \\
\hline $\begin{array}{l}\text { Hoist }(11 \mathrm{ft} / \mathrm{min}) \\
\text { Freeboard refrigeration device }\end{array}$ & $40-70$ & $1,902-3,02.1$ \\
\hline $\begin{array}{l}\text { Hoist }(3 \mathrm{ft} / \mathrm{min}) \\
\text { Automated cover }\end{array}$ & $40-80$ & $783-1,343$ \\
\hline $\begin{array}{l}\text { Hoist }(3 \mathrm{ft} / \mathrm{min}) \\
\text { Freeboard refrigeration device }\end{array}$ & $50-80$ & $1,9(2)-3,021$ \\
\hline $\begin{array}{l}\text { Hoist }(11 \mathrm{ft} / \mathrm{min}) \\
\text { Enclosed design sump cooling }\end{array}$ & $7(1)-80$ & 1,902 \\
\hline $\begin{array}{l}\text { Hoist }(3 \mathrm{ft} / \mathrm{min}) \\
\text { Enclosed design sump cooling }\end{array}$ & $80-90$ & 1,902 \\
\hline \multicolumn{3}{|l|}{ ln-line cleaners } \\
\hline Freeboard refrigeration device & $50-60$ & 3,357 \\
\hline Carbon adsorption & $50-60$ & 6,714 \\
\hline $\begin{array}{l}\text { Carbon adsorption } \\
\text { Sump cooling }\end{array}$ & $60-65$ & 8,393 \\
\hline $\begin{array}{l}\text { Freeboard refrigeration device } \\
\text { Sump cooling }\end{array}$ & $60-65$ & 5,036 \\
\hline $\begin{array}{l}\text { Superheated vapor } \\
\text { Sump cooling }\end{array}$ & 70 & 5,036 \\
\hline $\begin{array}{l}\text { Freeboard refrigeration device } \\
\text { Superheated vapor }\end{array}$ & $70-85$ & 6,714 \\
\hline
\end{tabular}

aSize of range indicates relative dependency on schedule of cleaning process.

${ }^{b}$ Electricity needed to power control technologies fitted on in-line cleaners is based on size of $38 \mathrm{ft}^{2}$. Standard OTVCs range from 2.2 to $48 \mathrm{ft}^{2}$ in air/solvent vapor interface area. Hoists move the parts basket through the solvent cleaner vapor (substitutes for human systems operators) and are capable of moving at different speeds $(\mathrm{ft} / \mathrm{min}$ ). This difference, however, is not considered in the estimated electricity requirements.

Source: Based on Tables 4-9 and 4-10 in EPA (1989a.) 


\subsubsection{Title III Provisions Pertaining to Municipal Waste Combustors}

Section 129 calls for the review of New Source Performance Standards (NSPS) for solid waste combustors and might have been more appropriately placed in Title I than in Title III. Technically, Section 129 does not fit neatly into either Title III or Title I; Section 129 specifically addresses only a handful of the 189 listed Title IIl HAPs (i.e., cadmium, mercury, dibenzofurans, hydrogen chloride, and lead) and regulates all of the Title I pollutants, including lead, sulfur dioxide $\left(\mathrm{SO}_{2}\right)$, particulate matter $(\mathrm{PM})$, nitrogen oxides $\left(\mathrm{NO}_{x}\right)$, and carbon monoxide $(\mathrm{CO})$. Thus, Section 129 is something of a "hybrid," regulating substances belonging to Title I and some Title III substances, but regulating in such a manner so as to ensure that the NSPS rules established for these substances also meet MACT criteria as established in Title III. In exchange for exempting MWCs from MACT requirements for the long list of HAPs, Congress required additional specified pollutants from Title I to be regulated to a level much like MACT so as to affect smaller units in the near future. The regulation of combustors under Section 129 precludes additional regulation under the general Title III provisions, which require standards for any sources that emit 10 TPY of a single HAP or 25 TPY of any combination of HAPs. Section 129 stipulates that "no solid waste incineration unit subject to performance standards under this section [129] and section 111 (of Title I) shall be subject to standards under section 112(d) of this Act." However, MWCs are still subject to the ultimate Title III evaluation of whether a residual risk standaid will later be necessary.

Requirements under the MWC section of Title III refer to facilities that combust any solid waste material from commercial, industrial, or general public sources but exclude the following:

- Facilities that combust waste for the primary purpose of recovering metals (i.e., primary or secondary smelters),

- Small power production facilities as defined in the Federal Power Act (FPA),

- Qualifying cogeneration facilities as defined in the FPA that burn homogeneous waste (i.e., tires or used oil, but not refuse-derived), and

- Air curtain incinerators that burn only wood wastes, yard waste, and clean lumber.

The CAAA defines municipal waste as refuse collected from the general public and from residential, commercial, institutional, and industrial sources, consisting of paper, wood, yard wastes, food wastes, plastics, leather, rubber, and other combustible materials such as metal, glass, and rock. Municipal waste does not include industrial process wastes or medical wastes that are segregated from such other wastes. To be considered a MWC by the CAAA, a unit must combust a fuel feed stream that is composed of more than $30 \%$ by weight of municipal waste. Section 129 explicitly exempts from the standards units that combust $30 \%$ or less municipal solid waste. A special provision in Title III pertaining to MWCs calls for a review of the availability of acid gas scrubbers prior to the promulgation of any performance standard.

In setting standards, the CAAA stipulates that EPA may distinguish among classes, types (including mass-burn, refuse-derived fuel (RDF), modular, and other types of units), and 
sizes of units within a category. Standards for new units must be as stringent as levels achieved by the "best controlled similar unit," as determined by EPA. Standards for existing units may be less stringent than standards for new units but shall not be less stringent than the average emission limitation achieved by the best $12 \%$ of units in the category, or in other words, based on MACT standards. The CAAA require that EPA consider costs and energy requitinents in setting these standards. Pursuant to both Section 111 of Title I and Section 129 of Title III, EPA is required to specify numerical emission limitations for:

- Cadinium

- Dioxins

- Hydrogen chloride

- Mercury

- Sulfur dioxide

- Opacity (as appropriate)
- Carbon monoxide

- Dibenzofurans

- Lead

- Nitrogen oxides

- Particulate matter (total and fine)

\subsubsection{Status of Municipal Waste Combustor Rulemaking}

Section 129 requires EPA to promulgate emissions standards for solid waste incineration units combusting 250 tons per day (TPD) or more within 12 months of enactment and for units combusting less than 250 TPD within 2 years of enactment. The regulatory schedule for large MWC units is among the earliest established pursuant to the CAAA.

Under coinciding Sections 111 (in Title I) and 129 (in Title III), the CAAA directs EPA to revise standards of performance and emissions guidelines for new and existing MWCs that combust more than 250 TPD on the basis of MACT standards. A new Section 111 rule for MWCs that was finalized on January 11, 1991, required states to develop standards based on EPA guidelines for 100 existing combustors - each with two or three combustion units - and 30 new plants. The standards were based on the best demonstrated technology (BDT), with consideration given to costs, energy, and environmental impacts. EPA based these BDT standards on good combustion practices and the postcombustion control of air. Good combustion practices apply to new and existing facilities and include the following four operating practices:

- Maintenance of load level at less than $100 \%$ of the maximum demonstrated temperature (MDT) during compliance testing,

- Maintenance of temperature at the PM control device inlet at no more than $30^{\circ} \mathrm{F}$ above the MDT to minimize the postcombustion formation of dioxins and furans,

- Maintenance of a $\mathrm{CO}_{2}$ emission limit that is deemed efficient for the particular combustor type, and

- Certification of all chief facility operators and shift supervisors by the American Society of Mechanical Engineers (ASME), annual establishment of site-specific training manuals, and on-site training for facility personnel. 
TABLE 2.9 Emission Standards for Municipal Waste Combustors Established under the Section 111 Rule

\begin{tabular}{|c|c|c|c|}
\hline \multirow[b]{2}{*}{ Pollutant } & \multicolumn{2}{|c|}{ Existing Facilities, by Size } & \multirow[b]{2}{*}{$\begin{array}{l}\text { New Facilities with } \\
>250 \text {-TPD Units }\end{array}$} \\
\hline & $\begin{array}{l}<1,100-\text { TPD } \\
\text { Facilities with } \\
>250-\text { TPD Units }\end{array}$ & $\begin{array}{l}>1,100-T P D \\
\text { Facilities with } \\
>250-\text { TPD Units }\end{array}$ & \\
\hline $\mathrm{PM}(\mathrm{g} / \mathrm{dscf})^{\mathrm{a}}$ & 0.03 & 0.015 & 0.015 \\
\hline $\begin{array}{l}\text { Organics, i.e., } \\
\text { dioxins and furans } \\
(\mathrm{ng} / \mathrm{dscm})^{b}\end{array}$ & $\begin{array}{c}125 \\
(250 \text { for RDF } \\
\text { facilities })\end{array}$ & 60 & $\begin{array}{c}30 \\
7 \% \text { oxygen }\end{array}$ \\
\hline $\begin{array}{l}\text { Acid gases, i.e., } \mathrm{SO}_{2} \\
\text { and } \mathrm{HCl} \\
(\% \text { reduction })^{\mathrm{c}}\end{array}$ & 50 & 70 & $\begin{array}{l}70 \text { for } \mathrm{SO}_{2} \\
90 \text { for } \mathrm{HCl}\end{array}$ \\
\hline $\mathrm{NO}_{\mathrm{x}}$ (ppmv) & & & $\begin{array}{l}\text { Limit of } 180 \text { ppmv } \\
\text { corrected to } 7 \% \text { oxygen } \\
\text { on a } 24-\text { hr block average }\end{array}$ \\
\hline $\mathrm{CO}$ (ppmv) & & .. - See footnote & $1 \ldots$ \\
\hline
\end{tabular}

${ }^{a}$ Achievement of these limits for particulate matter (PM) must be confirmed by manual sampling over 5 hours; $\mathrm{g} / \mathrm{dscf}=$ grams per dry standard cubic foot.

${ }^{b}$ Achievement of these limits must be based on manual sampling; $\mathrm{ng} / \mathrm{dscm}=$ nanograms per dry standard cubic meter.

'These reductions must be based on 24-hour geometric averages.

${ }^{\mathrm{d} C}$ Carbon monoxide limits vary according to the unit type. The following limits are all based on $7 \%$ oxygen on a 4-hour block average basis: modular starved air $=50$ parts per million by volume (ppmv); mass burn waterwall $=100 \mathrm{ppmv}$; mass burn refractory $=100 \mathrm{ppmv}$; rotary wall $=100 \mathrm{ppmv}$; coal $/$ RDF mixed-fuelfired $=150 \mathrm{ppmv}$; and fluidized bed $=100 \mathrm{ppmv}$. The limit for RDF (refuse-derived fuel) stoker MWCs was based on a 24-hour block average and was set at $150 \mathrm{ppmv}$.

Provisions calling for materials separation were omitted from the final rule based on the conclusion that costs of such a rule would be excessive in some communities. Table 2.9 shows the emission standards established under the Section 111 rule. EPA has estimated that the rule will cost about $\$ 170$ million for new combustors, or about $\$ 11$ per ton of burned waste, and about $\$ 302$ million for existing plants, or an average cost boost of $\$ 10$ per ton of burned waste. (Clean Air Report 1991a).

EPA's next step, after having established rules under Section 111, will be to review these limits under Section 129. EPA must determine whether the BDTs they determined for MWC categories under Section 111 sufficiently qualify as MACT's under Section 129. Title III, 
Section 129 requires EPA to review as well as promulgate any revisions and additional requirement for new and existing MWCs under both Sections 111 and 129. Rules for MWC combustor's are due:

- November 15, 1991, for combustors burning more than 250 TPD (called MWC II rules) and

- ivovember 15, 1992, for MWC units burning 250 TPD or less (called MWC III rules).

The size categorization is in recognition of the greater emissions potential from larger MWC facilities, the fact that more than $90 \%$ of new capacity will be attributed to large facilities, and the dramatic increase in costs associated with emission control for new small facilities.

Rules promulgated as a result of Section 129 of Title III will include reviews of emission limits for $\mathrm{PM}$, opacity, $\mathrm{SO}_{2}$, hydrogen chloride $(\mathrm{HCl}), \mathrm{CO}, \mathrm{NO}$ limits on new sources, dioxins, and furans. The rules will then go a step further to establish additional requirements for lead, mercury, and cadmium from new and existing units, plus $\mathrm{NO}_{\mathrm{x}}$ standards for existing units. Section 129 also requires the development of siting requirements for new sources to minimize potential health and environmental impacts.

Under Section 111 of Title I, EPA established spray dryer/fabric filter (SD/FF) combination controls as the BDT on which to base emission limits for new units. As far as new source limits are concerned, EPA will most likely adopt BDTs as MACTs under Section 129. An EPA staff member indicated that ". . . it is staff thinking at this point, that SD/FF appears to be MACT for MWC emissions" (Johnston 1991). Similarly, selective noncatalytic reduction (SNCR) for the control of $\mathrm{NO}_{x}$ is simultaneously established as a BDT under Section 111 and will also likely qualify as a MACT. Only four new facilities employ SNCR to reduce $N_{x}$. 'The review of the current NSPS standard in light of the MACT requirements will probably result in no revisions (Johnston 1991). Rules required for new sources under Section 129 will not deviate from those passed pursuant to Section 111 in Title I. EPA has stated that the main consideration of the review is whether the current emission limits reflect MACT for new sources by requiring an SD/FF and SNCR for $\mathrm{NO}_{x}$ control. EPA currently holds MACT as equivalent to the BDT established under the current NSPS (Johnston 1991).

The Section 129 review of standards for existing sources, however, may result in the revision of guidelines. MACT's are required to be based on limits that are no less stringent than the emissions from the best-controlled $12 \%$ of the sources. Twenty-five percent of current existing MWC units that are larger than 250 TPD use SD/FF. Although this level of control is not required in the current guidelines, it must now form the basis for regulation according to a strict reading of Section. 129. Because of the number of existing facilities with SD/FF, there is the potential for revision of the existing source guidelines (Johnston 1991). EPA has stated that ". . . the fact that $25 \%$ of existing units have SD/FF will require us to give strong consideration to applying SD/FF to large existing units" (Johnston 1991). In addition, while the appropriate MACT for $\mathrm{NO}_{x}$ reductions from existing sources has yet to be determined, EPA is seriously considering requiring the retrofit of SNCR, which EPA has concluded is "generally not difficult, either technically or in terms of cost" (Johnston 1991). Far fewer than 12\% of existing facilities have any $\mathrm{NO}_{x}$ controls at all. 
Section 129 requires the addition of mercury emisston limits for existing and new sources. However, EPA has concluded that the proposal of a mercury limit is currently not viable since data on mercury emissions are contradictory and there is no technology for mercury In operation on MWCs in the United States at this time (Johnston 1991). Section 129 also requires the addition of limits for lead and cadmium emissions from MWCs. However, because metals behave like conventional PM, they are controlled to levels exceeding $99 \%$ by current control technologies already in place, and EPA considers the level of particulate control being required $(0.03$ gram per dry standard cubic foot $[\mathrm{g} / \mathrm{dscf}$ ] for facilities combusting less than 1,100 TPD with units combusting more than 250 TPD and $0.015 \mathrm{~g} /$ dscf for MWC facllitles combusting more than 1,100 TPD with units combusting more than 250 TPD) as sulficlent to control lead and cadmium under Section 129 (Johnston 1991). Therefore, EPA will probably establish limits for lead and cadmium that are consistent with the level of control already required.

In summary, EPA will likely revise Section 111 rules or supplement them as Section 129 in Title III dictates in the following manner:

- No revision of Section 111 rules for new sources that were based on SD/FF control efficiency levels. MACT will also be based upon SD/FF.

- No revision of Section $111 \mathrm{NO}_{\mathrm{x}}$ rules for new sources under Section 129. MACT will be based on SNCR just as BDT was.

- Likely revision of Section 111 rules for existing sources over 250 TPD based on control efficiency levels of SD/FF.

- Postponement of Section 129 mercury control rules until more technology testing is performed in the United States.

- No revision to rules pertaining to other metals (i.e., lead and cadmium); current PM emission levels deemed sufficient and adopted as Section 129 metals limit.

\subsubsection{Emissions}

Emissions from MWCs are highly variable because the fuel combusted - - namely garbage - is not homogeneous in composition. Garbage streams can include a wide array of materials such as leaves and vegetables that release $\mathrm{NO}_{x}$ when burned, dyes and paints that release $\mathrm{HCl}$, household batteries that release lead, and insecticides and fungicides that release arsenic and mercury (Rathje 1991). Completeness of combustion can also vary from unit to unit, and new substances can be formed during burning. The air toxics released from MWC facilities are a function of variables such as capacity, throughput (fuel), operating characteristics, and air pollution control device operations (see Table 2.10). In general, MWC emissions can be categorized in the following way:

- Particulate matter is emitted because of the turbulent movement of the combustion gases with respect to the burning of refuse and resultant ash. PM also contains trace metals that are volatized in the combustion zone and later condense in the exhaust gas stream. 
TABLE 2.10 Emissions from Municipal Waste Combustors According to Different References

\begin{tabular}{|c|c|c|c|}
\hline $\begin{array}{l}\text { MWC Emissions } \\
\text { Identifled }\end{array}$ & $\begin{array}{l}\text { Documentation for } \\
\text { Source Category List } \\
\text { (EPA 1990a) }\end{array}$ & $\begin{array}{l}\text { Air Emissions } \\
\text { Species Manual } \\
\text { (EPA 199(0b) }\end{array}$ & $\begin{array}{l}\text { Toxic Alr Pollutant/ } \\
\text { Source Crosswalk } \\
\text { (EPA 1989e) }\end{array}$ \\
\hline Acetaldehyde & & & $x$ \\
\hline Arsenic & & $x$ & $x$ \\
\hline Benzene & $x$ & & $x$ \\
\hline Berylllum & & $x$ & \\
\hline Cadmium & & $x$ & $x$ \\
\hline Chlorine & & $x$ & \\
\hline Chlorobenzenes & & & $x$ \\
\hline Cluromiluma & $x$ & $x$ & $x$ \\
\hline Cobalt & & $x$ & \\
\hline Manganese & & $x$ & \\
\hline Mercury & & $x$ & $x$ \\
\hline Nickel & & $x$ & $x$ \\
\hline Phosphorus & & $x$ & \\
\hline POM ${ }^{b}$ & $x$ & & $x$ \\
\hline Selenium & & $x$ & \\
\hline Titanium & & $x$ & \\
\hline
\end{tabular}

${ }^{\mathrm{a}}$ Includes $\mathrm{Cr}^{+6}$.

${ }^{\mathrm{b}} \mathrm{POM}=$ polycyclic organic matter.

- Dioxins, in trace amounts, arrive at the MWC in bleached paper products. Modern combustors are extremely efficient at destroying dioxins (Rathje 1991). Tests, however, reveal dioxin in the fuel exhaust from incinerators, and some research indicates that dioxin reformulates when the gases that have been released by burning waste cool and attach to particulates as they fly up the stack (Rathje 1991). Of all the trace metals, organic chemicals, acid gases, and particulates that escape from incinerators, EPA reports that dioxin poses the greatest health risks (Rathje 1991). However, considerable debate continues on the actual cancer risk associated with dioxin.

- Acid gases, including $\mathrm{SO}_{2}, \mathrm{HCl}$, and hydrogen fluoride (HF), result from reactions of sulfur, chlorine, and fluorine in the feed.

- Metals are emitted when they are volatized by the heat of combustion. Condensation of the less volatile metals such as cadmium and lead occurs after they leave the furnace but before they enter the scrubber vessel. An EPA consultant report states that mass burn facilities may have uncontrolled lead emission rates that range around 32,000 micrograms per dry standard cubic meter ( $\mu \mathrm{g} / \mathrm{dscm}$ ), based on inlet data (Anderson 1991). The same report states that recently built spray dryer absorber/electrostatic 
precipitator (SDA/ESP) systems expertence lead emissions generally below $300 \mu \mathrm{g} /$ dscm when PM emissions are $0.010 \mathrm{~g} / \mathrm{dscf}$ (Anderson 1991).

- The main sources of cadmium are plastics and pigments.

- Lead emissions result from the burning of combustible and noncombustible discarded batteries, plastics, and pigments.

- Because cadmitum and lead adsorb onto PM, it may be impossible to set a numerical emission limit for cadmium or lead without setting a de facto surrogate standard for PM (Anderson 1991). Exactly what the ratio of metals to PM emissions is has proven to be a controversial issue, because the data used to determine such correlations are often not taken from tests in which cadmium, lead, and PM were simultaneously measured.

- Mercury is a metal but behaves differently in emission streams and is therefore handled as a separate category. The variability of emission data indicates that mercury content in MSWs is highly variable (Burton 1990). Emissions result from a few specific mercury-containing items such as batteries, fluorescent light bulbs, and certain electrical items. In addition to initial emissions resulting from the combustion of these products, EPA has some evidence that the potential exists for mercury to off-gas from ash and is seeking more information on this issue.

Setting numerical en ssion limits for metals will be complicated by two facts. First, the database is not very extensive. Metal emissions are almost 100\% fuel related and represent a snapshot of what has been transpiring over a large period of time. Currently, a few one- or twohour tests per year are used to quantify emissions resulting from about 8,000 hours of running time on a MWC unit. Second, the database was not generated using consistent methodology. Consequently, the bias of individual numbers is unknown and the accuracy of the database is in question (Sussman 1991). In addition, EPA's Air Emission Species Manual emphasizes the following two limitations to MWC emissions data: First, measurements of carbonaceous emissions and volatile elements (e.g., lead, arsenic, and mercury) that partially exist in a gaseous phase at high stack temperatures are particularly lımited and are not accurate unless special precautions such as dilution source sampling, aircraft, or balloon methods are exercised. Second, studies from literature ". . do not report a sufficiently broad range of particulate matter to account of the majority of the mass - often due to specific sampling and analytical protocols employed" (EPA 1990b). Studies that use source profiles such as receptor modeling may not apportion all of the ambient aerosol mass accurately.

Various emissions data on MWCs are available for screening purposes. Three EPA documents identify MWC emissions to varying degrees. EPA's Documentation for Draft Source Category List (EPA 1990a) provides very little information on emissions from MWCs and identifies only three chemicals as MWC emissions. EPA's Air Emission Species Manual (EPA 1990b) provides somewhat more specific information on MWC emissions and provides a long list of chemicals emitted from MWCs. (Those chemicals that are listed in Title III are shown in Table 2.11, although the list goes far beyond these chemicals to also include information on emissions that are not subject to Title III.) States are encouraged to derive emission rates with 
TABLE 2.11 Design Considerations for Advanced Pollution Control Systems Being Retrofit on Municipal Solid-Waste Incinerators

\begin{tabular}{lcccc}
\hline Pollutant & U.S. Proposed & $\begin{array}{c}\text { Gothenburg, } \\
\text { Sweden }\end{array}$ & $\begin{array}{c}\text { Munich, } \\
\text { Germany }\end{array}$ & $\begin{array}{c}\text { Bremerhaven, } \\
\text { Germany }\end{array}$ \\
\hline $\mathrm{HCl}(\mathrm{ppm})$ & 200 & 8 & 4 & 4 \\
$\mathrm{SO}_{2}(\mathrm{ppm})$ & 100 & Not regulated & 15 & 45 \\
$\mathrm{HF}(\mathrm{ppm})$ & Not regulated & 0.4 & $<1$ & 2 \\
$\begin{array}{l}\mathrm{Particulate} \\
\left(\mathrm{mg} / \mathrm{nm}^{3}\right)\end{array}$ & 69 & 10 & 10 & 20 \\
$\begin{array}{l}\mathrm{Mercury} \\
\left(\mathrm{mg} / \mathrm{nm}^{3}\right)\end{array}$ & Not regulated & 0.1 & Not regulated & Not regulated \\
$\begin{array}{l}\text { Dioxins } \\
\left(\mathrm{mg} / \mathrm{nm}^{3}\right)\end{array}$ & Not regulated & 0.1 & Not regulated & Not regulated \\
\hline
\end{tabular}

Source: J.R. Donnelly Davy Environmental (1990).

which to develop an air toxic regulatory program on the basis of MWC data provided by EPA's Air Emission Species Manual EPA's Crosswalk Database (EPA 1989e) which only identifies possible emissions but does not quantify emission amounts and is not based on monitored data, also identifies several potential HAPs. In addition to emissions listed in Title III, the Crosswalk Database also names benzo-a-pyrene, chlorophenols, and ethylene as possible emissions from MWCs. EPA's Toxic Release Inventory (TRI; EPA 1989b) does not address MWC emissions at all.

EPA's Air Emission Species Manual provides somewhat more specific information on MWC emissions, although it is still limited to data on four different control technologies, where only one profile is provided for each control method. The data are rated from $B$ to $E$, indicating that the information is not necessarily indicative of other similar-type facilities. The profiles included cover the following control methods:

- ESP (inoperative);

- ESP, baghouse, and scrubbers;

- Spray chamber and three-stage scrubbing tower; and

- Uncontrolled methods.

All four incinerator types have one common denominator: in conjunction with PM, chlorine consistently represents the largest weight percent. In fact, chlorine is alway's more than double any of the other chemical species in terms of percentage weight. The chlorine component of total measured emissions was $34.2 \%$ for incinerators without any control devices, while the chlorine 
component of emisstons from the incherators using a spray chamber and threestage scrubbing tower represented approximately $46 \%$ of the total emissions measured. It is important to note that assessing these emissions is difficult because of the fluctuating chlorine component associated with large amounts of plastic in the municipal waste stream.

Many technologies are available to control atmospheric emissions from MWCs. They can be divided into two groups: (1) PM collection systems such as ESPs and FFs and (2) acid gas reduction technologies such as duct sorbent injection (DSI), SDAs, and wet scrubbers. These two technology groups, however, are not limited to the control of PM and acid gases; PM devices are known to also effectively reduce the emission of metals like lead and cadmium, because these elements adsorb onto the PM. And the acid gas technologies may also control organics, as in the case of the two DSI technologies. Often some combination of PM and acid gas technologies are used in conjunction. Dry scrubbers, for example, are designed to convert metals, organics, and acid gases to a solid form that can then be collected as $\Gamma M$. Dry scrubbers are therefore followed by PM control technologies (e.g, ESPs or FFs). Additional information on MWC control technologies can be found in the appendix. 


\section{IMPLICATIONS OF AIR TOXICS REGULATIONS FOR ENERGY-RELATED INDUSTRIES}

Two aspects of the air toxics provisions of the CAAA arid energy-related industries complicate forecasting the impacts of Title II. The first aspect is that although the CAAA sets torth certain guidelines by which EPA will control air toxics, it also leaves EPA with a great deal of flexibility. Many of the rules that will affect energy-related industries have yet to be proposed. In fact, whether electric utilities are regulated under Title III will hinge on the outcome of a three-year risk assessment study, after which EPA will determine whether this additional regulation is warranted.

The second aspect of energy-related industries that makes it difficult to estimate future impacts on a general basis is the variant nature and diverse characteristics of fossil fuels, which makes it difficult to determine how Title. III will affect energy-related sources on any basis but an individual basis. Table 3.1 shows that the range of pollutants in coal can be quite wide. Similarly, the ranges of certain pollutants in oil can also be very wide (see Table 3.2). In general, the ranges appear to be far greater for domestic oil than imported oil, but this may only be a result of the fact that more domestic data were available. Foreign oil appears to contain higher concentrations of cadmium, while domestic oil contains higher concentrations of mercury and manganese. The ranges of the other pollutants are too broad from which to extrapolate any generalizations. Like industries that depend on coal as a fuel, industries dependent on oil will tace a complex task in responding to HAP regulations because of the multiplicity of substances contained in oil.

\subsection{PETROLEUM EXTRACTION, REFINING, AND TRANSPORT}

Oil is expected to continue to play a major role in U.S. energy supply well into the next century. The National Energy Strategy (DOE 1991a) projects that total U.S. demand for oil will increase from about 17 million barrels per day (bbl/d) in 1991 to 18.4 million bbl/d in 2000 and 19.2 million bbl/d in 2010. Therearter, oil demand will start to fall. in order to meet this demand without increasing oil imports, the National Energy Strategy contains several actions designed to increase domestic oil production. These include enhanced oil R\&D, access to the coastal Arctic National Wildlife Refuge, and access to certain Outer Continental Shelf areas. Domestic production of crude oil and natural gas liquids is projected to increase from 8.8 million $\mathrm{bbl} / \mathrm{d}$ in 1990 to 9.3 million bbl/d in 2000 and 10.6 million bbl/d in 2010 (DOE 1991a). Increasing domestic production and consumption of oil products pose a potential threat from additional emissions of air toxics.

Oil and oil products contain many toxic metal elements and yield toxic organic compounds through evaporation and combustion. According to the American Petroleum Institute (API), the production of oil would have likely borne the brunt of the capital costs incurred as a result of air toxics control proposed in earlier versions of the CAAA (Delia Management Group 1989; see Figure 3.1). The production sector of the oil industry could face high costs associated with implementing VOC controls such as the replacement of valves, flanges, and fittings, storage tank vapor recovery, and three-way catalysts. 


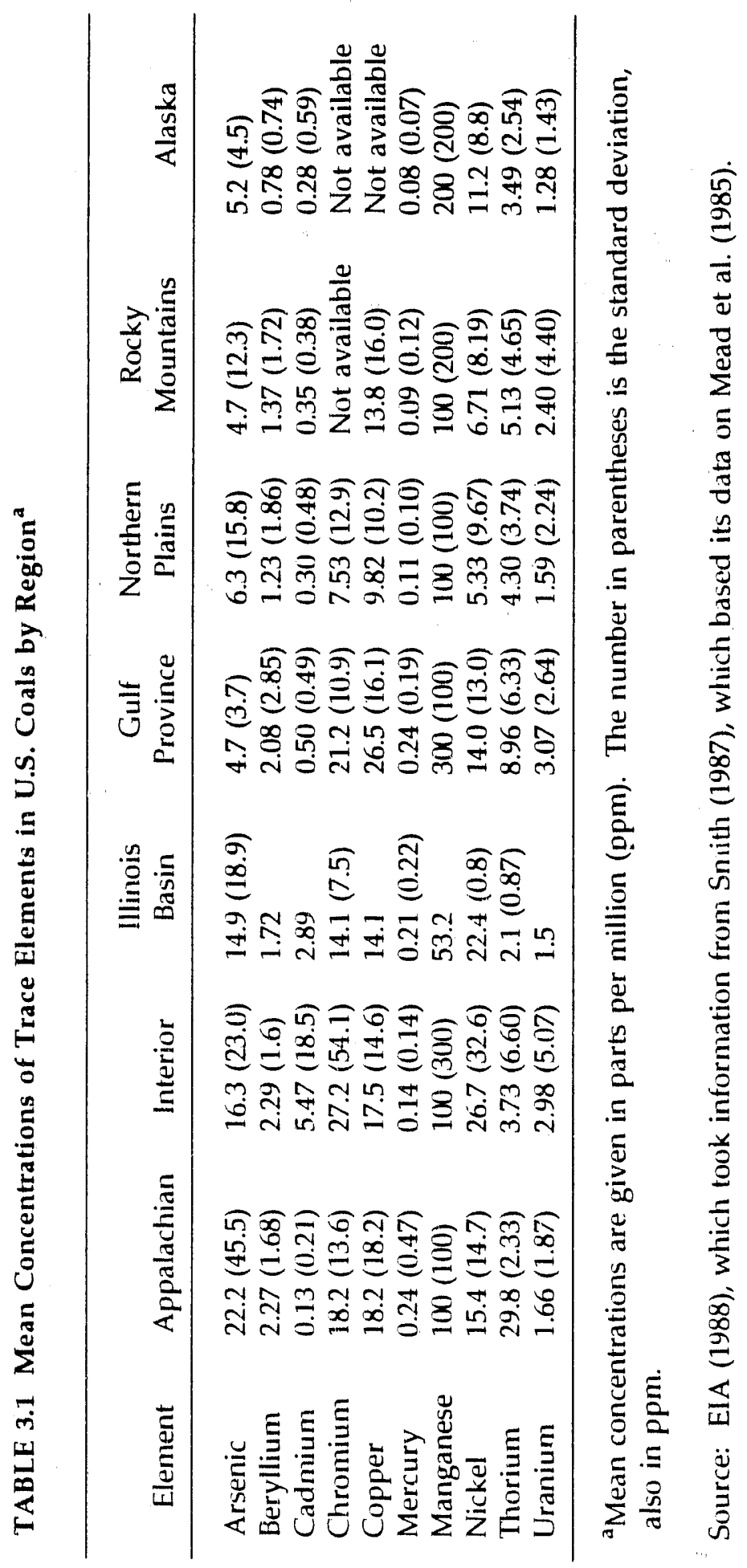


TABLE 3.2 Ranges of Selected Pollutants in Oil

\begin{tabular}{|c|c|c|c|}
\hline \multirow[b]{2}{*}{ Pollutant } & \multicolumn{2}{|c|}{ Mean Concentration (ppm) } & \multirow[b]{2}{*}{ References Listed in EPA 1989c } \\
\hline & Domestic Oil & Foreign Oil & \\
\hline Arsenic & $0.007-0.061$ & $0.01-0.13$ & Anderson 1973 \\
\hline Cadmium & $0.0015-0.027$ & $0.01-0.05$ & $\begin{array}{l}\text { Valkovic 1978; Youk and Piver 1983; } \\
\text { Yen 1975; Hofstader } 1976\end{array}$ \\
\hline Copper & $0.13-6.33$ & $0.19-0.21$ & Filby and Shah 1975; Yen 1975 \\
\hline Mercury & $0.27-3.24$ & $0.006-0.09$ & Pedco 1982; Anderson 1973 \\
\hline Manganese & $1.17-1.4$ & $0.048-0.79$ & $\begin{array}{l}\text { Yen 1975; Vouk and Piver 1983; } \\
\text { Pedco 1982; Valkovic } 1983\end{array}$ \\
\hline Nickel & $2.4-165.8$ & $0.609-117.0$ & Anderson 1973; Yen 1975; Pedco 1982 \\
\hline
\end{tabular}

Source: EPA (1989c.)

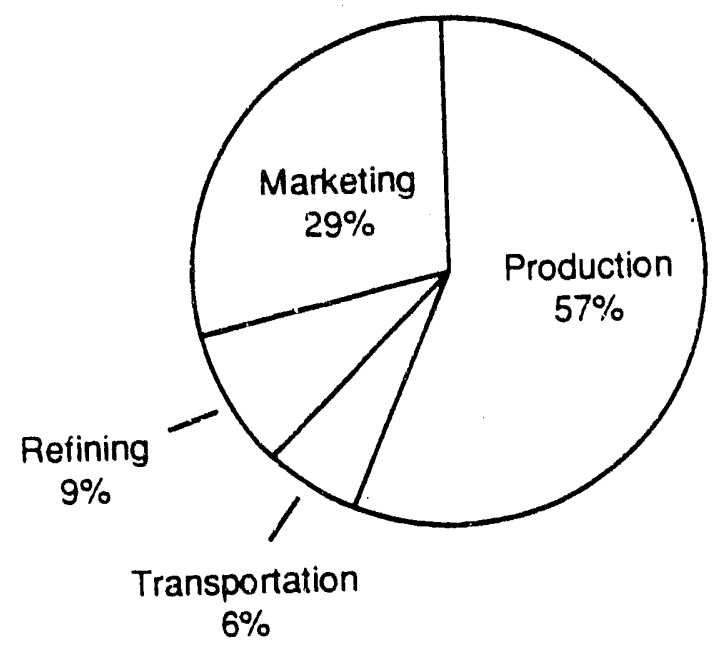

Total Estimated Cost: $\$ 15,000$ Million

FIGURE 3.1 American Petroleum Institute's Estimates of the Total Cost of Complying with the Clean Air Act Amendments (Source: Delta Management Group 1989. These estimates are noted in the original reference as being relatively crude. The cost is for compliance with Titles $(-\mathrm{V}$.) 
The refinery sector will perhaps be most impacted by the CAAA. It is estimated that 46 substances may be emitted during petroleum refining (EPA 1986). Chlorine emissions from cooling towers and hydrogen sulfide emissions during production and refining are potential problems for the petroleum industry, but VOC emissions are the greatest concern (Mueller 1989). The oil refining industry will additionally be burdened by the mobile source title sections that address air toxics. The potential impact on fuel consumption resulting from alternative fuel provisions could have far-reaching implications for the petroleum industry.

\subsubsection{Title III Provisions Pertaining to the Petroleum Industry}

Sources that emit 10 TPY of any single HAP or 25 TPY of any combination of HAPs are "major" sources under Title II and will have MACT standards set, by category of source. In EPA's most recently released draft source category list (EPA 1991b), several of the major source categories identified were directly associated with the petroleum industry. They were as follows:

\begin{tabular}{|c|c|}
\hline Industry Group & Category Name \\
\hline Fuel combustion & $\begin{array}{l}\text { Petroleum industry process heaters } \\
\text { Oil and gas steam generation }\end{array}$ \\
\hline Petroleum refineries & Petroleum refining \\
\hline $\begin{array}{l}\text { Petroleum and gasoline } \\
\text { production and } \\
\text { marketing }\end{array}$ & $\begin{array}{l}\text { Oil and gas production } \\
\text { Gasoline and petroleum storage } \\
\text { Petroleum marketing (bulk terminals and plants) } \\
\text { Manganese fuel additives } \\
\text { Dil shale retorting }\end{array}$ \\
\hline
\end{tabular}

A few special sections of Title III also pertain to the petroleum industry and will influence the degree to which the petroleum industry is affected by air toxics provisions:

- Section $112(\mathrm{n})(4)(\mathrm{a})$ exempts emissions from oil and gas exploration wells and associated equipment from being aggregated among similar units, whether or not such units are in a contiguous area or under a common control, in determining whether such units or stations are major sources.

- Section $112(\mathrm{n})(4)(\mathrm{b})$ exempts oil and gas production facilities from being listed as area sources, unless the production well is located in a metropolitan area with a population of more than 1 million and EPA can determine that emissions from such wells present more than a negligible risk of adverse effects to public health. This provision limits the regulation of facilities located outside metropolitan areas to those classified as major sources, i.e., those that emit 10/25 TPY.

- The section on prevention of accidental releases requires the operators of stationary sources involved with substances deemed particularly hazardous by this section to identify potential risks of accidents and to also take steps to prevent such accidents [Section $112(r)(1)$ ]. While this provision would 
appear to have ramifications for petroleum transport, the Chemical Safety and Hazard Investigation Board, established under this section, is not authorized to investigate marine oil spills. Possible regulations for the prevention of marine spills must be based on recommendations from the National Transportation Safety Board (NTSB) and cannot duplicate NTSB directives.

The initial list of chemicals in the section on prevention of accidental releases in Title III includes the following: chlorine, anhydrous chloride, ethylene oxide, vinyl chloride, methyl isocyanate, hydrogen cyanide, ammonia, hydrogen sulfide, toluene, diisocyanate, phosgene, bromine, anhydrous hydrogen chloride, hydrogen fluoride, anhydrous sulfur dioxide, and sulfur trio:ide. These substances are required by law to be designated as "extremely hazardous" under this section. The list must total at least 100 substances when it is published in November 1992.

The exemption from the aggregation/contiguity requirements in the general definition would appear to benefit the oil and gas industries and should result in a decreased impact on the exploration and production sectors of these industries (Energetics 1990). Thus, special provisions are included in Title III to limit impacts on the production, exploration, and transportation sectors of the petroleum industry.

\subsubsection{Hazardous Air Pollutant Emissions from the Petroleum Industry}

EPA's draft source category list (EPA 1991b) identified 29 different HAPs emitted from the major source categories within the petroleum industry. On the basis of other references, EPA's count of 29 could be a low estimate. Of these 29 HAPs identified by EPA, the following are considered "high risk" pollutants and are weighted differently than regular HAPs: chromium compounds, benzene, cadmium compounds, mercury compounds, acrylonitrile, ethylene oxide, and vinyl chloride.

Fugitive emissions of HAPs result from the following processes:

- Extraction and production (EEP) results in ongoing operational pollution. In both exploration and production operations, one can expect oily effluents due to minor mechanical defects in the system such as leaking pump seals, aqueous condensate, and the necessity in certain cases to depressure vessels involved in the treatment of the product.

- Exploration has the potential to result in two specific sources of air pollution. Oil-based drilling mud is sometimes used when certain rock formations that are adversely affected by water exist; spent drilling mud is usually disposed of by incineration, thereby yielding emissions. Major concern is also given to the potential threat, albeit statistically small, posed by an exploding well.

- Transport of petroleum products can result in emission leaks. Cargo is loaded into and removed from tanks by a system of pipelines placed near the ship's bottom that are connected to cargo pumps situated in a pump room usually sited aft of, but immediately adjacent to, the cargo tanks. On deck, there are small steel hatches for each tank, vent pipes to control the 
passage of air to hydrocarbon vapors between the tanks and the atmosphere, and some small access points such as those used for measuring or sampling the cargo and so forth.

The EPA Crosswalk Report (EPA 1989e), which identifies industries potentially associated with specific pollutants but does not include quantitative data on emissions, indicates that the following chemicals might be released during petroleum refining: 1,3-butadiene, carbon tetrachloride, chloroform, ethylene dichloride, ethylene oxide, methylene chloride; and trichloroethylene. Tetrachloroethylene is also identified as being potentially released during petroleum storage, either from fixed roof tanks or as fugitive emissions.

The EPA report on documentation on developing the source category list (EPA 1990a) indicates that many HAPs are released by various sectors of the petroleum industry (Table 3.3). Most of the data on these emissions is rated either $C$ (based on a small number of tests) or $D$ (based on a single source). API has embarked on a three- to five-year air toxics research program, spending about $\$ 400,000$ to update emission factors (Clean Air Report 1991b). Knowledge of these emissions will likely evolve as more research is done. Emissions may be higher that previously estimated at certain facilities. For example, a study of the Alyeska oil terminal at Valdez, Alaska, found that the tankers at the terminal emitted 43,000 tons of VOC anually, including 450 tons of benzene (Environment Reporter 1990). These emission levels were about three times higher than previously estimated.

\subsubsection{Mobile Source Provisions as They Affect Petroleum Refining}

Title II, Provisions Relating to Mobile Sources, and Title I, Provisions for Attainment and Maintenance of National Ambient Air Quality Standards, could affect HAPs from petroleum refining, independent of their control as a result of Title UI provisions. The provisions in Title II that could affect HAPs at the refinery include (1) Reformulated Gasoline and Oxygenated Gasoline (Section 219), (2) Mobile Source-Related Air Toxics (Section 206), (3) Clean Fuel Vehicles (Section 229), and (4) Diesel Fuel Sulfur Content (Section 217). It should be noted that the initial list of HAPs for stationary sources is contained in Title III, Section 112. However, uir toxics as defined in Title II are a subset of the HAPs list contained in Title III. Therefore, the influence of Title II on refineries is not limited to those provisions associated with air toxics alone. For example, diesel fuel hydrodesulfurization required under Section 217 of Title II may affect hydrogen sulfide $\left(\mathrm{H}_{2} \mathrm{~S}\right)$ emissions at the refinery. However, $\mathrm{H}_{2} \mathrm{~S}$ may be controlled at the refinery under Title III if EPA finds (pending a study authorized by the CAA) it is a HAP. In addition, the increased refining severity of diesel fuel to maintain a minimum cetane index of 40 could change the HAP mix. Section 206 of Title II mandates a study within 18 months after enactment to focus on automobile air toxics emissions that pose the greatest risk to human health or about which significant uncertainty remains, including benzene, formaldehyde, and 1,3-butadiene emissions. EPA is directed to establish HAP standards for motor vehicles within four and one-half years after enactment on the basis of the mandated study. These regulations must contain standards for fuels or vehicles or both, depending on what EPA determines can achieve the greatest emission reductions, with consideration of technology feasibility, availability, cost, noise, energy, safety factors, lead time, and effects of other standards. 
TABLE 3.3 Hazardous Air Pollutants Released by Various Sectors of the Petroleum Industry

\begin{tabular}{|c|c|c|}
\hline Process heaters & Refinery & Gasoline/petroleum storage \\
\hline Chromium compounds & Cadmium compounds & 1,1,2,-Trichloroethane \\
\hline Formaldehyde & Formaldehyde & Chlorobenzene \\
\hline Hexane & Lead compounds & Cumene \\
\hline Lead compounds & Mercury compounds & Ethyl benzene \\
\hline Manganese compounds & Nickel compounds & Xylene, o- \\
\hline Nickel compounds & Selenium compounds & Xylenes, mixed \\
\hline Benzene & $\begin{array}{l}\text { Benzene } \\
\text { Hexane }\end{array}$ & Polycyclic organic matter \\
\hline Petroleum marketing (with & Toluene & Oil anả gas steam generation \\
\hline bulk terminals and plants) & Xylenes, mixed & Benzene \\
\hline 1,1,2,-Trichloroethane & Acetaldehyde & Chromium compounds \\
\hline 2,2,4-Trimethylpentane & Acrylonitrile & Formaldehyde \\
\hline Xylenes & Ethyl acrylate & Hexane \\
\hline Benzene & Ethyl chloride & Lead compounds \\
\hline Chlorobenzene & Ethylene oxide & Manganese compounds \\
\hline Cumene & Methanol & Nickel compounds \\
\hline Ethyl benzene & Methyl chloride & Toluene \\
\hline Hexane & Phenol & \\
\hline Toluene & Propylene oxide & Oil shale retorting \\
\hline Xylene, $0-$ and $p-$ & Styrene & Polycyclic organic matter \\
\hline Styrene & Vinyl chloride & \\
\hline Polycyclic organic matter & Hydrogen fluoride & \\
\hline
\end{tabular}

Source: EPA (1990)a).

\subsubsection{Reformulated Gasoline and Oxygenated Gasoline Requirements}

The reformulated gasoline provisions (Section 219) associated with oxygen content, benzene content, heavy metals, and aromatic hydrocarbon content may affect HAPs from petroleum refineries and downstream operations. An important aspect of the reformulation of gasoline involves the addition of cxygenates, which can be either alcohols or ethers. Alcohols routinely added to gasoline include methanol and ethanol, and the ethers blended into gasoline include methyl tertiary butyl ether (MTBE), tertiary amyl methyl ether (TAME), and ethyl tertiary butyl ether (ETBE).

There are many ways the reformulated gasoline and oxygenated gasoline provisions may affect HAP emissions at the refinery. First, increased production of certain oxygenates could affect refinery HAPs. For example, production of methanol, a feedstock for MTBE, will need to be increased, potentially affecting refinery emissions compliance under Title III since methanol is a listed HAP. Second, reduction in benzene content to no more than $1 \%$ (volume) under Title II would require refineries to find a "sink" for this substance, since it is also listed as a HAP under Title III. Third, the potential allowance of certain heavy metals in gasoline may affect heavy metal emissions from refinery operations associated with producing and blending the metals. Section 219 specifies that certain heavy metals may be added to gasoline (other than lead or manganese) if the Administrator determines that ". . the addition of the heavy metals will 
not increase, on an aggregate mass or cancer-risk basis, toxic air pollutants from motor vehicles [emphasis added]." However, this provision is linked through Title IIl, given that most heavy metals are listed as HAPs, Last, at least one method of aromatics reduction would result in rejected heavy aromatics streams (consisting of primarily benzene and toluene) of up to 300,000 barrels per day nationwide (Yepsen and Witoshkin 1991). The transport and downstream conversion of benzene and toluene may result in additional emissions of these HAPs.

\subsubsection{Mobile-Source-Related Air Toxics}

Toxic air pollutants are defined in Title II as emissions of benzene, 1,3-butadiene, polycyclic organic matter, acetaldehyde, and formaldehyde. All are included in Title III as HAPs. Section 206 requires the study of the need for, and feasibility of, controlling emissions of toxic air pollutants that are unregulated under the CAA. (Benzene is controlled under Section 219 , so it can be assumed that further control under this provision is possible. Likewise, formaldehyde emission standards are prescribed under the clean fuel vehicles provision, Section 229 of Title [I.) Toxic air emissions as a result of motor vehicles and motor vehicle fuels could be regulated. Fuel reformulation measures to reduce air toxics could affect petroleum refinery compliance under Title III.

\subsubsection{Clean Fuel Vehicles}

Clean fuel vehicle provisions (Section 229) define clean fuels and provide for various programs to implement these fuels. The provisions include a clean-fuel, centrally fueled fleet requirement and a California pilot test program. The degree of impact that these provisions will have on petroleum refiners' compliance with Title III provisions depends on (1) whether lowemitting-vehicle exhaust standards can be met with improved vehicle emission control equipment and reformulated gasoline and (2) the extent of voluntary "opt-in" of the California pilot test program by other siates as provided for in the CAA.

From a longer-term perspective, the clean fuel vehicles program could pave the way for widespread adoption of mandated alternatives to petroleum-based fuel, such as methanol, ethanol, natural gas, liquefied petroleum gas, hydrogen, or electricity. The impact on refinery operation and HAP emissions in this case would be substantial.

\subsubsection{Sulfur Content of Diesel Fuel}

On first inspection, there appears to be no link between refinery H.APs and the reduction of the sulfur content in diesel fuel (and maintenance of a minimum cetane index). However, additional hydrodesulfurization (HDS) and hydrodearomatization processes will have to be installed to remove sulfur and aromatics (improving the cetane index) respectively. As mentioned previously, $\mathrm{H}_{2} \mathrm{~S}$, a candidate HAP, may be released from HDS processes at the refinery. A Claus sulfur recovery unit is used on the $\mathrm{H}_{2} \mathrm{~S}$-rich tail gas of the HDS unit to recover sulfur. In the Claus process, some $\mathrm{H}_{2} \mathrm{~S}$ oxidizes to sulfur dioxide and water (Lagas 1989). The remaining part of the $\mathrm{H}_{2} \mathrm{~S}$ reacts with the sulfur dioxide to form elemental sulfur and water. The by-product sulfur is sold. The tail gas from the Claus unit is typically directed to a Wellman-Lord sulfur dioxide recovery plant that oxidizes the remaining sulfur compounds to 
sulfur dioxide, which is captured in a sodium sulfite absorber, separated, and recycled back to the Claus unit (EPA 1984). However, additional HDS capacity maly result In additional release of $\mathrm{H}_{2} \mathrm{~S}$ as a result of refinery operations. The removal of aromatics could result in additional releases of HAPs, primarily benzene.

\subsection{COAL MINING, PREPARATION, AND DISTRIBUTION}

Coal mining, preparation, and distribution have not been indicated in EPA's draft source category list (EPA 1991b) as major sources of air toxics under Title III. (A map showing the states that produced coal in 1988 is given in Figure 3.2). EPA's Crosswalk Report (EPA 1989e), however, shows that coal mining operations have the potential to emit several chemicals - many of which are listed in Title III (see Table 3.4), In general, the Crosswalk Report associates chloracetic acid*; ammonia; 1,1,1,2,2-pentachloroethane; hydrogen sulfide*; and mercury* with coal mining. (Substances listed as a HAP in Title III are noted with an asterisk.) It is important to note that the Crosswalk Report provides no quantitative data on these emissions. According to the Crosswalk Report, a potential exists for the release of the following pollutants from these specific processes:

- Bituminous coul and lignite mining:

1,1,1-Trichloroethane

Hydrogen sulfide*

Polyvinyl chloride latex

- Bituminous coal and lignite surface mining:

Ammonia

Hydrogeri sulfide*

Mercury*

2,4-Diisocyanate toluene*
- Anthracite mining:

Arsenic*

Benzo(a)pyrene

Polycyclic organic matter*

Tetrachloroethylene*

2,4-Diisocyanate toluene*

- Coal mining services:

Arsenic* $^{*}$

2,4-Diisocyanate toluene*

Coal dusts and gases may be released in a variety of ways. Dusts result from the jostling of coal during transport, and these dusts are released into ambient air if the means of transport is not properly covered. Dusts and gases also result during exploration of coal from the drilling and explosions that take place. Blasting with explosives is the principal method of fracturing and loosening coal (Shobert 1987). Dusts and gases are also released during the actual mining of coal. Mine ventilation is required to ensure worker safety and minimize the threat of explosions. These gases are expelled from mine shafts into the open air.

Long before the CAA was in existence, emissions of dusts and gases were a serious concern to coal producers because of their potential to lead to explosions and fires. When fine dust particles of any flammable material are suspended in the air, an explosion can occur. The worst explosion of this type happened in Manchuria in 1942 and claimed 1,572 lives (Shobert 1987). Thus, even before the heightened awareness about air pollution, there was an incentive to minimize the production of hydrogen sulfide - a listed HAP. Hydrogen sulfide can be released when acidic mine water reacts with pyrite in coal and also when worked-out areas of a mine catch fire. Some releases of hydrogen sulfide with methane occur as a result of natural processes. 


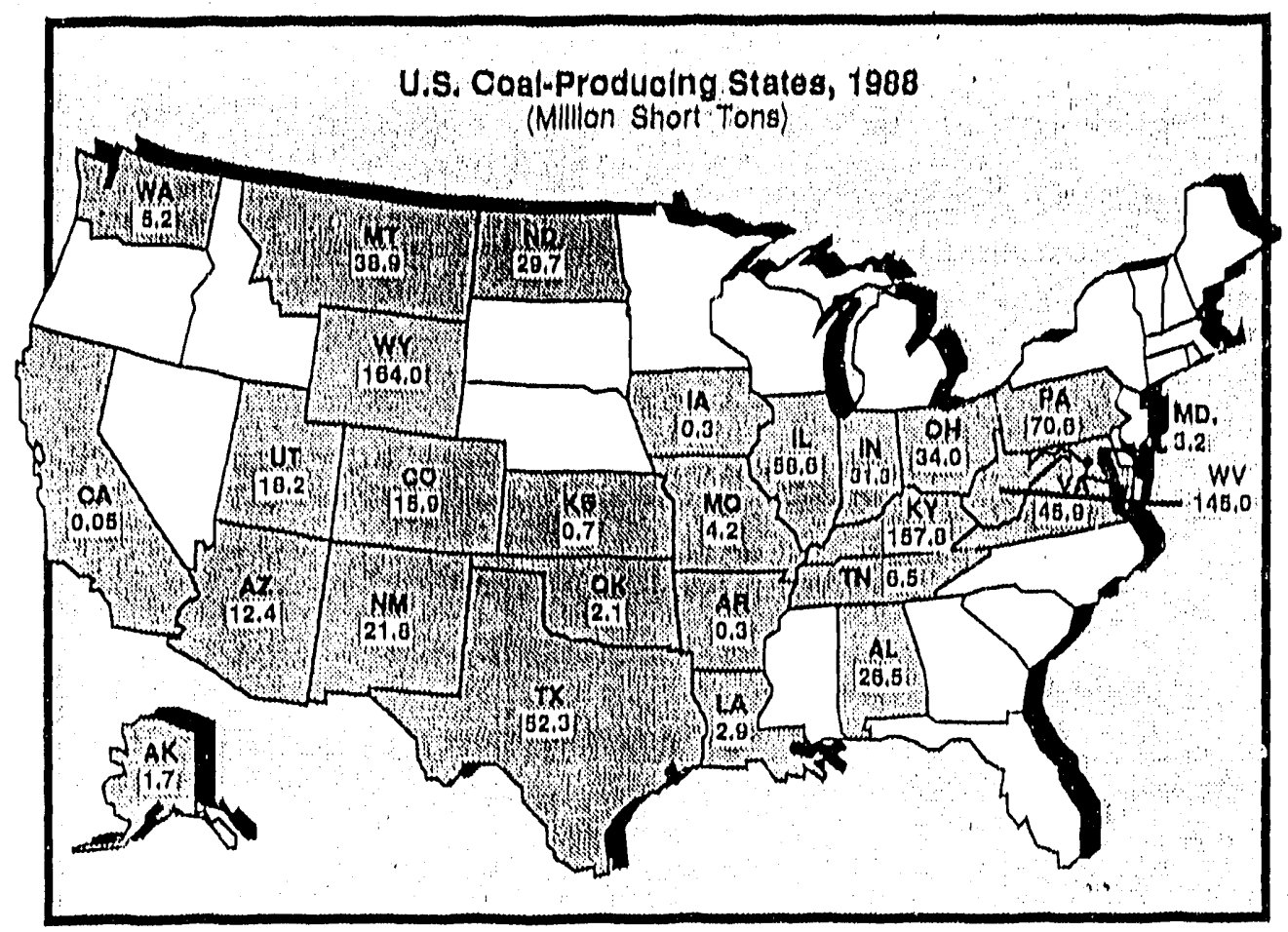

FIGURE 3.2 Coal Production by State in 1988 (Source: EIA 1988)

TABLE 3.4 Potential Emissions from Coal Storage and Handling

\begin{tabular}{|c|c|c|c|}
\hline Pollutant & $\begin{array}{l}\text { Listed in } \\
\text { Title III }\end{array}$ & Pollutant ${ }^{a}$ & $\begin{array}{l}\text { Listed in } \\
\text { Title III }\end{array}$ \\
\hline Aluminum & & Manganese & $x$ \\
\hline Sillicon & & Chlorine & $\mathrm{x}$ \\
\hline Phosphorus & $x$ & Strontium & \\
\hline Sulfur & & Indium & \\
\hline Zinc & & Lead & $x$ \\
\hline Potassium & $x$ & Titanium & \\
\hline Calcium & & Barium & \\
\hline Titanium & & Iron & \\
\hline Chromium & $x$ & Copper & \\
\hline
\end{tabular}

a Based on samples that were sieved and resuspended. The data received rankings of $B$ and $C$, meaning they are held to be fairly representative of similar facilities. On the basis of these data, the substances above make up fugitive coal dust emissions in the absence of any type of dust control.

Source: EPA (199)b). 


\subsection{NATURAL GAS EXTRACTION, PREPARATION, AND DISTRIBUTION}

Processes involved in the extraction, preparation, and distribution of natural gas are not specifically included in EPA's dralt source category list (EPA 1991b). EPA's Crosswalk Report (EPA 1989e), however, Identifies chemicals that might potentially be emitted from natural gas production sources. With few exceptions, much of the information provided in the Crosswalk Report combines ofl and gas production categories and does not isolate natural gas sources. Table 3.5 lists the chemicals emitted during various processes assoclated with natural gas and oll production.

The Crosswalk Report's list of potential alr emissions specifically identifles benzene with natural gas production (as opposed to identifying it with the category that includes both natural gas and petroleum production). According to these nonquantitative estimates, benzene could be emitted during natural gas stripping from cumpressors, wells, and gas lifts.

While many chemicals may be assoctated with the production of natural gas, the provision included in Title III that protects ofl producers to some extent also applies to the producers of natural gas: Section $112(n)(4)(b)$ exempts oil and gas production facilities from being listed as area sources, unless the production well is located in a metropolitan area with a population of more than 1 million and EPA can determine that emissions from such wells present more than a negligible risk of adverse effects to public health. This provision prevents EPA from requiring MACT on processes that emit less than 10 (single) or 25 (combined) TPY of HAPs. Section $112(\mathrm{n})(4)(a)$ exempts emissions from oil and gas exploration from being aggregated among similar units, whether or not such units are in a contiguous area or under a common conirol in determining whether such units or stations are major sources. Thus, classifying oil exploration units/stations as major sources becomes more difficult and minimizes the likelihood of such units being subject to Title III emission limits.

\subsection{ELECTRIC UTILITIES}

Electric utilities are treated in a unique manner in Title III. Programs under other titles of the CAAA are expected to affect this industry heavily. For example, under the acid rain control program in Title IV, electric utility units are the primary targets of $\mathrm{SO}_{2}$ and $\mathrm{NO}_{x}$ emission reductions. Also, units in some geographic areas may be required to reduce VOC and / or $\mathrm{NO}_{x}$ emissions to comply with nonattainment plans under Title I. Because of the extensive emission reduction demands on utilities imposed by the Amendments, Congress mandated a study of the health hazards from utility emissions that would remain after the utilities complied with these other provisions.

The type of regulatory action, if any, that will be taken to control HAPs from this category will depend on EPA findings, based on its study of ". . . the hazards to public health reasonably anticipated to occur as a result of emissions by electric utility steam generating units of pollutants listed under subsection (b) after imposition of the requirements of this Act" (CAA Section $112(n)(1)(A))$. The results of this study are to be reported to Congress three years $A E$. Also required in this report are descriptions of alternative control strategies for utility emissions of HAPs that may warrant regulation under Section 112 of the CAA. Furthermore, EPA is 
TABLE 3.5 Chemicals that Can Be Emitted during Oil and Gas Extraction, Production, and Distribution ${ }^{n}$

Crude petroleum and natural gas extraction

Ammonia
Sodium hydroxide
Acetone
Benzene*
Chlorobenzene
Ethylbenzene*
p-Tert-butyl-benzolc acid
Butane
Chlorine*
Chromlum*
Coal tar
Bis(2-ethylhexyl)phthalate (DEHP)*
Ethyl chloride*
Ethylene dichloride*
1,1,1-Trichloroethane*
Ethylene
Ethylene glycol*

Oll and gas exploration

Benzene*

Chlorobenzene*

1,2-Dichlorobenzene

Ethylbenzene*

Carbon tetrachloride*

1,2-Dichloroethane

1,1,1-Trichloroethane

Oil and gias field services

Chromium*

Oil and gras drilling

1,1,1-Trichloroethane Hydrogen sulfide*
Gasoline

Hydrogen chloride*

Hydrogen sulfide*

Methanol

Naphthalene

Octane, n-

Pentane

Polycyclic organic matter

Polyvinyl chloride latex

Sodium hyclroxide

Styrene

Sulfuric acid

Tetrachloroethylene*

Toluene*

Xylene, $0^{*}$

$1,2,3,5,7,8$-Hexachlorodibenzofuran

N,N-Dimethylformamide Hydrogen sulfide* Bromochloromethane Polyvinyl chloride latex Toluene*

Xylene, m-*

aSubstances listed as a HAP in Title III are noted with an asterisk. 
directed to regulate emissions under the HAPs provisions if the EPA Administrator finds that such regulation is appropriate and necessary after consideration of the study, it is this study that makes the impact of the air toxics title upon the electric utility industry uncertain.

Two additional studies specifically addressing mercury $(\mathrm{Hg})$ are also required:

- A four-year EPA study to characterize $\mathrm{Hg}$ emissions from utilities and other categories of sources, along with the health and environmental effects of these emissions and costs of avallable $\mathrm{Hg}$ control technologies (CAA Section $112(\mathfrak{n})(1)(B)) ;$ and

- A three-year study by NIEHS (National Institute of Environmental Health Sclences) of the general threshold level of $\mathrm{Hg}$ below which adverse human health effects are not expected (CAA Section $112(n)(1)(C))$.

The potential costs to be incurred by the electric utility industry as a result of air toxics requirements following an affirmative decision by EPA after this study could be substantial. Cost estimates vary dramatically, depending on the control methods assumed and the number of plants assumed to be subject to additional controls (see Energetics [1990] for all estimates):

- Annual cost estimates range from $\$ 0.43$ billion (Energetics) to $\$ 11$ billion (EEI), with the lower-end estimates reflecting installation of baghouses and scrubbers and the upper-end estimates reflecting the installation of high-efficiency fabric-filter (HEFF) baghouses.

- Capital cost estimates range from $\$ 2.2$ billion (Energetics) for baghouses and scrubbers to $\$ 33$ billion (EEI) for baghouses and scrubbers as well as lime injection for $\mathrm{Hg}$ control.

Even when assumed control technology scenarios are similar, cost estimates can be widely divergent; an example are estimates of $\$ 11$ billion (EEI) and $\$ 0.75$ billion (EPA), both for HEFF baghouse control of particulates (Energetics 1990).

The uncertainty of air toxics requirements complicates whether utilities should factor the possibility of these requirements into acid rain or ozone precursor control plans. Some technologies, such as conventional scruhbers, may provide emission reductions for more than one requirement. For example, utilities may be dissuaded from coal switching as an acid rain compliance method because of the uncertainty of the outcome of the EPA study.

\subsubsection{Fossil Fuel Variability}

Utilities and other industries combusting fossil fuels face a complex task in responding to HAPs regulation, in part because of the variable nature of fuel. The majority of U.S. electricity is generated by the combustion of fossil fuel, with coal accounting for more than half of U.S. electricity production (Figure 3.3). 


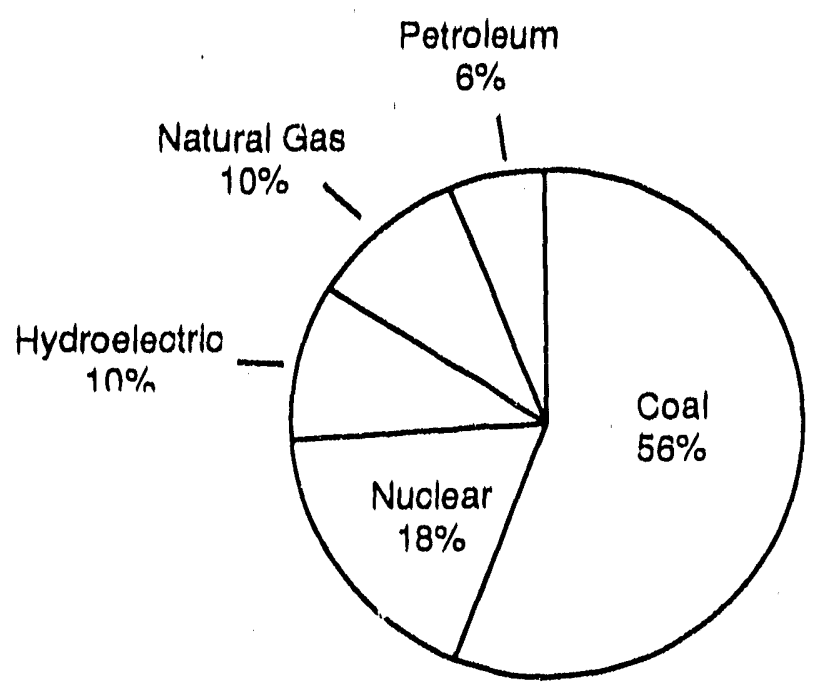

Total: $2,784 \mathrm{kWh}$

FIGURE 3.3 Distribution of Electricity Generation by Fuel Type (Source: EIA 1991)

It is virtually impossible to generalize about the chemical characteristics of coal. Even within regions, the constituents of coals vary by an order of magnitude, as shown in Table 3.6. Preliminary data indicate that many of the compounds identified as hazardous in Tile III are either present in coal or can be created during its combustion (EPA 1989c). The emissions of these compounds, some of which are the product of incomplete combustion, are possible even though combustion efficiency is relatively high - the conversion of carbon to carbon dioxide generally being $99 \%$ or greater (EPA 1989c).

\subsubsection{Hazardous Air Pollutant Emissions from Utilities}

The highly variable nature of fossil fuels complicates identifying which HAPs are emitted from utility units. Because related data are still in the early stages of development, the identification of these chemicals varies. EPRI identified at least 37 of the 189 substances listed in Title III, but EPA identified only 22 chemicals in its December 1990 documentation for the source category list (EPA 1990a), which characterized emissions from different fossil fuel utility boiler types (see Table 3.7). The EPA and EPRI lists have 16 chemicals in common, identifying a total of 47 different HAPs associated with utilities (Table 3.8).

The mandated EPA study of electric utility air toxics should improve the incomplete database. EPA has ranked utilities as either $C$ (based on a small number of source tests) or $D$ (based on a single source test), on a scale of $A$ (best) to $E$ (worst). EPA acknowledged considerable uncertainty in estimates because of the wide variability of trace elements and compounds in coal, variations in boiler and control equipment design and operation, and the uncertainty in sampling and analytic methodologies for cietecting trace pollutants (Chow et al. 1991). More recent analyses, for example, would support lower emission factors for chromium, manganese, and nickel (Chow et al. 1991). 


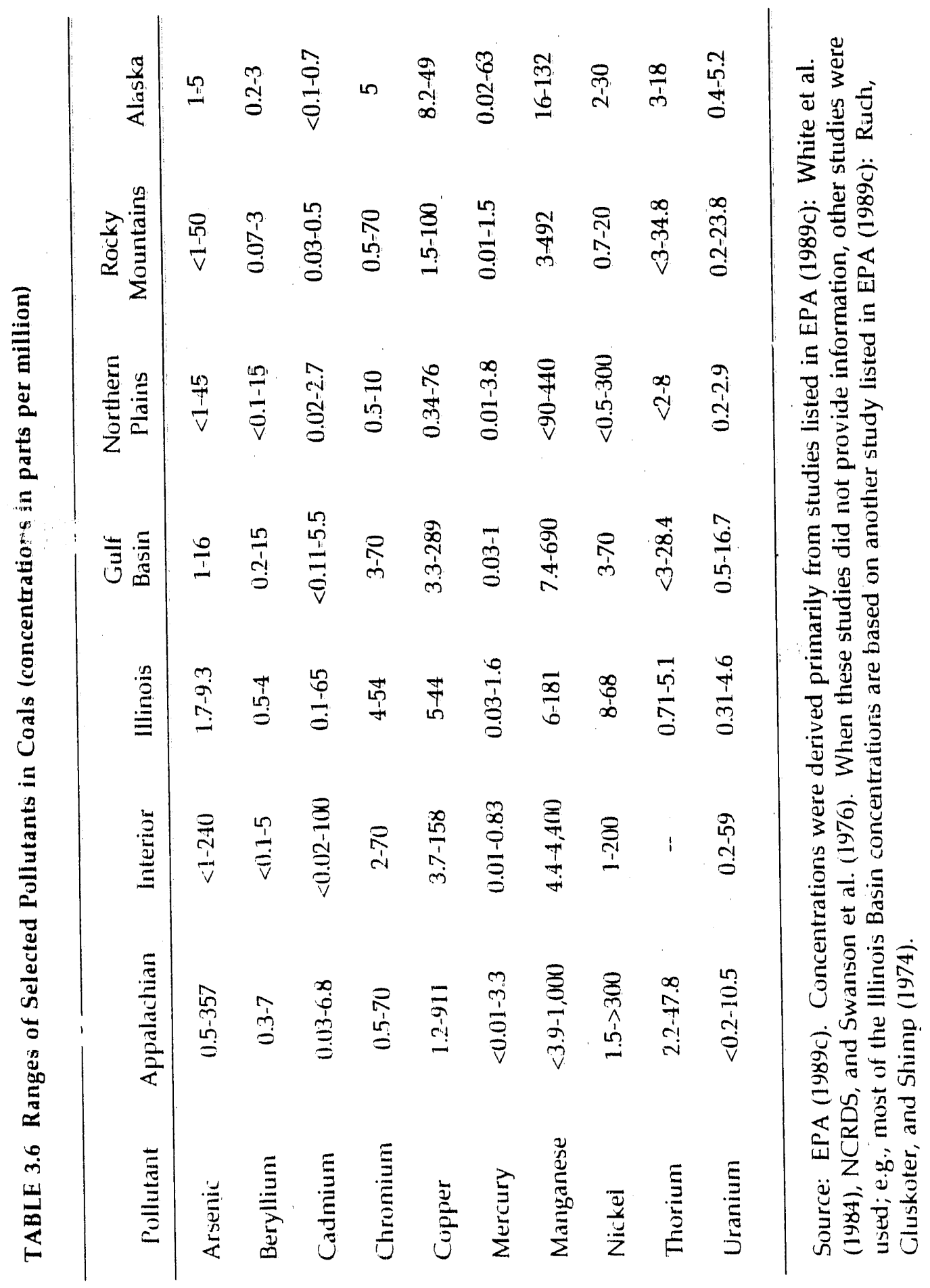




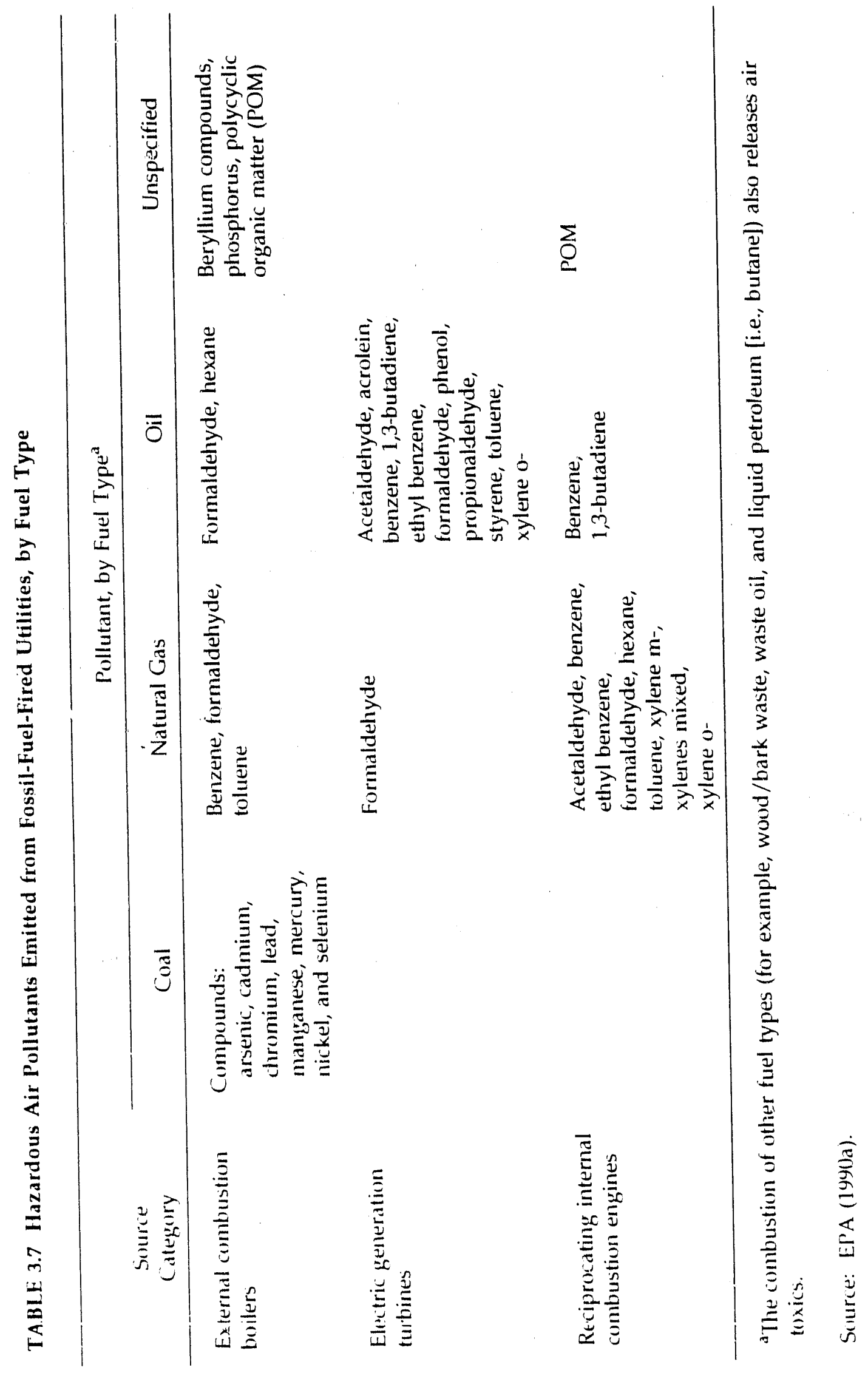




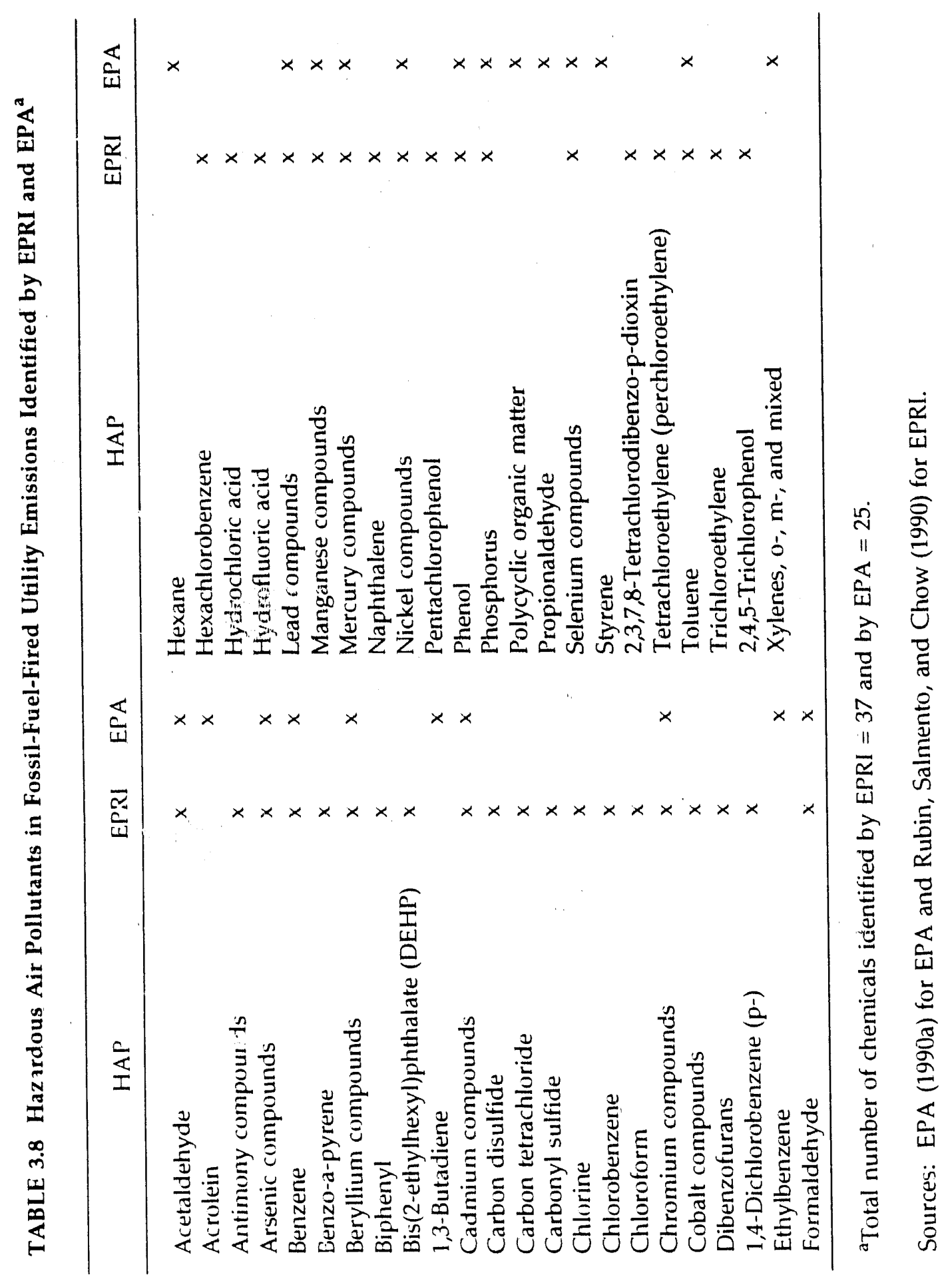


On the tasis of several emission characterizations, utilities could be major HAP sources on the basis of either the 10-TPY single pollutant or 25-TPY combined pollutant thresholds:

- Approximately 550 coal-fired units with a combined generating capacity of $194 \mathrm{GW}$ would exceed the threshold (Energetics 1990).

- About 40 oil-fired units with a combined generating capacity of $196 \mathrm{GW}$ would exceed the threshold (Energetics 1990).

Together, these 590 units constitute $40 \%$ of all utility units and $60 \%$ of utility generating capacity. In addition, it is estimated that the potential cost impact of the air toxics' rule would not fall equally across the nation; $80 \%$ would fall on utilities east of the Mississippi River, most heavily in the Northeast, with the bulk of the remainder in Texas (Energetics 1990).

Some HAPs emitted by electric utilities deserve special discussion, either because there is special treatment authorized by the CAAA ( $\mathrm{Hg}$ and radionuclides) or because emissions widely fluctuate $(\mathrm{HCl})$.

- Hydrogen chloride may be emitted in large quantities from coal-fired utilities. Results of tests of the 725-MW Ottumwa generating station, while it was using low-sulfur Wyoming coal, indicate an annual emission rate of $\mathrm{HCl}$ of 1,050 metric tons. A $600-\mathrm{MW}$ unit burning medium-sulfur coal would emit 1,450 TPY of $\mathrm{HCl}$. Although lime and limestone scrubbers consistently achieve $\mathrm{HCl}$ removal efficiencies of $95 \%$ and better, even the best scrubbers could only reduce $\mathrm{HCl}$ emissions to 70 TPY at a typical large plant.

- Mercury, although it is emitted in small quantities by utilities - a typical 500-MW coal unit emits about 0.25 TPY - could be controlled either as part of the overall requirement for MACT to cover all pollutants emitted from a major HAP source or because of its potency. The CAA authorizes EPA to set lower thresholds for HAPs on the basis of potency, persistence, or (relevant particularly to $\mathrm{Hg}$ ) potential bioaccumulation. Coal-fired utilities were named in major studies $\mathrm{a}_{\mathrm{i}}$ a source of $\mathrm{Hg}$ deposition in lakes in Michigan and Wisconsin (Mueller $1989)$.

- Radionuclide emissions, which are hazardous because of their radioactivity, will have a different threshold level set by EPA than the 10 TPY applicable to other HAPs. Here again, emissions of radionuclides from tossil utilities could be controlled under the MACT requirement to cover all HAPs emitted, even those not emitted in major amounts.

\subsubsection{Emissions of Hydrogen Chloride}

Chlorine concentrations vary widely in U.S. coals, from virtually unmeasurable levels to more than $0.5 \%$. Altnough eastern high-sulfur coals generally have higher chlorine 
concentrations than western subbituminous and lignite coals (Chow et al. 1991), there are exceptions. For example, the unpredictably high level of chlorine emissions found in testing the Iowa Southern Utility Co.'s Ottumwa plant (see Table 3.9) could be repeated for other chemicals because of the dramatic variability in fuel constituents. Neither EPA nor EPRI was aware that chlorine could be emitted in such large quantities from low-sulfur coal, although EPA, after review, agreed with the results (Bergstrom 1989). Tests conducted by Union Electric and supervised by EPA supported the results (Union Electric 1982).

It is interesting to note that hydrochloric acid emissions from utilities are not a major health concern; a plant emitting $10 \mathrm{TPY}$ of $\mathrm{HCl}$ with a GEP (good engineering practice) stack height would only create an average ground concentration of $1 \mu \mathrm{g} / \mathrm{m}^{3}$ - a negligible amount compared with the occupational exposure limit of $7,000 \mu \mathrm{g} / \mathrm{m}^{3}$ (Chow et al. 1991).

\subsubsection{Emissions of Radionuclides}

Nuclear electric utility units, responsible for about $20 \%$ of net generating capacity, are afforded special treatment by the CAAA in order to minimize federal regulatory duplication. Those commercial power reactors regulated by the U.S. Nuclear Regulatory Commission (NRC) may be exempted trom EPA air toxics regulation if EPA determines that the NRC rules are sufficient to protect the public health with an ample margin of safety (CAA Section 112 (d) (9)). In making an affirmative finding in July 1991, EPA proposed to rescind its existing HAPs regulations applicable to these sources (EPA 1991c).

There are no similar exemption provisions for fossil fuel utility units, since there is no similar duplication of federal regulation. Coal contains trace amounts of natural uranium and thorium, which along with three isotopes, are released in the form of ash from coal combustion. The rates of release are dependent on the following factors:

- Initial concentration of radionuclides in coal;

- Boiler type, capacity, heat rate, and emission controls; and

- Ash partitioning (dependent on coal type, firing method, and furnace type, i.e., wet or dry).

Of these factors, ash partitioning provides the basis for most of the uncertainty in estimating emissions of radionuclides. Radionuclides are emitted as particulates, and the concentration mechanism between bottom and fly ashes is not yet fully understood. Table 3.10 provides estimates of radionuclides emissions from typical coal-fired utilities, indicating the variability in emissions of this pollutant.

\subsubsection{Emissions of Mercury}

Mercury emissions from power plants are relatively small. Although emissions are estimated to be about $50 \mathrm{lb} / \mathrm{yr}$ from a typical 500-MW coal plant, actual emissions are likely to be less, given the levels of removal by existing environmental controls. Combustion sources of 
TABLE 3.9 Profile of 12 Hazardous Air Pollutants Emitted from the Ottumwa Generating Station

\begin{tabular}{lrlc}
\hline \multicolumn{1}{c}{ Element } & $\begin{array}{c}\text { Amount } \\
\text { Emitted } \\
\text { (tons/yr) }\end{array}$ & Element & $\begin{array}{c}\text { Amount } \\
\text { Emitted } \\
\text { (tons/yr) }\end{array}$ \\
\hline Arsenic & 1.5 & Lead & 2.0 \\
Beryllium & 0.5 & Manganese & 9.8 \\
Cadmiuny & 0.5 & Mercury & 0.5 \\
Chlorine & $1,050.0$ & Nickel & 3.0 \\
Chromium & 0.5 & Selenium & 2.0 \\
Cobalt & 1.0 & & \\
\hline
\end{tabular}

aAge: Commercial operations of this lowa Southern power plant began in May 1981. Size: 725 MW (gross). Annual coal combustion: $2.1 \times 10^{6}$ tons. Emission control equipment: electrostatic precipitator with $99.4 \%$ efficiency. Average $\mathrm{SO}_{2}$ emissions: $0.5 \mathrm{lb} / 10^{6} \mathrm{Btu}$.

Source: Bergstrom (1989).

TABLE 3.10 Radionuclide Emissions from Typical Coal-Fired Utilities and Corresponding Cancer Risks

\begin{tabular}{|c|c|c|c|c|}
\hline \multirow[b]{2}{*}{$\begin{array}{l}\text { Location of } \\
\text { Facility }\end{array}$} & \multicolumn{2}{|c|}{$\begin{array}{l}\text { Emissions } \\
(\mathrm{mCi} / \mathrm{yr})\end{array}$} & \multicolumn{2}{|c|}{ Estimated Fatal Cancer Risk } \\
\hline & U-238 & Th-232 & $\begin{array}{l}\text { To Nearby } \\
\text { Individuals }^{\mathrm{a}}\end{array}$ & $\begin{array}{l}\text { To Regional } \\
\text { Population }^{b}\end{array}$ \\
\hline Remote & 5.6 & 3.2 & $3 \mathrm{E}-6$ & $2 E-4$ \\
\hline Rural & 5.6 & 2.3 & $1 E-6$ & $2 E-4$ \\
\hline Suburban & 9.4 & 5.4 & $3 \mathrm{E}-6$ & $3 E-3$ \\
\hline Urban & 5.1 & 2.4 & $2 \mathrm{E}-6$ & $6 \mathrm{E}-3$ \\
\hline
\end{tabular}

${ }^{\mathrm{a}} 3 \mathrm{E}-6=3$ in $1,000,000 ; 1 \mathrm{E}-6=1$ in $1,000,000$; and $2 \mathrm{E}-6=2$ in $1,000,000$.

${ }^{b}$ Region $=0-80 \mathrm{~km} .2 \mathrm{E}-4=2$ in 10,$000 ; 3 \mathrm{E}-3=3$ in 1,$000 ;$ and $6 \mathrm{E}-3=$ 6 in 1,000 .

Source: Tables 7-10 and 7-14 in EPA (1989f). 
mercury typically emit the substance in its elemental form, posing little direct environmental threat (Chow et al. 1991). It is the possible indirect environmental threat that has been the more serious concern.

Anthropogenic sources of mercury in surface waters include distant incinerators, smelters, and coal-fired power plants. A study of the mercury entering one Ontario, Canada, lake indicated that direct deposition or rain accounted for about half of the mercury entering the lake (Raloff 1991). The elemental mercury deposition to surface waters thought to result from combustion sources - whether directly or in precipitation - may react chemically in lakes to become methyl mercury. Combustion sources may also accelerate the transformation of mercury into methyl mercury by their contribution to acidic deposition to these same waters. (The conversion of mercury to methyl mercury is more rapid at lower $\mathrm{pH}$.) Unlike elemental mercury, which has difficulty passing through a fish's gills and which fish eliminate quite quickly, methyl mercury is easily assimilated by fish and accumulates in the edible muscles (Raloff 1991). This conversion product therefore poses a greater threat to humans eating contaminated fish.

Two studies of mercury emissions - including those from electricity generating units and their health and environmental effects are required under Title III, as earlier discussed in Section 3.4. These reports should increase knowledge about this HAP and its control.

\subsection{URANIUM PROCESSING AND PRODUCTION}

Uranium is a silvery white radioactive metal that is principally used as a fuel for nuclear reactors. Heat is produced by fissioning U-2.35, which is, in turn, used to generate steam for the generation of electricity. Nuclear-powered utilities generate approximately $19 \%$ of the nation's total net energy, and in 1988, domestic producers of uranium supplied 17.6 million pounds to domestic utilities. One pound of uranium produces as much energy as 14,000 pounds of coal. (See Figure 3.4 for a comparison of generation by energy source.)

Radionuclide emissions from uranium production are of special concern with regard to the CAAA of 1990 because EPA is granted the flexibility to promulgate threshold levels (other than the 10/25-TPY levels) for air toxics that are deemed special, as are radionuclides. Whether or not MACT standards are required for uranium mines and processes will depend on the trigger thresholds that EPA determines are appropriate. On the basis of language in the CAAA and the most recent draft source category list, it is likely that EPA will establish a unique trigger threshold for radionuclides. The most recent preliminary draft source category list of June 21 , 1991 (EPA 1991b), states, "The EPA may establish different criteria for a major source in the case of radionuclides."

\subsubsection{Radionuclide Emissions from Uranium Production and Processing}

EPA's first draft source category list (EPA 1990a) included a source category called "radionuclide emitters." Included in this source category were surface uranium mines, underground uranium mines, and uranium mill tailings piles (including operation and disposal). Radionuclide emitters were deleted as a source category from the more recent preliminary source category list published in the Federal Register on June 21, 1991 (EPA 1991b). 


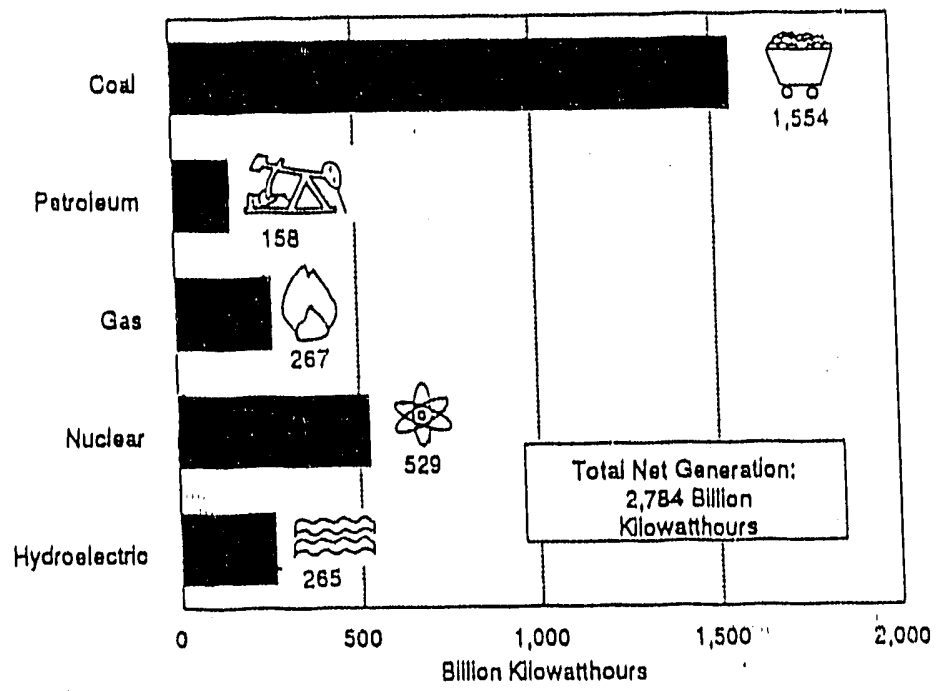

\begin{abstract}
Notes: Total net generation yalue Includes 11 billion kilowathours of generation by other energy sources including geothermal, wood, wind, waste, and solar. Totals may not equal sum of components because of independent rounding.

FIGURE 3.4 Net Generation by Energy Source (Source: Form EIA-759, Monthly Power Plant Report, DOE/Energy Information Administration)
\end{abstract}

The processes involved in producing uranium include exploration, milling of the raw uranium, enrichment of the uranium, and fuel fabrication. Basically, the processes involve the crushing and grinding of uranium, followed by a chemical leaching process to separate the uranium from the ore, and the recovery of the product from the leach solution for drying and packaging. The waste product (mill tailings) is then piped as a slurry to an impoundment area (tailings pile). Many of these processes generate dust that contains radioactive materials, including natural uranium and thorium along with their natural decay products (e.g., radium, lead, radon). These radionuclides (with the exception of radon) are released as particulates. Uranium mill tailings, in particular, are considered one of the largest contributors to radionuclide emissions. Although the number of mills declined drastically during the 1980s, from 21 operating mills processing 50,000 tons of ore per day in 1981 to four operating mills in 1988 that processed 9,600 tons per day, EPA concluded in 1989 that emissions from uranium mills caused the greatest doses and cancer risks when compared with emissions from the uranium conversion, fuel fabrication, and light water reactor stages of the fuel cycle (see Table 3.11).

Radionuclide emissions from uranium processing associated with the production of uranium include these specific activities:

- Exploration.

- Ore storage. Although ore is moist upon arriving at a storage pad, it dries during storage, making it prone to dust formation. Once dried, the release of radioactive material can result from wind erosion and/or during its transport to the next processing ciep. 
TABLE 3.11 Estimated Distribution of the Fatal

Cancer Risk from Uranium Mills to Regional $(0-80 \mathrm{~km})$ Populations

\begin{tabular}{|c|c|c|}
\hline Risk Interval ${ }^{\mathrm{a}}$ & $\begin{array}{c}\text { Nutiver of } \\
\text { Persons }\end{array}$ & $\begin{array}{l}\text { Number of } \\
\text { Deaths per } \\
\text { Year }\end{array}$ \\
\hline $1 E-1$ to $1 E+0$ & 0 & 0 \\
\hline $1 \mathrm{E}-2$ to $1 \mathrm{E}-1$ & 0 & 0 \\
\hline $1 E-3$ to $1 E-2$ & () & () \\
\hline $1 \mathrm{E}-4$ to $1 \mathrm{E}-3$ & 84 & $2 \mathrm{E}-4$ \\
\hline $1 \mathrm{E}-5$ to $1 \mathrm{E}-4$ & 6,500 & $1 E-3$ \\
\hline $1 E-6$ to $1 E-5$ & 32,000 & $2 \mathrm{E}-3$ \\
\hline$<1 E-6$ & $2,200,000$ & $2 \mathrm{E}-3$ \\
\hline Total & $2,200,000$ & $5 E-3$ \\
\hline \multicolumn{3}{|c|}{$\begin{aligned}{ }^{a} 1 E-1 & =1 \text { in } 10 ; 1 E-2=1 \text { in } 100 ; 1 E-3=1 \text { in } 1,000 \\
1 E-4 & =1 \text { in } 10,000 ; 1 E-5=1 \text { in } 100,000 ; \text { and } \\
1 E-6 & =1 \text { in } 1,000,000\end{aligned}$} \\
\hline \multicolumn{3}{|c|}{$\begin{array}{l}\mathrm{b}_{2} \mathrm{E}-4=2 \text { in } 10,000 ; 1 \mathrm{E}-3=1 \text { in } 1,000 ; 2 \mathrm{E}-3=2 \mathrm{in} \\
1,000 ; \text { and } 5 \mathrm{E}-3=5 \text { in } 1,000 .\end{array}$} \\
\hline
\end{tabular}

- Uranium mills. The process of extracting uranium from ore, or milling, begins with crushing and grinding of the material. When milling reties on dry crushing and packaging, this process can generate the most significant levels of radioactive emissions.

- Uranium tailings. After the uranium product is separated from the ore in the leaching process, the residual ore is pumped as a slurry to a tailings impoundment. As sections of the pile dry, the tailings become a source of windblown dust. The slime component contains twice the concentration of uranium as do the sands and is especially prone to becoming fly-away dust because of the small particle size.

In general, the drying out and crushing of uranium result in the majority of radioactive releases during processing, estimated to account for $90 \%$ of the releases. U-234 and U-238 are released from the dryer area; crushing results in emissions of Th-230 and V-226. It is important to note that emissions result from both active and shut-down facilities where final stabilization has not yet occurred. A facility classified as inactive may still emit radionuclides.

As shown in Figure 3.5, emissions from uranium processing facilities are region specific; mining (usually accompanied by processing) is generally limited to states in the Southwest and Northwest, including Arizona, Colorado, New Mexico, Texas, South Dakota, Utah, Washington, and Wyoming. 


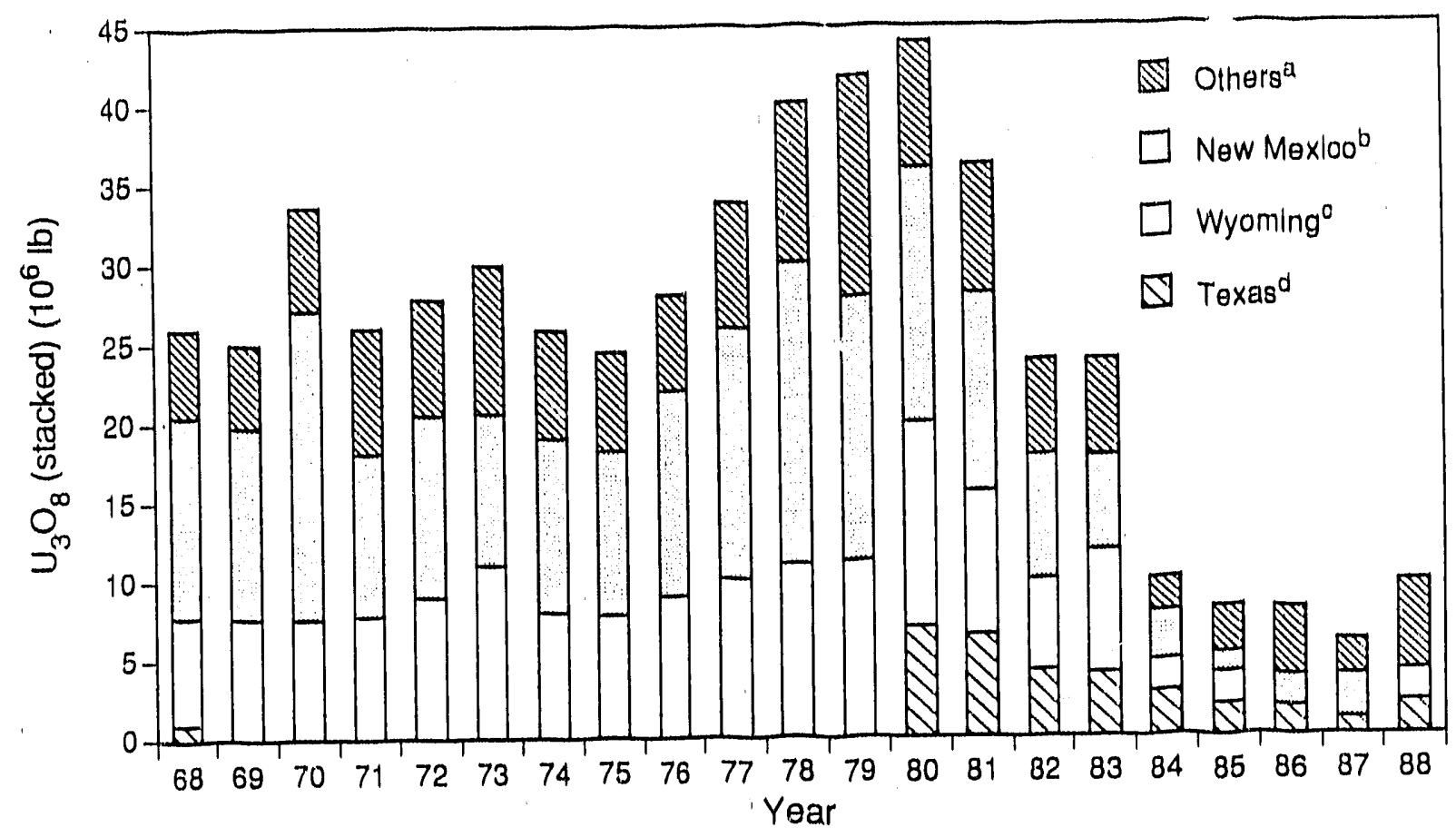

a For various years, Includes Alaska, Ariz, Colo., N.M., N.D., S.D., Texas, Utah, Wash, and Wy.

b Value tor 1988, included in "Others."

CValues for 1986 and 1987 included in "Others."

dValues for 1969 through 1979 included In "Others."

FIGURE 3.5 Mine Production of Uranium by State, 1968-1988 (Source: EIA 1989)

\subsubsection{Radionuclide Control Techniques for Uranium Produstion}

Various techniques can be employed to minimize the emission of radionuclides. These techniques can involve maximizing the moisture of uranium (to minimize dust release in the first place), reducing procedural steps in processing uranium (to minimize potential releases of dust), and capturing dust with emission collection technologies. EPA has estimated the annual costs associated with implementing many of these emission control techniques at specific processes capable of releasing radionuclides. These process-specific emission controls and associated costs (where available) are as follows:

- Ore storage

- Build windbreaks (fences to surround piles) to reduce the tendency of the wind to dry the piles and carry dust away.

- Routinely spray piles using a tank truck equipped with pumps and hoses to maximize moisture and minimize dust emissions.

- Milling

- Use the newer autogenous grinding process that eliminates the dry crushing step altogether. 
- Control dust with alr exhaust hoods at the crusher, screens, and transfer points.

- Place a dust separation system at the drying oven to capture dust as it is vented tnto amblent air.

- Implement a wet scrubber to remove dust particles by impacting them with water droplets. Wet scrubber types and their respective removal efficiency levels include the ortfice scrubber (most commonly used) at $93.6 \%$, the impingement scrubber at $97.9 \%$, and the venturi scrubber (requires more energy than the other two scrubbers and is infrequently used) at $99.5 \%$,

- Use baghouses to remove the dust from crushing and packaging. These devices are frequently used and have a $99.9 \%$ removal efficiency level. However, they cannot clean dryer off-gas due to its higher temperature and the moisture content of its emissions.

- Tailings pile

- Wet the tailings using a truck that sprays (like storage control method). This method is the most common.

Costs: On the basis of assumptions that tailings are generated at a rate of 675 metric tons per day and that tailings are discharged to a 30hectare site that is surrounded by embankments, the annual costs over a 15-year period of renting trucks to perform spraying amounts to $\$ 549,000$ per year. The total cost over a 15 -year period amounts to $\$ 8.2$ million. If trucks are purchased instead of rented, the annualized costs over a 15 -year period are $\$ 318,000$, and the total cost is $\$ 5.1$ million.

- Wot the tailings with a sprinkler system.

Cuis: Total costs over a 15 -year project life are $\$ 1.9$ million; average annual costs over this period are $\$ 126,000$.

- Discharge the slurry from multiple points instead of a single point, thereby maximizing the area that is kept moist.

- Fixate the tailings.

Costs: Asphalt fixation requires a facility to heat the asphalt, mix it with the tailings, and dry the mixture. Average annual costs over a 15-year period amount to $\$ 7.5$ million, and the total estimated cost is $\$ 138$ million.

- Apply chemical stabilizer on the surface of pile to form a crust that encapsulates the material. This is a temporary measure that tequires annual maintenance.

Costs: Average annual costs over a 15 -year period amount to $\$ 2,280$ per hectare, and total costs, on the basis of 30 hectares treated annually, amount to $\$ 1.03$ million. 
- Cover the tailings above or below the ground with natural (e.g, soil, gravel, or clay) or artificial (asphalt or plastic liners) covers.

Costs: Total costs for above-ground encapsulation amount to $\$ 23$ million, and annual average costs would be $\$ 1.2$ million. Total costs for underground encapsulation amount to $\$ 33$ million, and annual average costs are $\$ 345,000$.

- Leach the tallings to remove residual reactivity.

Costs: Total costs of leaching with nitric acid amount to $\$ 283$ million.

- On the basis of estimated costs to control windblown particulates from tailing piles, EPA concluded that the application of latex stabilizers to the tailings piles is the most cost-effective method for controlling dust. This method is currently in use and is effective when applied annually.

- EPA concluded that the stationary sprinkler system was the second most cost-effective alternative. If installed in-house, sprinklers are actually more cost effective than the application of stabilizers.

- Uranium hexafluoride conversion plants

- Add particulate control technologies such as fabric filters and scrubbers to existing control systerns.

Costs: The capital cost of providing additional fabric filters for wet process plants is $\$ 2.1$ million and for dry process plants is $\$ 4.5$ million (1979 dollars). The annual cost for operating wet units is $\$ 0.6$ million and for operating dry units is $\$ 1.3$ million. 


\section{OVERVIEW AND ASSESSMENT OF AIR TOXICS DATABASES}

This section reviews major air toxics databases that are either currently in use or in later stages of development. The relative levels of detall in the databases are identified in Table 4.1. More descriptive information is provided in the following discussions that address their individual strengths and limitations. The databases surveyed include EPA's Toxic Release Inventory (TRI) database (EPA 1989b), EPRI's Power Plant Integrated Systems: Chemical Emissions Studies (PISCES) model (Balfour, Chow, and Rubin 1989), the National Acid Precipitation Assessment Program (NAPAP) VOC database (EPA 1989d), EPA's PM Species Manual (EPA 1990b), and the National Aeronautics and Space Administration (NASA) T'oxics Emission Inventory database.

TABLE 4.1 Characterization of Databases

\begin{tabular}{|c|c|c|c|c|}
\hline Paramoter & $\begin{array}{l}\text { EPA's TR! } \\
\text { Database }\end{array}$ & $\begin{array}{l}\text { EPRI's PISCES } \\
\text { Model }\end{array}$ & $\begin{array}{l}\text { NAPAP's VOC } \\
\text { Database }\end{array}$ & $\begin{array}{l}\text { EPA's Spocios } \\
\text { Manual }\end{array}$ \\
\hline Yuar(s) of data & 1987 & $1972-1988$ & 1985 & 1989 \\
\hline Sources & $\begin{array}{l}\text { Manufacturing } \\
\text { industrles }\end{array}$ & $\begin{array}{c}\text { Fossil-fuul-firud } \\
\text { utilities }\end{array}$ & $\begin{array}{l}\text { Utility, industrial, } \\
\text { commercial, } \\
\text { residential, and } \\
\text { transportation } \\
\text { sectors }\end{array}$ & $\begin{array}{l}\text { Agricultural, } \\
\text { Industrial, utlity, } \\
\text { residontial, and } \\
\text { transportation } \\
\text { sactors }\end{array}$ \\
\hline Slzo crituria & $10,000) \mathrm{lb}$ & $>50 \mathrm{MW}$ & 100 tons per year & $N A^{d}$ \\
\hline Number of sources included & 19,278 & 142 & 8,454 & 277 \\
\hline Number of chemicals & 328 & 273 & 32 hydrocarbons & $N A^{a, b}$ \\
\hline Area sources included? & & & $x$ & $x$ \\
\hline $\begin{array}{l}\text { Engineered emission } \\
\text { ustimates provided? }\end{array}$ & & $x^{\prime}$ & $x$ & Mixed \\
\hline $\begin{array}{l}\text { Ranking for data quallty } \\
\text { provided? }\end{array}$ & & $x$ & $x$ & $x$ \\
\hline $\begin{array}{l}\text { Pollution control information } \\
\text { included? }\end{array}$ & $x$ & $x$ & $x$ & $x$ \\
\hline \multicolumn{5}{|l|}{${ }^{\mathrm{N} A}=$ not available. } \\
\hline \multicolumn{5}{|c|}{$\begin{array}{l}\text { "Chemical species vary in each emission source profile. A list of the most commonly roported species in the literature } \\
\text { contains } 36 \text {, but many profiles include as few as four or five chemicals. }\end{array}$} \\
\hline
\end{tabular}




\subsection{TOXIC RELEASE INVENTORY}

EPA's TRI database (EPA 1989b) is based on data collected under Section 313 of the Emergency Planning and Communtty Right-to-Know Act of 1986. T'RI provides data on toxic air, water, and land pollution. The database derives its information from surveys completed by facillties that manufacture, import, or process more than 10,000 pounds of the 328 TRI chemicals and employ at least 10 full-time workers. In 1987, 19,278 facilities reported to TRI. Of these, more than $91 \%$ indicated that their production or use of TRI chemicals resulted in releases to the environment or transfers off site for treatment or disposal. In 1987, each facility reported, on average, four TRI chemicals they processed, manufactured, or otherwise used. EPA has recently released the third annual TRI.

The results of 'TRI suggest two points regarding the regulation of air toxics. First, only six of the TRI chemicals for which air releases were reported are currently regulated under the CAA - mercury, beryllium, asbestos, vinyl chloride, benzene, and arsenic - and these account for only about $1 \%$ by weight of total TRI alr releases (Lillenthal 1990). This fact suggests that the bulk of air toxics (in terms of weight) have not been affected by the NESHAP program.

The second point made evident by TRI is that 10 of the TRI chemicals reported in 1987 accounted for a disproportionately large share $(66 \%)$ of total TRI releases (see Figure 4.1 ). The 10 chemicals were ammonia, toluene, methanol, acetone, 1,1,1-trichloroethane, methyl ethyl ketone, xylene, carbon disulfide, dichloromethane, and chlorine. Acetone was the only one of

Total TRI Air Emissions: 2.6 billion lb

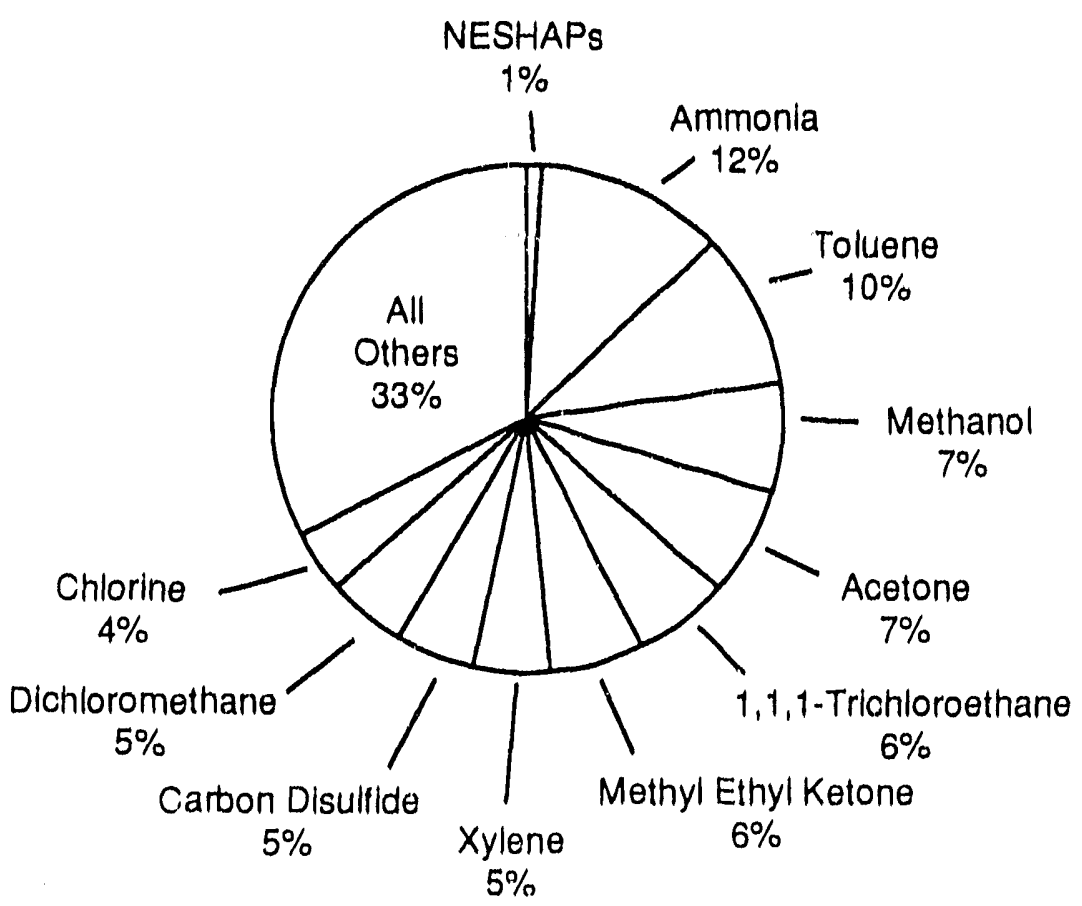

FIGURE 4.1 Top Ten Chemicals Emitted in 1987 according to TRI Database (Source: Lillienthal 1990) 
these 10 chemicals not listed to be regulated under the CAAA (Lillienthal 1990). This point indicates that a substantial portion of HAPs could be reduced by regulating the sources of a relatively small number of chemicals. Although it is important to keep in mind that HAPs vary dramatically in terms of toxicity, it is also helpful to note the concentration (in weight) of various HAPs released into the air, because this is a factor in exposure levels. In view of both points, the problem with the NESHAP program may not have been due to the small number of chemicals regulated but rather to the specific chemicals that were chosen for regulation.

The most recent TRI reported that 22,650 industrial plants and sites across the country released 5.7 billion pounds of TRI chemicals in 1989 - a decrease of 1.3 billion pounds from the amount reported in 1987 and 723 million pounds less than industries released in 1988. Companies have proposed the withdrawal of three pollutants from reporting requirements: phosphoric acid, sulfuric acid, and ammonium sulfate (none of which were listed as a HAP in the CAAA). The three chemicals accounted for 1.2 billion pounds of pollutants released into the environment by manufacturers in 1989. Ammonium sulfate alone accounted for 750 million pounds of toxic emissions in 1989 and has been the single largest source of pollution for three years (Schneider 1991).

\subsubsection{Strengths}

The TRI database contains very detailed, facility-specific information. In comparison to some databases that describe releases only in generic terms, i.e., "volatile organics," TRI information on chemical releases is very detailed. TRI includes 20 broadly defined chemical categories but also lists 308 chemicals specifically. The specificity of the information provided, in turn, makes information retrievable in many forms: by chemical, chemical class, location (state, county, city, zip code, latitude, and longitude), industry, activity (use of chemical), and source type (point or fugitive); see Table 4.2 for an example. The vast nature of the inventory (including reports from 19,278 bacilities) may provide a better cross section of pollution sources and the variances among them than are found in other databases that make estimates on the basis of a single or a few case studies.

Each facility reporting to TRI was also required to indicate the type of on-site waste treatment methods used and its treatment efficiency or the percentage of the TRI chemical that was removed from the waste stream. In addition, facilities could voluntarily provide additional information on their efforts to minimize chemical waste generation. Technology-based regulations proposed in legislation will depend on this type of information. Greater accessibility to information on various waste treatment methods could also accelerate the development and implementation of new technologies overall.

\subsubsection{Limitations}

The most obvious limitation of TRI is that it covers only manufacturing industries, thus excluding nonmanufacturing sources and processes used in other businesses, such as warehouses, photographic processing plants, dry cleaners, and mining operations, which are also potential sources of toxic chemical releases. Because participating facilities required to participate in TRI must employ at least 10 full-time workers, information on very small facilities 
TABLE 4.2 Ten Worst Emitting

States according to TRI Database

\begin{tabular}{llll}
\hline & \multicolumn{3}{c}{$\begin{array}{c}\text { Total Emissions } \\
\left(10^{6} \mathrm{lb} / \mathrm{yr}\right)^{\mathrm{a}}\end{array}$} \\
\cline { 2 - 4 } \multicolumn{1}{c}{ State } & 1987 & 1988 & 1989 \\
\hline Texas & 856.9 & 882.2 & 792.8 \\
Louisiana & 857.0 & 767.3 & 473.5 \\
Ohio & 421.3 & 366.4 & 358.7 \\
Tennessee & 293.6 & 254.6 & 264.3 \\
Indiana & 258.9 & 278.5 & 255.0 \\
tllinois & 273.1 & 255.8 & 248.0 \\
Michigan & 268.9 & 248.2 & 220.0 \\
Pennsylvania & 230.9 & 212.9 & 194.2 \\
Florida & 304.2 & 157.8 & 192.0 \\
Kansas & 135.4 & 175.7 & 185.1 \\
\hline
\end{tabular}

"The total amount of more than

300 chemicals released into the air,

water, and tand.

Source: EPA, as noted in Schneider

(1991).

and area sources is not captured in the TRI data base. Another obvious limitation is that TRI divides sources by SIC codes but does not use the more descriptive source classification code (SCC), an industry activity code. Also, it is a survey-derived database; not all facilities that should have reported to TRI always did so.

One feature of the TRI database may be viewed both as a strength and a limitation. As a survey-derived database, TRI is dependent on facilities to not only provide actual measurements but also to provide estimates when actual measurements are not available. For example, only $16 \%$ of the estimates on air emissions treatment efficiency were based on actual operating data. Efficiency estimates not based on operating data were based on either information from flow rates, equipment supplier's literature, published data for similar processes, or other means. Therefore, the average efficiency of gaseous waste treatment that was reported by facilities $(94 \%)$ was likely an upper-end estimate. This point raises the question of how capable facilities are of providing accurate estimates. On one hand, the special interests of a facility could jeopardize the objectivity and accuracy of its estimates. On the other hand, a facility is nearest to its own processes and is most likely to understand the intricacies involved therein. Critics of TRI have recommended the initiation of reporting requirements on the amount of raw materials used for each plant in manufacturing and on the number of chemicals that appear in finished products in order to spur increased efficiency in the use of raw chemicals and inform employees of the compounds to which they are exposed (Schneider 1991). New Iersey, Massachusetts, and Oregon have enacted laws with such requirements. 
The inventory has become the focus of criticism from environmental groups because many of the nation's biggest polluting industries, including agriculture, mining, forestry, electrical utilities, commercial hazardous waste incinerators, and the federal government's munitions and nuclear weapons plants, are exempted from reporting toxic chemical releases (Schneilder 1991).

Among the 29 facilities that emitted $23 \%$ of the 10 billion pounds of chemical releases reported in 1987, according to the National Wildlife Federation, emissions reportedly decreased $39 \%$ by 1988 (Poje and Horowitz 1990). In certain cases, however, the emission reductions were the result of accounting changes, i.e., switching from mass balance calculations in 1987 to direct measurement in 1988 (Poje and Horowitz 1990). The lack of standardized measurement procedures makes interpretation of these results very complicated. Environmental groups also attribute part of the reduction to the large number of toxic substances that have been deleted from the list of chemicals that the EPA requires industries to report; 10 chemical pollutants that companies were required to report in 1987 were no longer listed (Schneider 1991).

\subsubsection{Status and Technical Capabilities}

The TRI database currently includes 1987, 1988, and 1989 data. Although facilities with capacities of $75,000 \mathrm{lb} / \mathrm{yr}$ or more were surveyed in the 1987 data, the requirement was dropped to $50,000 \mathrm{lb} / \mathrm{yr}$ for 1988 and $25,000 \mathrm{lb} / \mathrm{yr}$ for subsequent years, thus significantly increasing the number of facilities that report emissions. EPA is analyzing a list of industries suggested by environmental groups, states, and agency regions, including waste management firms, public sewage treatment plants, mining, chemical warehouses, commercial laundries, and photo processing plants. A preliminary analysis found that 29,000 more plants would be eligible for reporting the current set of toxic chemicals (Air Toxics Report 1991).

Because TRI is designed for public access, anyone with a computer, modem, and modicum of skill at data manipulation can phone into TRI and have access to the information. Registered on-line service users are able to access TRI on the TOXNET system by direct dial or through various telecommunication networks including TELNET, TYMNET, or COMPUSERVE.

\subsection{POWER PLANT INTEGRATED SYSTEMS: CHEMICAL EMISSIONS STUDIES}

EPRI'S PISCES database is in the final stages of development. It will contain information on all chemical species of interest to the electric utility industry for both conventional and advanced power generating systems. One important application of this model will be its ability to characterize the chemical composition of utility wastes, coal cleaning refuse, and other streams of interest to utility operators (Rubin, Salmento, and Chow 1990). The goal of PISCES is to trace the routes of key chemicals through the various plant process streams in order to help utilities improve the design and operation of plants where there is a probability of hazardous emissions at levels equal to or greater than current and/or anticipated regulated limits or recognized health/environmental effect thresholds. PISCES managers describe the approach in the following way: ". . the idea is to take a holistic approach to understanding and quantifying how various chemical inputs to the plant - the fuel and additive - are chemically transformed within the facility and partitioned through plant components iritu various chemical outputs the gaseous, aqueous and solid waste" (Rubin, Delleney, and Chow 1989). In this way, PISCES 
could improve the ability of power generating facilities to accurately estimate the impacts of operational changes on waste streams, including toxic air emissions. Heretofore, operators of power systems have had to rely largely on unqualified information for estimated impacts of operational changes on emissivits (Rubin, Delleney, and Chow 1989).

The database currently contains 142 different operating units firing either coal, oil, or natural gas and some 80,000 records of species measurements spanning from 1972 to 1988 . The project involves the collection and review of existing data on the source, distribution, and fate of chemicals in both conventional and advanced fossil-fuel-fired power systems (Rubin, Salmento, and Chow 1990). In compiling the PISCES database, EPRI obtained data points for plant emissions of various chemical that were actually going up the stack but for which there was very little paired data - what goes in and what comes out - for a given control device (Rubin, Salmento, and Chow 1990). Consequently, there is not much information on the species removal efficiencies for these devices available, and the existing data exhibit a wide variability.

PISCES consists of several major products and activities including the following:

- A relational database of information gathered from the literature and other sources,

- A computerized power plant systems model to track the pathways of chemical substances and quintify emissions,

- A field monitoring program to measure emissions of 24 chemicals in utility flue gases at plants employing a variety of emission control technologies, and

- Emission control technology guidelines.

The PISCES database also contains descriptive data such as information on (1) the plant configuration (e.g. type of boiler and pollution control equipment); (2) whether the process stream is solid, liquid, or gas; (3) the concentration of each species in a stream; (4) the analytical methods for each chemical; and (5) the relevant regulations.

In May 1990, EPRI began its field monitoring project to measure 24 inorganic and organic substances in the process and discharge streams of several power plants representing different mixes of fuel type, configuration, and control systems (e.g., ESPs, FFs, dry and wet FGD systems, low $-\mathrm{NO}_{x}$ burners, and postcombustion $\mathrm{NO}_{x}$ systems). Data obtained from this project will be used to fill data gaps and validate modeled results. Plant mass balances are being conducted for all the relevant chemicals to determine their sources and pathways and how they are partitioned in the power plant. The project also entails the collection of information in the technical literature on emerging or innovative technologies for controlling emissions of air toxics.

EPRI is concurrently attempting to complement its HAP database with a model that addresses the controversial issue of risk assessment -- linking health risks of different HA.Ps with the exposure of populations to these emissions. It was around this latter aspect that some of the most intense debate regarding residual risk standards in the 1990 CAAA revolved. This debate is likely to continue, and the way in which EPRI handles exposure to chemicals in its model may prove to be very instructive. 
EPRI is also developing another model in parallel with the PISCES database to estimate the probability that a chemical substance may occur in a process stream at or above a given value. Figure 4.2 depicts an example of such a feature, where there is a $90 \%$ probability that Alue-gas emissions of a given trace metal will be less than $1.5 \mathrm{lb} / \mathrm{h}$. This probability curve could also mean that $10 \%$ of the time, emissions are expected to exceed $1.5 \mathrm{lb} / \mathrm{h}$. This probabilistic assessment incorporates the uncertainty of input data and facilitates assessment of various power systems and control technologies.

\subsubsection{Strengths}

The two models being developed to complement PISCES represent significant strengths of the database. EPRI's database stands apart in that it will attempt to place HAP quantities in the context of human exposure, thus combining the quantification of emissions with the qualification of each HAP substance. This difference will be particularly beneficial if facilities must respond to health-based standards in Phase 2 of air toxics regulation. EPRI's Environmental Risk Analysis Program is using data developed in PISCES and other programs, in conjunction with other models such as the Airborne Emissions Risk Assessment Model (AERAM) to determine the risk to human health from air toxics emissions. AERAM calculates the transportation and dispersion of plant emissions in the atmosphere, human exposures, and ultimately the human health risks from a particular power plant. Another model called AirTox expands on the capabilities of AERAM by permitting multiple decisions on controls to be analyzed and provides information on a range of outcomes, including costs. A third model, called Risk PISCES, is being developed to consider routes of exposure besides inhalation, including food intake, drinking water, etc.

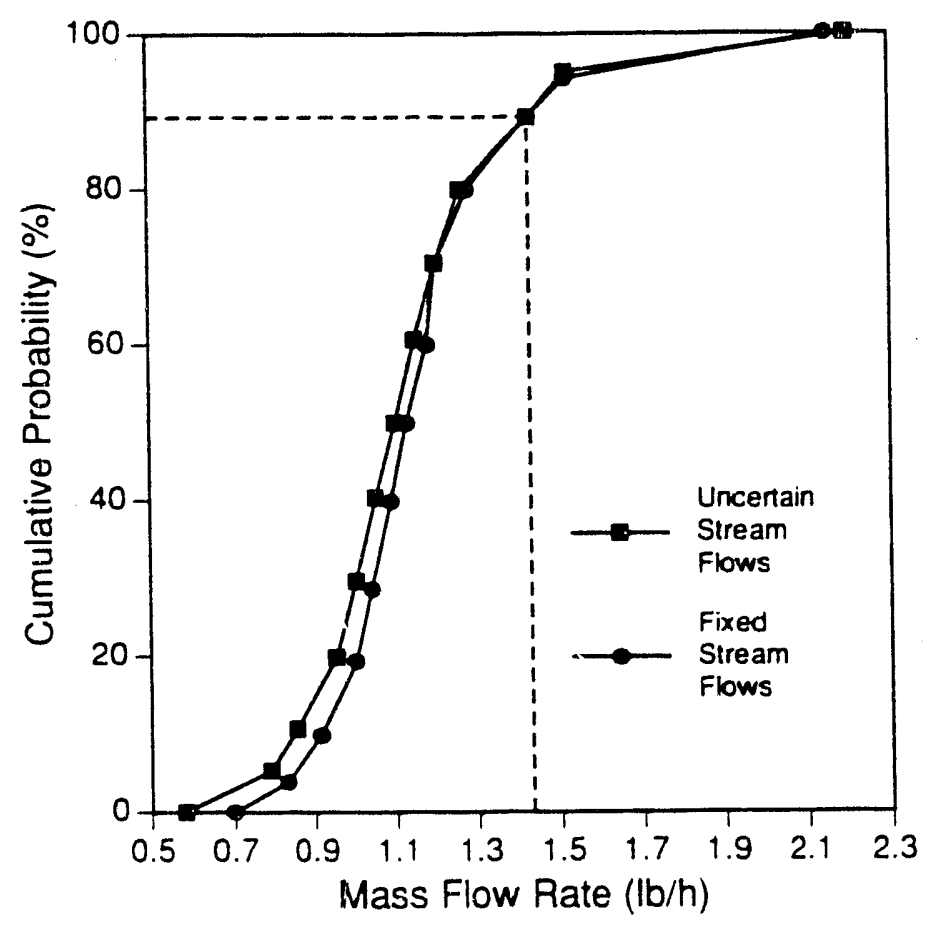

FIGURE 4.2 Stack Gas Emissions (Source: Chow 1990) 
The model's ability to express results as a range of probable outcomes instead of as a single (deterministic) result is also an advantage of special worth to the energy sector, which must grapple with the uncertainty that often accompanies fossil fuel input data. This kind of a probability curve is especially crucial for facilities that combust fossil fuels, since the uncertainty of the input data is often very high because of the variant nature of fossil fuels and their combustion processes. The probabilistic representation also facilitates the assessment of potential compliance problems with regulatory limits.

Other strengths of PISCES include its utilization of thoroughly screened and reliable data and its ability to rank its results in terms of relative reliability. Data are screened before they enter the PISCES database and are deemed acceptable only if accompanied by detailed descriptions of the methods involved in sampling and analyzing substances. Information currently exists for 300 sampling methods and 88 analytical methods. The credibility of the data is ranked as either acceptable, unacceptable, or unknown, on the basis of the reported sampling and analytical procedures, the conditions under which the samples were obtained, and any reported quality control data. This is particularly useful when emission estimates are modeled and based on mass balance and mass flow rate calculations that involve model parameters or assumptions whose degrees of uncertainty vary and are not readily apparent.

\subsubsection{Limitations}

Because this database is still under development and findings have not been published (except for a few select pollutants such as mercury), the particular methodological limitations of PISCES are unknown. As opposed to some of the other more broadly based databases, this database centers specifically on the utility industry.

\subsubsection{Status and Technical Capabilities}

Phase 1 of the PISCES project, which addresses conventional oil-, gas-, and coal-fired power systems, is not yet fully operational. Data are currently being reevaluated and validated through field sampling. It is expected that this database validation process will continue another two years. Records of quantity data currently exist in the database for 575 chemicals at conventional power plants. More than 1,200 records of regulations or health effect information currently exist in the database for 425 substances.

A new PISCES-related project on field data acquisition is now underway: 25 substances will be measured in process and discharge streams at six utility plants. Each plant site will represent contrasts in plant configuration, fuel type, and environmental controls. Future efforts will extend the model and database developments to include advanced power generating systems and a broader set of environmental control technology options.

Subsequent work will include the incorporation of economic cost models and expansion of the technology set to include a number of advanced power generation options including fluidized-bed combustion, integrated gasification combined cycle systems, refuse-derived fuels, and other new technologies (Rubin, Salmento, and Chow 1990). While new model developments are occurring, the database will continually be updated to facilitate the chemical characterization of power plant waste streams. In addition, a user-friendly interface with the PISCES database is also under development. 
The PISCES database system is currently being implemented on a Sun computer, using Empress/32 relational database management software. Selected utilities are currently alphatesting the PISCES database by modem from the contractor's Sun network. Further development of automated interfaces and user-friendly software is planned. A formal mechanism for access has yet to be defined.

\subsection{THE 1985 NAPAP EMISSIONS INVENTORY}

The 1985 NAPAP 'atabase is distinguished from other databases in a few general ways. First, it was primarily interi ' $d$ as a database to facilitate acid rain research and is relevant to the air toxics issue insofar as it contains information on VOC. Second, unlike the other databases described thus far in this report, the NAPAP database includes estimates of HAPs from not only point but also area sources. Thirc, the NAPAP database includes emissions data from Canada.

NAPAP, which was established by Congress in 1980 to coordinate and expand federal research on problems posed by acidic deposition, called for the development of an emissions inventory. The database was initially geared toward the acid rain issue and therefore focused on a relatively narrow list of "criteria" pollutants: $\mathrm{SO}_{2}, \mathrm{NO}_{x}, \mathrm{VOC}$, total suspended particulates (TSP), and CO. Some of the VOC data were derived from the National Emissions Data System (NEDS) but was then extensively revised and supplemented. EPA later added estimates of other pollutant emissions associated with acid deposition, which included primary sulfate particulates $\left(\mathrm{SO}_{4}{ }^{-2}\right)$ as well as three HAPs listed in the early versions of the air toxics title - $\mathrm{HCl}, \mathrm{HF}$, and ammonia $\left(\mathrm{NH}_{3}\right)$. (Although both the House and the Senate versions had the same list of 191 chemicals, the House Committee removed ammonia from its list based on the presumption that this chemical was mainly a problem from an accidental release standpoint [NATICH Newsletter 1990a]. Ammonia was dropped from the list of HAPs that was adopted in the final CAAA of 1990.) Emission estimates for the four additional species were calculated by applying SCC-level emission factors to the operating and activity rates data provided in the inventories.

Point sources that emitted at least 10 cons in 1985 of any of the criteria pollutants were included in the database. The NAPAP source emissions inventory also accounts for emissions from sources that were not included in the point source inventory, such as mobile sources, stationary combustion sources that vrere too numerous and too small to be treated as point sources (i.e., plants that emitted less: than $10 \mathrm{TPY}$ ), and point sources that emitted less than 25 TPY or that were too difficult to iriventory individually (e.g., residential space heating). Miscellaneous area sources include solid waste disposal, gasoline marketing, organic solvent consumption, unpaved air strip use, forest wildfires, managed burning, agricultural burning, and structural fires.

Area source emissions were calculated with EPA emission factors and activity data such as published fuel deliveries. County-level emissions derived from this combination were then summed to produce national emissions estimates. 
The NAPAP database permits highly detailed retrieval of information by the following categories:

- Plant characteristics

- Sector (e.g., utility, industrial combustion or process, transportation, commercial/residential)

- Plant size

- SCC operating characteristics

- Temporal

- Season (four 3-month increments)

- Day type (i.e, weekend or weekday)

- Hour (24 hours in a day)

- Spatial

- EPA region

- State

- County

- Longitude/latitude points

- Speciation

- Pollutant type (e.g., VOC, $\mathrm{SO}_{2}, \mathrm{NO}_{x}, \mathrm{CO}, \mathrm{TSP}, \mathrm{HF}, \mathrm{HCl}$, or $\mathrm{NH}_{3}$ )

- 32 hydrocarbon species

The temporal and spatial data provided in the NAPAP database are extremely specific. The spatial distribution of residential emissions was based on population and housing data. Population data were also used to estimate the spatial distribution of HAPs from the following energy-related activities: gasoline marketing; minor point sources fueled by coal, oil, and gas processes; and fugitive emissions from petroleum refinery operations and crude oil and natural gas production fields. Urban land data and Landsat satellite imagery information were used to estimate the spatial distribution of HAPs from commercial, institutional, and industrial fuels. The temporal distribution of VOC by season, type of day, and hour was derived froin operating data (e.g., days per week and hours per day of process operation). Fuel-and season-specific use patterns were averaged by state, then normalized to generate the Northeast Corridor Regional Modeling Project (NCRMP) hourly patterns. Saturday and Sunday hourly profiles were developed from EPRI Regional Systems data. The Flexible Regional Emissions Data System (FREDS) split the annual VOC emissions into 32 chemical species classes, which could then be matched to point and area sources.

\subsubsection{Emission Factors Used}

Continuous emissions monitoring data, source test data, or materials balance information was the preferred form of emissions information. This sort of emissions measurement data, however, was often not available for VOC emissions, and states most frequently used a special emission factor to estimate VOC emissions. Emission factors are multipliers that are applied to a facility characteristic, such as annual fuel use, to estimate its total annual emissions. Estimates in the NAPAP database for $20.6 \%$ of VOC emissions from point sources and for nearly all of the VOC emissions from area sources are based on emission factors. Stack tests were rarely used 
to estimate VOC emissions. The reliability of these emission factors varies drastically according to the amount of information used to derive the factors and the degree to which the factors were reviewed.

In general, $\mathrm{VOC}$ emission factors are rated as being of low quality relative to emission factors used to estimate $\mathrm{SO}_{2}$ and $\mathrm{NO}_{x}$ emissions. More than $92 \%$ of the emission factors for both $\mathrm{SO}_{2}$ and $\mathrm{NO}_{x}$ received quality ratings of $\mathrm{C}$ or higher, while only $27 \%$ of VOC emission factors received the same confidence ratings. (Ratings range from $A$, the highest in confidence, to $E$, the lowest.) Many of the emission factors derived from NEDS had low quality ratings. In addition, many new VOC factors had to be developed by NAPAP for many processes that were not available in NEDS, and these additions were generally considered less reliable than those adopted from NEDS because they were not subject to the same rigorous review. Some VOC emission factors were simply borrowed from emission factors of similar industries or received no ratings at all. Quality of the data varies from very poor (as in the case of coke ovens, for which only a small amount of data from Poland made up the information source) to fairly good (as in the case of petroleum refineries).

The NAPAP inventory also provides specific information on the emission factors it used to estimate $\mathrm{HCl}$ and $\mathrm{HF}$. These factors, which were closely related to the energy sector, are listed in Table 4.3 along with their quality ratings. The emission factors used to estimate $\mathrm{HCl}$ and HF emissions from coal-fired utility and industrial boilers were assigned the highest-quality

TA.BLE 4.3 Hydrogen Chloride and Hydrogen Fluoride Enission Factors

\begin{tabular}{lccc}
\hline $\begin{array}{c}\text { Sector and } \\
\text { Coal Type }\end{array}$ & $\begin{array}{c}\mathrm{HCl} \text { Factor } \\
\text { (lb/ton) }\end{array}$ & $\begin{array}{c}\text { HF Factor } \\
\text { (lb/ton) }\end{array}$ & Rating \\
\hline $\begin{array}{l}\text { Utility/industrial } \\
\text { Bituminous }\end{array}$ & 1.90 & 0.23 & $\mathrm{~A}$ \\
Anthracite & 0.91 & 0.18 & $\mathrm{~A}$ \\
Lignite & 0.01 & 0.01 & $\mathrm{~A}$ \\
& & & \\
Commercial/institutional & & & \\
Bituminous & 1.48 & 0.17 & $\mathrm{C}$ \\
Anthracite & 3.07 & 0.13 & $\mathrm{C}$ \\
Lignite & 0.35 & 0.063 & $\mathrm{C}$ \\
& & & \\
Incineration & & & \\
$\quad$ Municipal waste & 5.00 & $\mathrm{NA}$ & $\mathrm{E}$ \\
Industrial waste & 5.35 & $\mathrm{NA}$ & $\mathrm{E}$ \\
\hline
\end{tabular}

${ }^{5} \mathrm{~A}$ rating of $\mathrm{A}$ indicates the highest confidence and $\mathrm{E}$ indicates the lowest confidence in the application of the factor to the specific process.

${ }^{\mathrm{b}} \mathrm{NA}=$ not available. 
ratings because of the number of tests conducted and the availability of information concerning the accuracy and type of test methods used. Emission factors used to estimate $\mathrm{HCl}$ emissions from commercial and institutional boilers received only mediocre ratings. Emission factors used to estimate $\mathrm{HCl}$ emissions from incinerators received the lowest-quality ratings. The more assumptions that were needed to compensate for missing information, the lower the quality ratings were.

\subsubsection{Strengths}

The 1985 inventory contributed to "ground-breaking" VOC research by including VOC sources not previously considered, such as hazardous waste treatment, storage, and disposal facilities. As in PISCES, the emission factors used in the NAPAP database were reviewed and assigned quality ratings. This characteristic is crucial to any database that relies on emission factors to estimate VOC. In one of the reviews, EPA reported that $\mathrm{HF}$ and $\mathrm{HCl}$ emission factors in the NAPAP database compare favorably with those develnped by DOE's Pittsburgh Energy Technology Center, thus validating the use of these factors to some extent.

As a database devoted solely to VOC, the NAPAP database is able to focus on very unique aspects of VOC emissions. This database takes into account the significant effect that warmer temperatures have on VOC releases and attempts to adjust for this effect. The database is also very spatially specific. The 48 contiguous states were divided into grid cells, which measured a half a degree in latitude by a fourth degree in longitude. The database is composed of a total of 37,441 of these grid cells and provides extremely detailed information, even beyond the county level.

The NAPAP database may prove especially useful for energy-related sources because it contains data on petroleum refineries, MWCs, coal-fired and oil-fired external combustion boilers, wood-burning stoves, mobile sources, power plants, and coal and coke dust. The database also estimates contributions of PM by natural sources.

\subsubsection{Limitations}

An extensive quality assurance and quality control program was conducted during the inventory development to correct erroneous, questionable, or missing data elements for a list of high-priority point-source data items. Point sources that were assigned the highest priority in the quality control program were those that emit. $\mathrm{d}$ at least 25 TPY of VOC and that were from plants that emitted at least 1,000 TPY of VOC. Sources not falling in this category were not checked as rigorously; these sources accounted for $94 \%$ of all plants included in the database. Thus, the quality control activities were limited.

For area sources, specific information contributed by the states was the exception rather than the rule. Area-source emission estimates were usually calculated by multiplying the activity rate by an emission factor, for which quality ratings varied.

Control devices were not factored into the calculations of $\mathrm{HCl}$ and $\mathrm{HF}$ emissions from coal combustion, although the efficiency of wet scrubbing devices has been reported to be about $80 \%$, for both $\mathrm{HCl}$ and $\mathrm{HF}$ emitted from bituminous-coal-fired utility boilers and about $95 \%$ for 
the removal of $\mathrm{HCl}$ with the use of nacholite and sodium bicarbonate as dry sorbent combustion. Thus, the emissions reported for sources employing certain control devices are probably overestimated.

Of the hydrocarbons speciated, $50 \%$ were given the two lowest (D or E) confidence ratings. Thus, there is a relatively large amount of uncertainty associated with identifying the sources of species. (None of the hydrocarbon species received the highest confidence rating, $A$, but almost a third of the species received the next highest rating, $\mathrm{B}$.)

Point sources that emitted at least 100 TPY of VOC in 1985 were included in the database. However, $64 \%$ of the plants recorded emitted under 100 TPY of VOC in 1985 . The emissions resulting from the sources that were included in the database accounted for a mere $3 \%$ of total VOC emissions from point sources, which is probably a low estimate.

The hourly distribution of emissions from industrial coal and oil use is based on a study conducted in Philadelphia, where 50\% of the emissions were allocated uniformly from 7 a.m. to 4 p.m. and the remaining $50 \%$ were uniformly allocated to the remaining hours in the day. This pattern was applied nationwide to all industrial fuel use categories.

Several of the VOC emission factors were developed from source tests that used flame ionization detection (FID) as the measurement technique. This technique does not respond to aldehydes, and therefore the VOC estimates for those sources represent hydrocarbons minus aldehydes. Estimates of VOC and total hydrocarbons (THC) were adjusted to account for aldehydes. Emission factors used to estimate VOC in the NAPAP database involve a large amount of uncertainty relative to factors used to estimate other pollutants. This uncertainty could be reduced through extensive review of the factors and studies on individual sources.

\subsubsection{Status and Technical Capabilities}

The NAPAP inventory is a very large database that is currently stored on magnetic tape. It can be downloaded to a personal computer or any other computer in either an ASCU or SAS format. The official release, Version 2, is available from EPA. Most users select a subset of the database to work with in their studies.

\subsection{PARTICULATE MATTER SPECIES MANUAL}

A recent study by Dockery and Schwartz (1991) concluded that particulates played a major role in $7 \%$ of the deaths recorded in Philadelphia between 1973 and 1980. It also claimed that microscopic particulates contributed significantly to nearly 60,000 human deaths annually. It cited another study conducted by the same authors in St. Louis that matched the Philadelphia findings. (It should be noted, however, that there are very few case studies to confirm these results.) Dockery and Schwartz (1991) further noted that "... the increased deaths in this study are being seen at levels of TSP that are less than one half the current acceptable levels set pursuant to the CAA." This study of Philadelphia attributed the PM levels mainly to fossil fuel combustion, steel mills, factories, and diesel fuel exhaust, but it noted that ". . power plants have fairly stringent controls and thus do not bear much of the responsibility" (Environment Reporter 1991). The authors of the study aiso added that automobile exhaust does not contribute as much PM pollution as do old factories. 
Ir. 1987, EPA revised the way it regulates particulates. Until then, TSP had included all airborne particulate matter. Then EPA developed a standard for $\mathrm{PM}_{10}$ particles - particles smaller than 10 microns in diameter - which was set at an annual average limit of $150 \mu \mathrm{m} / \mathrm{m}^{3}$ of air. The smaller particulates make up about half of the TSP and are especially problematic because they are small enough to penetrate the respiratory tract and inflict damage (Environment Reporter 1991). The 1990 CAAA do not change the $1987 \mathrm{PM}_{10}$ standard. Particulates that also happen to be HAPs, however, might be further regulated under the new Title III.

The database used in EPA's PM Species Manual (EPA 1990b) was developed from multiple sources of information. Many PM profiles were extracted from the source composition library and given minor changes in format to facilitate inclusion of additional information in this profile. A large number of the profiles were developed by contacting researchers working in the areas of PM species profile development and source receptor modeling.

\subsubsection{Strengths}

The manual includes a broad range of PM emission sources, including both point and area sources:

- External combustion boilers (power plants)

- Chemical manufacturing

- Food and agriculture

- Primary metal production

- Secondary metal production

- Mineral products

- Petroleum industry

- Pulp and paper

- Surface coating

- Solid waste disposal

- Metal fabrication

- Heavy construction

- Unpaved roads

- Natural sources

- Wood combustion

- Agricultural field burning

- Mobile sources

- Aircraft

- Other

Many of the source profiles distribute the PM emission data by particulate size (i.e., 0-2.5, 2.5-10, and $0-10 \mu \mathrm{m}$ ) providing information specific enough to taid in the development of health risk assessments. 
Since the process involved in generating PM emission estimates for this long list of source categories was complicated and was not stzudard for all cattegories, the rolle of data quallity ratings is especially important. EPA provided data quallity ratings that took into consideration the uncertainties associated with mass fraction data, calculational procedures used for the 0-10 um size interval, and general assumptions used in filling data gaps.

\subsubsection{Limitations}

In some cases, only generic particle size distribution data were identified, and the more specific distributions by particulate size were unavailable. There were too few species profiles available to EPA for it to estimate the PM emissions released by the broad list of source categories included in the report. To make up for this deficiency, EPA often assigned a PM profile of one category to other "similar" categories. Where possible, engineering judgement was used to estimate PM emissions based on the available data. In cases where engineered estimates were not possible, EPA developed average industry-specific profiles based on profiles that represented other SCCs but that were within the same group. In cases where it was not possible to even develop an average industry-specific profile, EPA used what it labeled a "zero" profile, which was based on an average of all profiles in the database. This sort of profille was used in cases where SCCs had "zero" or "negligible" PM emission factors.

EPA's report (EPA 1990b) states that the "... reader/ user should be aware of limitations of each data set, specifically with respect to measurements of carbonaceous emissions and volatile elements (e.g., lead, arsenic, and mercury) that partially exist in the gaseous phase at high stack temperatures. Only special precautions such as dilution source sampling and aircraft or balioon tnethods can adequately capture these elements in the data." However, this waming applies to most databases reporting these emissions and is not unique to EPA's PM Species Manual.

\subsubsection{Status and Technical Capabilities}

This document was an expansion of the 1980 and 1C,5 PM. Species Manual. EPA is expected to again update and expand the current report as more emissions data are obtained.

\subsection{TOXICS EMISSION INVENTORY DATABASE}

NASA's database on off-gassing tests of VOC from thousands of materials used in the space shuttle program is clearly the largest source of information characterizing indoor VOC (Ozkaynak et al. 1987). NASA (MCDonnell Douglas, contractor) has tested VOC emissions from more than 5,000 materials used in the space program. Much of the database is relevant to more than just the space program, however, because many of these paints, epoxies, pens, cosmetics, etc., under study are available commercially and commonly found in homes and offices.

Detailed analyses of the database have been conducted to identify the VOC emissions and their sources that could commonly be found in households and offices (Ozkaynak et al. 1987). Materials were tested in an enclosed chamber at a reduced pressure of 12 pounds per square inch absolute (psia). The chamber is heated to a test temperature of $120^{\circ} \mathrm{F}$ for a period 
of 72 hours, at which time off-gassed products in the chamber are sampled and analyzed at room temperature. Data are available by emission, test report number, product description, and manufacturer's name.

\subsection{CONCLUDING NOTE}

Even if databases are accepted as reliable indicators of the amount of HAPs released by manufacturing sources, these releases cannot be equated directly to exposure, since each chemical in each individual release circumstance undergoes a different transformation after its release (EPA 1989b). For example, gaseous emissions may be either chemically transformed into harmless by-products or lead to byproducts of even greater concern than the original releases. As EPA points out, each release scenario has its own unique characteristics. Furthernore, one cannot get the whole picture of a chemical's effect by measuring the amount of a released chemical alone; the amount must be assessed in the context of the chemical's toxicity. A small release of a highly toxic chemical might be of much greater concern than a large release of a lowtoxicity substance (EPA 1989b). 


\section{REFERENCES}

Air Toxics Report, 1991, EPA Cautions Law Makers against Extraordimary TRI Expansion, Business Publishers, Inc., Silver Spring, Md., p. 51, July.

Anderson, R.F., 1991, Comments of Wheelabrator Environmental Systems Inc. before the National Air Pollution Control Techniques Advisory Committee, in Minutes of Meeting: January 29-31, 1991, U.S. Environmental Protection Agency, Research Triangle Park, N.C., pp. 465-511.

Balfour, W.D., W. Chow, and E. Rubin, 1989, PISCES: A Utility Database for Assessing the Pathways of Power Plant Chemical Substances, presented at the Annual Meeting of the Air and Waste Management Association, Anaheim, Calif., June; also paper 89-71.6, Electric Power Research Institute, Palo Alto, Calif.

Bergstrom, R.B., Jr., 1989, Testimony of Robert B. Bergstrom, Jr., Attorney, lowa Southern Ltilities Company, before the U.S. House of Representatives, Subcommittee on Health and Envircrment, June 22.

Burton, B.K., 1990, letter from Burton, Institute of Resource Recovery, Washungton, D.C., to F.L. Porter, U.S. Environmental Protection Agency, Oct. 19.

Chow, W., 1990, PISCES: Tracking Trace Chemicals in Power Plants, Journal of the Air and Waste Management Association, 40(5):806-808, May.

Chow, W., et al., 91, Managing Air Toxics under the Netv Clean Air Act Amendments, Power Engineering, pp. 30-34, Jan.

Clean Air Report, 1991a, EPA Rule Sets Nezu Standard for Big Municipal Solid Waste Incinerators, pp. 9 and 10, Jan. 17.

Clean Air Report, 1991b, Oil Industry Advocates Certainty, Simplicity in Clean Air Rulemakings, p. T-14, April 11.

Delta Management Group, 1989, An Analysis of Petroleum Industry Costs Associated with Air Toxics Amendments to the Clean Air Act, interim final, prepared for American Petroleum Institute, Washington, D.C., Oct. 17.

Dockery, D., and f. Schwartz, 1991, Funding of Study on Behalf of the U.S. Environmental Protection Agency, Air Quality Office and the Harvard School of Public Health, presented at the 1991 International Conference of the American Lung Association, May 12.

DOE, 1991a, National Energy Strategy, First Edition 1991/1992, U.S. Department of Energy, Feb.

Eckart, D.E., 1990, House Clean Air Act Debate, testimony by Representative D.E. Eckart (D-OH) on Oct. 26, as presented in Clean Air Report, p. 32, Nov. 22.

EIA, 1987, Quarterly Coal Report; October-December 1987, report DOE/EIA-0121(87/4Q), U.S. Department of Energy, Energy Information Administration, Office of Coal, Nuclear, Electric and Alternative Fuels. 
EIA, 1988, Coal Production 1988, report DOE/ELA-0118(88), U.S. Department of Energy, Energy Information Administration, Office of Coal, Nuclear, Electric and Alternate Fuels.

ELA, 1989, Uranium Industry Annual 1988, report DOE/EIA-0478(88), U.S. Department of Energy, Energy Information Administration, Office of Coal, Nuclear, Electric and Alternate Fuels.

EIA, 1991. Electric Power Annual, report DOE/EIA-0348(89), U.S. Department of Energy, Energy Information Administration, Office of Coal, Nuclear, Electric and Alternate Fuels.

Energetics, Inc., 1990, Proposed Air Toxics Legislation: Potential Cost to U.S. Energy Industries, final report Columbia, Md., prepared for U.S. Department of Energy, Office of Environmental Analysis, July 17.

Environment Reporter, 1990, Study Says Benzene, Other VOC Emissions at Alyeska Termintal Highter than First Thought, p. 1283, The Bureau of National Affairs, Inc., Washington, D.C., Nov. 9.

Environment Reporter, 1991, Airborne Particulates Greatly Contribute to About 60,000 Deaths Annually, Study Says, 22(3):131, The Bureau of Nationai Affairs, Inc., Washington, D.C., May 17.

EPA, 1984, Sulfur Oxides Emissions from Fluid Catalytic Cracking Unit Regenerators - Background Information for Proposed Standards, report EPA-450/3-82-013a, Office of Air Quality Planning and Standards, Research Triangle Park, N.C.

EPA, 1986, U.S. EPA Handbook: Control Technologies for Hazardous Air Pollutants, report EPA625/6-86-014, U.S. Environmental Protection Agency, Sept.

EPA, 1987, National Emission Standards for Hazardous Air Pollutants; Coke Oven Emissions from WetCoul Charged By-Product Coke Oven Batteries, U.S. Environmental Protection Agency, Federal Register, 52(78):13586-13604, April 23.

EPA, 1988, Chromium Emissions from Industrial Process Cooling Towers, draft background information document, chapters 3 through 8, U.S. Environmental Protection Agency, Office of Air Quality Planning and Standards, Research Triangle Park, N.C., Aug. 31.

EPA, 1989a, Alternative Control Technology Document - Halogenated Solvent Cleaners, report EPA450/3-89-030, U.S. Environental Protection Agency, Office of Air Quality Planning and Standards, Research Triangle Park, N.C., Aug.

EPA, 1989b, The Toxics-Release Inventory (TRI) - A National Perspective, 1987, report EPA 560/489-005, 2nd printing, U.S. Environmental Protection Agency, Office of Toxic Substances, Economics and Technology Division, Washington, D.C., June.

EPA, 1989C, Estimating Air Toxics Emission from Coal and Oil Combustion Sources, report EPA450/2-89-001, U.S. Environmental Protection Agency, Office of Air Quality Planning and Standards, Research Triangle Park, N.C., April.

EPA, 1989d, The 1985 NAPAP Emissions Inventory (Version 2); Development of the Annuui Data und Modelers' Tapes, report EPA-600/7-89-012a, U.S. Environmental Protection Agency, Air and Energy Engineering Research Laboratory, Research Triangle Park, N.C., Nov. 
EPA, 1989e, Toxic Air Pollutant/Source Crosswalk: A Screening Tool for Locnting Possible Sources Emitting Toxic Air Pollutants, Second Edition, report EPA-450/2-89-017, U.S. Environmental Protection Agency, Office of Air Quality Planning and Standards, Research Triangle Park, N.C., Dec.

EPA, 1989f, Environmental Impact Statement, NESHAPS for Radionuclides: Background Information Document - Volume 2, report EPA/520/1-89-006-1, U.S. Environmental Protection Agency, Office of Radiation Programs, Sept.

EPA, 1990a, Documentation for Developing the Source Category List, preliminary draft, U.S. Environmental Protection Agency, Office of Air Quality Planning arid Standards, Research Triangle Park, N.C., Dec. 14.

EPA, 1990b, Air Emissions Species Manual, Volume II: Particulate Matter Species Profiles, report EPA-450/2-90-001b, U.S. Environmental Protection Agency, Office of Air Quality Planning and Standards, Research Triangle Park, N.C., Jan.

EPA, 1991a, National Emission Standards for Hazardous Air Pollutants for Source Categories, U.S. Environmental Protection Agency, Code of Federal Regulations, Title 40, Part 63, pp. 6550-6560.

EPA, 1991b, Preliminary Draft List of Categories and Subcategories under Section 112 of the Clean Air Act, U.S. Environmental Protection Agency, Federal Register, 56(120):28548-28557, June 21.

EPA 1991c, National Emission Standards for Hazardous Air Pollutants, U.S. Environmental Protection Agency, Federal Register, 56(150):37196, Aug. 5.

Hodges, R.E., 1991, Recommendations Regarding Proposed E.P.A. Marine Vapor Control Regulations, in Minutes of Meeting: January 29-31, 1991, National Air Pollution Control Techniques Advisory Committee, U.S. Environmental Protection Agency, Research Triangle Park, N.C., pp. 539-543.

Johnston, M.G., 1991, Municipal Waste Combustors: Status Report on the Development of Proposed Standards for Units with Capacity Greater Than 250 Tons per Day, in Minutes of Meeting: January 29-31, 1991, National Air Pollution Control Techniques Advisory Committee, U.S. Environmental Protection Agency, Research Triangle Park, N.C., pp. 373-392.

J.R. Donnelly Davy Environmental, 1990, Design Considerations for MSW Incinerator APC System Retrofit, in Minutes of Meeting: January 29-31, 1991, National Air Pollution Control Techniques Advisory Committee, U.S. Environmental Protection Agency, Research Triangle Park, N.C., Jan. 31 .

Lagas, J.A., et al., 1989, Claus Process Gets Extra Boost, Hydrocarbon Processing, April.

Lillienthal, N., 1990, A Special Report: Air Toxics in Our Air, 1(1), Inform, Inc., New York, N.Y.

Markwordt, D., 1991, Tank Vessel Standards: Background Information ant Regulatory Alternutives, EPA Presentations, Status Report, in Minutes of Meeting: January 29-31, 1991, National Air Pollution Control Techniques Advisory Committee, Research Triangle Park, N.C., pp. 513-538.

Mueller, E.A., 1989, Air Toxics Emissions: A Status Report, prepared by Intech, Inc., for the U.S. Department of Energy, Office of Environmental Analysis, Dec. 
NATICH Newsletter, 1990a, Clean Air Act Update - Air Toxics, prepared by Radian Corp., Research Triangle Park, N.C., for National Air Toxics Information Clearinghouse, U.S. Environmental Protection Agency, Research Triangle Park, N.C., pp. 7, 10, and 11, May.

NATICH Newsletter, 1990b, EPA Publishes Final Emission Standards for Comfort Cooling Totvers, prepared by Radian Corp., Research Triangle Park, N.C., for National Air Toxics Information Clearinghouse, U.S. Environmental Protection Agency, Research Triangle Park, N.C., Pp. 8-9, Sept.

NATICH Newsletter, 1991, Hazardous Air Pollutants -- Provisions of Title III Described, prepared by Radian Corp., Research Triangle Park, N.C., for National Air Toxics Clearinghouse, U.S. Environmental Protection Agency, Research Triangle Park, N.C., p. 2-7, March.

Ozkaynak, H., et al., 1987, Source and Emission Rutes of Organic Chemical Vapors in Homes and Buildings, paper presented at the Fourth International Conference on Indoor Air Quality and Climate, West Berlin, Aug.

Poje, G., and D. Horowitz, 1990, Phantom Reductions: Tracking Toxic Trends, report by National Wildlife Federation, as presented in Clean Air Report, p. 21, Sept. 13.

Ralotf, J., 1991, Mercurial Risks from Acid's Reign, Science News, 139:152-156, March 9.

Rathje, B., 1991, The Past Imperfect Life on Incinerators, Garbage: Practical Journal of the Environment No. 3, p. 47.

Robinson, R.H., 1991, EPA's New Strategy for Pollution Prevention: What Does This Voluntary Program Offer Industry? Environment Reporter, p. 245. The Bureau of National Affairs, Inc., Washington, D.C., May 24.

Rubin, E.S., D. Delleney, and W. Chow, 1989, A Probabilistic Assessment Model for Power Plant Chemical Substances, paper presented at 51st American Power Conference, Chicago, April.

Rubin, E.S., J.S. Salmento, and W. Chow, 1990, Chemical Characterization of Potver Plant Waste Streams, paper presented at 83 rd Annual Meeting of the Air and Waste Management Association, Pittsburgh, June; also paper 90-37.1, Electric Power Research Institute, Palo Alto, Calif.

Schneider, K., 1991, Pollution from Toxic Chemicals Shous Decline in U.S. since 1987, New York Times, pp. A1 and A10, May 26.

Shobert, H.H., 1987, Coal, The Energy Source of the Past and Future, American Chemical Society, Washington, D.C.

Smith, J.M., 1987, Trace Elements from Coal Combustion: Emissions, report [EACR/01, International Energy Agency, Coal Research, London, June.

Stuntz, L., 1991, personal communication from L. Stuntz, Deputy Under Secretary for Policy, Planning and Analysis, U.S. Department of Energy, to W. Rosenberg, Assistant Administrator for Air and Radiation, U.S. Environmental Protection Agency, Feb. 14. 
Sussman, D.B., 1991, Testimony before the National Air Pollution Control Techniques Advisory Committee, in Minutes of Meeting: January 29-31, 1991, U.S. Environmental Protection Agency, Research Triangle Park, N.C., pp. 415-442.

U.S. Department of Commerce, 1988, Survey of Current Business, Bureau of Economic Analysis.

Union Electric Company, 1982, Technical Evaluation of Proposed Plans to Incinerate PCB/Waste Oil Blinds in a High Efficiency Boiler, Environmental Services Department, St. Louis, April.

Yepsen, G., and T. Witoshkin, 1991, Refiners Have Options to Deal with Reformulated Gasoline, Oil and Gas Journal, Apr. 8. 


\section{BIBLIOGRAPHY}

Anderson, R.C., T.J. Lareau, and R.D. Wollstadt, 1988, The Economics of Gasoline Ethanol Blends, research paper 045, American Petroleum Institute, Washington, D.C., Nov.

Blaikley, D.R., 1979, Pollution Occurring during Exploration and Production on Land and Sea, in The Prevention of Pollution, J. Wardly-Smith (ed.), Halsted Press, New York, N.Y.

Cannon, R.E., 1990, Environment and Marketplace Forcing Major Changes in Gas Processing, Oil and Gas Journal, pp. 47-49, July 9.

Chow, W., 1989, Improving Laboratory QA/QC for Regulatory Compliance, ECS Update, No. 16, pp. 7-9, Electric Power Research Institute, Environmental Control Systems Department, Palo Alto, Calif., fall.

Chow, W., and M. Miller, 1988, Controlling Toxic/Hazardous Substances: An EPRI RED Strategy, paper presented at the 50th Annual Meeting of the American Power Conference, Chicago, April.

Chow, W., et al., 1990, Managing Air Toxics, presented at the 83rd Annual Air and Waste Management Association Meeting, Pittsburgh, June; also paper 90.108.1, Electric Power Research Institute, Palo Alto, Calif.

Cleàn Air Report, 1990, p. 12, Aug. 16.

Clean Air Report, 1991, All Northeast States Ready to Opt into Reformulated Gasoline Program, p. 3, April 25.

Clean Air Report, 1991, Refiners Way of Making Capital Expenditures with Patential EPA Waiver, p. 5, May 23.

Crow, P., 1990, U.S. Industry Refighting Battles on Clean Air Act, Oil and Gas Journal, pp. 15-18, July 23.

Dougher, R.S., and R.O. Jones, 1990, Gasoline Distribution and Service Station Margins: An Assessment of EPA Assumptions and Implications for Methanol, research paper 055, American Petroleum Institute, Washington D.C., Sept.

EIA, 1988, International Energy Annual 1987, DOE/EIA-0219(87), U.S. Department of Energy, Energy Information Administration.

EIA, 1989, International Energy Outlook 1989: Projections to 2000, DOE/EIA-0484(89), U.S. Department of Energy, Energy Information Administration, Office of Energy Markets and End Use.

Environmental Update, 1990, Further Utility Tests of Air Toxic Models, p. 9, Dec. 
Environment Reporter, 1990, After One-Month Deadlock, Staff Agrees on Tailpipe Emissions, Fuels, p. 1139, The Bureau of National Affairs, Inc., Washington, D.C., Oct. 12.

EPA, 1989, Assessing Multiple Pollutant Multiple Source Cancer Risks from Urban Air Toxics, report EPA-450/2-89-010, U.S. Environmental Protectior. Agency, Office of Air Quality Planning and Standards, Research Triangle Park, N.C., April.

EPRI, 1991, The Question of Airborne Toxics, EPRI Joumal, pp. 5-13, Electric Power Research Institute, Palo Alto, Calif., March.

Fields, J., 1990, House Clean Air Act Debate, testimony by Representative J. Fields (R-TX) on Oct. 26, as presented in Clean Air Report, p. 29, Nov. 22.

Jones, R.O., and T.J. Lareau, 1991, Meeting the Oxygenate Requirements of the 1990 Clean Air Act Amendments, research paper 058, American Petroleum Institute, Washington, D.C., June.

Jones, R.O., and T.L. Thomas, 1989, The Cost of Alcohol Fuel Mandates: Transportation, Marketing, Distribution, Fire and Safety, and Measurement, research paper 059, American Petroleum Institute, Washington, D.C., Oct.

Kut, D., and G. Hare, 1981, Waste Recycling for Energy Conservation, Wiley and Sons, Inc., New York, N.Y.

Lareau, T.J., 1989, The Economics of Alternative Fuel Use: Substituting Methanol for Gasoline, research paper 047, American Petroleum Institute, Washington, D.C., Aug.

Melia, M.T., R.S. McKibben, and B.W. Pelser, 1984, Utility FGD Survey; October 1983-September 1984, Vol. 1, prepared by PEI Associates, Inc., Cincinnati, Ohio, for.Electric Power Research Institute, Palo Alto, Calif.

NATICH Newsletter, 1990, Proposed Revisions to C.AA Outlined, prepared by Radian Corp., Research Triangle Park, N.C., for National Air Toxics Information Clearinghouse, U.S. Environmental Protection Agency, Research Triangle Park, N.C.., pp. 5 and 10, March.

Oil and Gas Journal, 1990, Nerv Shell Gasoline Biended to Reduce Air Emissions, p. 27, April 23.

Oil and Gas Journal, 1990, Clean Air Bill Advances, p. 39, May 28.

Oil and Gas Journal, 1990, Industry Split on House Clean Air Measure, p. 24, June 4.

Oil and Gas Journal, 1990, Chevron Starts Reformulated Fuels Program, p. 17, June 18.

Oil and Gas Journal, 1990, Tough Air-Quality Goals Spur Quest for Transportation Fuel Changes, p. 33-41, June 18 .

Oil and Gas Journal, 1990, Fuel Reformulations, Alternatives Cover Broad Spectrum, pp. 42-50, June 18 .

Oil and Gas Journal, 1990, Netv and Modified Processes and Catalysts Needed for Netw Fuels, pp. 5257, June 18. 
Oil and Gas Journal, 1990, GAO: Reformulation Threatens Small Refiners, p. 34, July 2.

Oil and Gas Journal, 1990, Methanol Supplies Could Be Pinched by Mid-1990s, Sept. 17.

Ruch, R.R., H.J. Gluskoter, and N.F. Shimp, 1974, Occurrence and Distribution of Potentially Volatile Trace Elements in Coal, report EPA-650/2-74-054, U.S. Environmerttal Protection Agency, Control Systems Laboratory, Research Triangle Park, N.C.

Stokes, G.M., et al., 1990, Reformulated Gasoline Will Change FCC Operations and Catalysts, Oil and Gas Journal, pp. 58-63, July.

Stump, F.D., K.T. Knapp, and W.D. Ray, 1990, Seasonal Impact of Blending Oxygenated Organics with Gasoline on Motor Vehicle Tailpipe and Evaporative Emissions, Journal of Air and Waste Management Association, 40(6):872-880, June.

Swanson, V.E., et al., 1976, Collection, Chemical Analysis and Evaluation of Coal Samples in 1975, USGA report 76-468, U.S. Department of the Interior.

Sussman, D.B., 1991, Testimony before the National Air Pollution Control Techniques Advisory Committee, in Minutes of Meeting: January 29-31, 1991, U.S. Environmental Piotection Agency, Research Triangle Park, N.C., pp. 415-442.

Temple, Barker \& Sloane, Inc, 1990, Clean Air Response: Guidebook to Strategies, final report GS7105, Electric Power Resę,rch Institute, Palo Alto, Calif., Dec.

Unzelman, G.H., 1990, Options to Meet 1990s Fuel Composition Rules Limited, Oil and Gas Journal, pp. 91-93, April 23.

U.S. Senate, 1987, Clean Air Standards Attainment Act of 1987: Report of the Committee on Environment and Public Works Together with Additional and Minority Vietus to Accompuny S. 1894.

U.S. Senate, 1989, Clean Air Act Amendments of 1989: Report of the Committee on Environment and Public Works Together with Additional and Minority Viezus to Accompany S. 1631), Report 101-228, Calendar No. 427, 101st Congress, 1st Session, p. 171, Dec. 20.

Weisskopf, M., 1990, EPA Links Diesel Fumes to Cancer, The Washington Post, p. A4, July 19.

White, D.M., et al., 1984, Correlation of Coal Properties with Environmental Control Technology Needs for Sulfur and Trace Elements, report EPA-600/7-84-066, U.S. Environmental Protection Agency, Industrial Environmental Research Laboratory, Research Triangle Park, N.C.

Williams, J.R., 1990, remarks, Coal Week International, 11(7):1, Feb. 13.

Williams, R., 1990, Reformulated Fuels Set the Stage for U.S. Supply Pinch, Price Spikes, Oil and Gas Journal, pp. 21-24, July 9.

Williams, R., 1990, Sun: Refiners Facing Market/Air Rules Crunch, Oil and Gas Journal, pp. 36-39, July 16 . 


\section{APPENDIX: \\ EMISSION CONTROL TECHNOLOGIES FOR MUNICIPAL WASTE COMBUSTORS}

The most frequently discussed emission control technologies for municipal waste combustors (MWCs) are the following:

- Electrostatic precipitators (ESPS) are devices in which flue gas flows between a series of high-voltage discharge electrodes and grounded metal plates. Negatively charged ions formed by this high-voltage field attach to particulate matter (PM) in the flue gas, causing the charged particles to migrate toward the grounded plates, whereupon the particles are ccllected. The resulting dust is later removed by rapping, washing, or some other method and collected in a hopper. Factors affecting the efficiency of ESPs include the specific collection area, leakage control, gas flow distribution, control of rapping losses, and electrical charging methods. One of the most common types of ESPs usea by MWCs is plate wire units, which use bottom-weighted or rigid wire as thie discharge electrode. This type of ESP is best suited for use with fly ash containing large amounts of small PM and high flue-gas rates. Another common type of ESP used by MWCs is flat plate units, which use flat plates rather than wire as the discharge electrode.

- Fabric filters (FFs), like ESPs, are used for particulate control and are frequently used in conjunction with acid gas controls. As the PN is collected on filter media, a particulate filter cake is formed, increasing the pressure drop across the filter. Once excessive pressure drop across the filter cake is reached, the filter is cleaned. Effectiveness depends on flue-gas and filter characteristics, including the air-to-cloth ratio (ratio of flue-gas flow to filter surface area) and the filter cleaning mechanism. The filter cake on FFs can provide secondary removal of acid gas because of the presence of unreacted sorbent. When FFs are used following acid gas controls, the U.S. Envirorumental Protection Agency (EPA) estimates that they can remove more than $99 \%$ of particulate.

- Wet scrubbing has been used for controlling acid gas emissions in the past and refers to several technologies, including spray towers, centrifu yal scrutibers, and venturi scrubbers, in which the flue gas enters the absorber, where it is contacted with enough alkaline solution to saturate the gas stream. The alkaline solution reacts with the acid gas to form salts, which are generally insoluble and may be removed by sequential clarifying, thickening, and vacuum filtering. Dewatered salts or sludges are then landfilled. No new MWCs are being built with wet scrubbers.

- Spray dryers (SDs) are the most frequently used acid gas control technology for MWCs in the United States. An SD can by used either in combination with FFs or an ESP for particulate control. (In the United States, ESP/FF combinations are more common). In spray drying, lime slurry is injected into the spray dryer, the water in the slurry evaporates to cocl the flue gas, and the 
lime reacts with acid gas to form salts that can be removed by a PM control device. The simultaneous evaporation and reaction increases the moisture and particulate content in the flue gas. Effectiveness of this technology depends on the spray dryer outlet temperature and the lime-to-acid-gas stoichiometric ratio. EPA estimates that removal efficiencies are $50-90 \%$ for $\mathrm{SO}_{2}(70 \%$ is typical) and $70-95 \%$ for $\mathrm{HCl}(90-95 \%$ is typical).

- Dry sorbent injection is another acid gas control method and refers to two different types of systems. A duct sorbent injection (DSI) system involves injection of dry alkali sorbents into flue gas downstream of the combustor outlet and upstream of the particulate control device. By lowering the acid content of the flue gas, downstream equipment can be operated at reduced temperatures while the potential for acid corrosion of this equipment is minimized. Reaction products, fly ash, and unreacted sorbent are collected with either an FF or ESP. EPA estimates that some DSI systems can achieve removal efficiencies comparable to those of SDs. Removals of $60-95 \%$ for $\mathrm{HCl}$ and $40-70 \%$ for $\mathrm{SO}_{2}$ have been reported. In addition, by combining flue-gas cooling with DSI, it may be possible to increase the potential for removing organics. DSI is more widely used than furnace sorbent injection (FSI), in which sorbent is directly injected into the furnace section of the combustor. By injecting surbent directly into the furnace, limestone can be calcined in the combustor to become more reactive, thereby allowing use of less expensive limestone as a sorbent. The injection of sorbent into the furnace rather than into a downstream duct allows additional time for mixing between the sorbent and the acid gases, resulting in possible removal of $\mathrm{SO}_{2}$ and $\mathrm{HCl}$ at lower sorbent stoichiometric ratios than with DSI.

In general, state-of-the-art combustion technology was not widespread until the early 1980s. Older units do not generally have acid gas controls and do not provide as thorough combustion as recently installed units, meaning the uncontrolled emissions from older units are generaily mor? than those for new units (with the exception of medium-size units combusting between 250 and 800 tons per day (TPD). Of the $87 \mathrm{MWC}$ mass burn units with capacities larger than 250 TPD located in facilities with capacities greater than 500 TPD, about $57 \%$ of these use SD and FFs or ESPs as air pollution devices (Sussman 1991). Of the 32 units with capacities of larger than 250 TPD located in facilities with aggregate capacities of between 250 and 1,000 TPD, about a third have SD and FFs that were part of the initial construction and were not retrofitted (Sussman 1991). Of the 55 units with capacities larger than 250 TPD in plants combusting more than 1,000 TPD, just over $40 \%$ use SD and FFs.

In establishing the best demonstrated technologies (BDTs) on which it tased its Section 111 rules in January 11, 1991, EPA deemed the most effective control method to be the $\mathrm{SD} / \mathrm{FF}$, which is capable of reducing emissions for organics, acid gases, and metals to very low levels. Only slightly less effective, according to EPA, are the SD/ESP and dry sorbent injection systems. These rules did not mandate the use of these specific technologies; they merely provided EPA with potential efficiency levels of control technologies on which to base emission limits. Sources complying with Section 111 may apply any technology of their choosing, so long as the chosen technology achieves similar levels of reductions. In the Section 111 rules, the BDTs on which EPA based specific emission recuuction standards varied according to the size and iype of facility. The BDTs were as follows: 
- Retrofit DSI onto an existing ESP for existing MWC facilities combusting less than 1,100 TPD with units combusting more than 250 TPD.

- Retrofit an SD onto an existing ESP for MWC facilities combusting more than 1,100 TPD with units combusting more than 250 TPD.

- Use SD/FF for all new facilities with units combusting more than 250 TPD.

- Apply selective noncatalytic reduction (SNCR) on all new facilities with units combusting more than 250 TPD to limit $N_{x}$ to 180 ppmv.

Industry experts remain divided with regard to the appropriate level of emission reductions achieved by MWCs. At one end of the spectrum, experts cite the far more stringent emission standards established in Europe as a reason to promulgate more stringent standards than have been promulgated or proposed in the United States thus far (see Table 2.10). At the other extreme, many experts emphasize the lack of data on the performance of MWC controls in the United States and argue that the EPA does not have sufficient evidence to conclusively determine whether or not MWCs could feasibly achieve certain proposed emission limits with available technology.

The appropriateness of a particular emission control technology depends on the degree and nature of the required emission reductions. A single technology may not always be adequate to remove different emission species, and often two or more technologies in combination must be employed. A discussion of the technology concerns associated with the required reduction, by specific emission types, follows in the next subsections.

\section{A.1 PARTICULATE MATTER}

PM is difficult to control because the particle size distribution and the concentration of the PM emissions leaving the incinerator vary widely, depending on the composition of the refuse being burned and the type and operation of the combustion process. The control of PM is essential because it also results in the control of other emission types. Strategies for controlling organic emissions, metals, and acid gas emissions are directly or indirectly related to the techniques for controlling PM emission. (Brna and Kilgroe 1990).

- ESPs are the most frequently used method to control PM.

- Other PM controls are also used (e.g., cyclone, electrified gravel beds, venturi scrubbers), but they are used infrequently on the systems that are currently installed and are not anticipated to be used frequently in future MWC systems.

- FF systems and ESPs can be used in combination to remove PM.

- FFs used in conjunction with and following acid gas controls can achieve greater than $99 \%$ PM removal. The effectiveness of FFs depends on filter and flue-gas characteristics, including the air-to-cloth ratio and the filter cleaning mechanism. 


\section{A.2 METALS}

Metalls, such as lead and cadmium, generally behave like PM in MWC flue gas. Accurdingly, PM emission controls simultaneously reduce metals significantly. Some industry experts disagree with EPA's assumption about the degree to which PM emission reductions are correlated to metal emission reductions. This controversial issue is extremely important because future Title WII limits on metals are expected to be based on whatever metal emission reductions are achieved by application of current PM limits, but if PM and metal emissions are not correctly correlated, a new PM limit could be established de facto, thereby changing the limits allready deemed sufficient. EPA ascribes a different relationshup between metals and PM than do some industry analyses.

- EPA data show that SD/FF systems can control lead to $200 \mu \mathrm{g} / \mathrm{dscm}$ and cadimium to $20 \mu \mathrm{g} / \mathrm{d}$ dscm.

- EPA data show that tacilities using FF control systems achieve very good lead/PM control; most test results yield a total removal of lead (Anderson 1991).

- EPA data show that SD/ESP systems are less effective, controlling lead to $400 \mathrm{\mu g} / \mathrm{dscm}$ and cadmium to $30 \mathrm{ig} / \mathrm{dscm}$.

- EPA data show that DSI/ESP systems can control lead to $1,000 \mu \mathrm{g} / \mathrm{dscm}$ and cadmium to $60 \mu \mathrm{g} / \mathrm{dscm}$.

- EPA's consultant report states that recently built SD/FF systems provide greater control of fine PM than do ESPs and that PM emission rates of roughly $0.010 \mathrm{~g}$ usually yield corresponding lead emission rates of $100 \mu \mathrm{g}$ or less.

- Whetlabrator Environmental Systems Inc. (WESI) rejects EPA's correlation between lead and PM levels (i.e., that lead is $300 \mu \mathrm{g}$ when PM is less than $0.010 \mathrm{~g}$ ) and maintains that EPA did not use enough data points in the $0: 010-0.015-g /$ dscf $P M$ range to calibrate the linear relationship with statistical accuracy. (WESI currently operates 11 MWC facilities in seven different states, is constructing three additional facilities, and ha:s new permits for three more facilities pending.)

- WESI claims EPA did not base PM/metal ratios on measurements taken of both species simultaneously at the same facility.

- At a WESI plant using ESP only, the calibration of expected lead levels given a $0.010-0.015-g$ PM range indicated respective lead levels between 358 and $472 \mu \mathrm{g} / \mathrm{dscm}$; a PM compliance level of $0.015 \mathrm{~g}$ may not constantly yield lead emissions below $300 \mu g$ (Anderson 1991).

- When EPA data (only those based on actual simultaneous measurements of lead and PM emissions) are combined with WESI data, lead is $811-1,231 \mu \mathrm{g}$ in cases where PM is $0.010-0.015 \mathrm{~g}$, respectively. 
- Although WESI acknowledges that a cluster of low lead/low PM data does exist, WESI maintains that this cannot necessarily be ascribed to the effectiveness of SD/ESP systems.

- WESI supports a PM standard of $0.015 \mathrm{~g}$ but conditionally concludes that at a $0.015-g$ PM standard, lead will range up to in excess of $1,200 \mu \mathrm{g}$; a $300-\mu \mathrm{g}$ lead standard has not been demonstrated to be consistently achievable (Anderson 1991).

- Combined EPA and WESI data on facilities fitted with FFs indicate that cadmium emission rates are 53.6-80 $\mu \mathrm{g}$ when PM rates are 0.010-0.015 g, respectively (Anderson 1991).

- Facilities utilizing FF control systems exhibit very good lead and PM control. However, some emission data extend well beyond the average cluster, and it is unclear whether these measurements are aberrations or part of the normal population of lead/PM measurements.

- Relatively high emission rates occurring at some facilities, however, suggest that as the database increases, the probability of wider variance in metal emission rates will also broaden.

\section{A.3 MERCURY}

Mercury $(\mathrm{Hg})$ does not behave like other metals, and its control options are therefore different. Debates about the precise way in which mercury is released from MWCs continue. Previously, it was believed that ammonia injection in an SD/FF system was capable of $75 \%$ control of mercury. However, it is now held that mercury control is related to the carbon in the fly ash leaving the combustor. On the source reduction side, proposals to separate mercurycontaining waste before combustion as a means to reduce mercury emissions were omitted in recent New Source Performance Standards (NSPS) rules because of the problems noted by EPA: elevated mercury levels in battery storage areas, potential for explosions, and potential for ingestion. EPA has concluded that there is no mercury control technology in use in the United States on which to base emission standards at this time. Most available data on mercury are based on control technologies in use in plants in Europe and Canada.

- Sodium sulfide injection systems are applied at four European facilities and one Canadian facility. Sodium sulfide solution is injected upstream of the quench chamber throu gh nozzles in the duct, where sodium sulfide is thought to react with mercury and $\mathrm{HgCl}_{2}$ in the flue gas, thus precipitating $\mathrm{HgS}$ that is collected as PM; hydrogen sulfide is off-gassed and can be vented or injected into the combustor to burn. Although aqueous sodium sulfide is corrosive, problems at these plants have not been reported thus far. Data from two facilities indicate the system is capable of reducing mercury by $75-95 \%$. Costs are estimated roughly at $\$ 1-3$ per ton of waste burned, based on vendor quotes and Canadian facility estimates (Johnston 1991). 
- Activated carbon is another duct injection technology that has been used on a full-scale basis at a Swiss mass burn plant already equipped with SD/ESP in Zurich. The activated carbon is injected upstream of the acid gas control device at rates of $30 \mathrm{mg} / \mathrm{nm}^{3}$. Data from the Swiss plant indicate that $85-93 \%$ reduction is possible. Activated carbon has also been tested at a Danish mass burn facility already equipped with an SD/FF system with similar mercury reduction results. The ability of this method to be elfective at both SD/ESP and SD/FF facilities represents a potential benefit of activate carbon systems.

- Wet scrubbing is employed at European facilities to control mercury. Wet scrubbing involves techniques like injection of a wet solvent into a spray or packed tower following an ESP and is characterized by very low outlet temperatures resulting in the condensation of $\mathrm{Hg}$. On the basis of emission data from three facilities, EPA estimates that wet scrubbing can reduce mercury emissions by more than $90 \%$. Current emission data are based on the use of lime for the neutralization of acid gas, with outlet temperatures at $150^{\circ} \mathrm{F}$.

The validity of using data from countries other than the United States is currently under debate because the waste streams vary from country to country. The mercury load in U.S. municipal solid waste (MSW) is more than twice the mercury load in European MSW (Anderson 1991). Furthermore, industry experts have complained that little is known about the conditions under which the mercury tests were conducted and that the test methodology used was different than that used in the United States (Burton 1990). The lack of consistent test method applications in different laboratories may distort mercury concentration measurements (Anderson 1991). There are weaknesses in the data gathered for each of the aforementioned mercury control technologies:

- Sodium sulfide as an additive to sorbent or duct injection systems results in the creation of mercuric sulfide, and systems equipped with ESPs have not demonstrated the ability to effectively capture small particles (Burton 1990).

- Activated carbon injection has been applied only in a few European plants. Test results reported by Joy Technologies for three MWCs in Europe contradict the theory that lower SDA outlet temperatures result in lower mercury emissions. Some data from the Amager facility indicates that the addition of carbon does not necessarily result in lower mercury emissions, that the use of activated carbon results in a small amount of absorbed mercury on an activated carbon particle, and that systems equipped with ESPs without dry scrubbers do not have a demonstrated ability to effectively capture these particles of low resistivity.

- Wet scrubbing data were provided to EPA by only one vendor source.

EPA discussions of proposed rules state that a lime SD/FF system could achieve a $70 \%$ removal rate and a lime DSI/ESP system could achieve a 30\% removal rate. However, these results are inconsistent with mercury control at other plants (Brna and Kilgroe 1990). 


\section{A.4 ACID GAS}

The acid gas controls used most frequently include wet scrubbers, dry sorbent injection, and spray drying. All three of these technologies are anticipated to be used on future MWC systems.

- Spray drying, wherein lime slurry is injected into the SD and reacts with acid gases to form salts, is the most frequently used system in the United States.

- FFs, which are frequently used in conjunction with acid gas controls, can provide secondary acid gas removal because of the presence of unreacted sorbent. SDs can be used in conjunction with $\mathrm{FFs}$ to achieve $\mathrm{SO}_{2}$ removal efficiencies of $50-90 \%$ (70\% is typical) and $\mathrm{HCl}$ removal efficiencies of $70-95 \%$ (90-95\% is typical).

- Scrubbers - either spray towers, centrifugal scrubbers, or venturi scrubbers - have also been used to control acid gases but are not being built into new MWCs.

- Dry sorbent injection technologies achieve $\mathrm{SO}_{2}$ removal efficiencies of $40-70 \%$ and $\mathrm{HCl}$ removal efficiencies of $65-95 \%$. A typical new combustor costs $\$ 50-60$ per ton; with acid gas control, these costs would be increased 10-15\%, amounting to \$12-15 per ton of waste burned (Johnston 1991).

In-fumace sorbent injection is used in several MWCs to control $\mathrm{HCl}$ and $\mathrm{SO}_{2}$. A test on a 325-TPD, mass burn waterwall unit that was equipped with an ESP averaged $\mathrm{HCl}$ and $\mathrm{SO}_{2}$ concentrations of $67 \%$ and $82 \%$, respectively, for average outlet $\mathrm{HCl}$ and $\mathrm{SO}_{2}$ concentrations of 166 and 37 ppmv with 7\% oxygen (Bma and Kilgroe 1990).

Although acid gas scrubbers are intended primarily for controlling $\mathrm{HCl}$ and $\mathrm{SO}_{2}$, they also remove organic and heavy metal pollutants, because the flue gas entering the dry scrubber has been cooled and because most of the heavy metals that were volatilized from the MSW feed during combustion are condensed onto ash or adsorbed onto the surtace of other fly ash. These particles are then removed with the PM, partly in the SD, if present, but mostly in the following FF or ESP.

\section{A.5 ORGANICS}

The removal of organics (dioxins and furans) might possibly be achieved by flue-gas cooling. Cooling has the added benefit of also possibly facilitating PM control by decreasing the effective flue-gas flow rate and reducing the resistivity of particles. EPA has not seer: a significant difference between the performance of wet and dry scrubbers, particularly with regard to dioxin and furan control, but debate surrounds this issue and it will be studied again (Porter 1991). Control of organics may be less than for dry acid gas control systems.

Good combustion practices are thought to affect organic emissions. Organic emissions may originate from (a) compounds contained in the waste that are not destroyed during combustion, (b) waste thermal decomposition products that are not completely destroyed, and 
(c) chemical reactions that occur at relatively low temperatures downstream of the combustor. Good combustion practice can maximize in-furnace destruction of organics, minimize entrairment and carry-over of the PM from the furnace, and minimize the occurrence of lowtemperature reactions that form dioxins and furans (Brna and Kilgroe 1990).

MWC facilities equipped with orly an ESP for PM control exhibit higher dioxin/furan concentrations at the outlet than at the inlet where ESP operating temperatures are higher than $450^{\circ} \mathrm{F}$, perhaps indicating that $\mathrm{PM}$ control devices can operate as reactors to generate dioxins and furans (Brna and Kilgroe 1990).

\section{A.6 NITROGEN OXIDES}

EPA considers SNCR technologies to be the BDTs for the removal of $\mathrm{NO}_{\mathrm{x}}$ from flue gas in municipal waste combustors. These technologies are currently installed on four MWCs in the United States and involve the injection of a reducing agent, either ammonia or urea, into the upper furnace to reduce $\mathrm{NO}_{\mathrm{r}}$. Although the appropriate $\mathrm{MACT}$ for $\mathrm{NO}_{\mathrm{x}}$ reductions from existing sources has yet to be determined, EPA is seriously considering requiring the retrofit of SNCR, which EPA has concluded is ". . generally not difficult, either technically or in terms of cost" (Johnston 1991).

\section{A.7 REFERENCES TO APPENDIX A}

Anderson, R.F., 1991, Comments of Wheelabrator Environmental Systems Inc. before the National Air Pollution Control Techniques Advisory Committee, in Minutes of Meeting: January 29-31, 1991, U.S. Environmental Protection Agency, Research. Triangle Park, N.C., pp. 465-511.

Brna, T.G., and J.D. Kilgroe, 1990, The Impact of Particulate Emissions Control on the Control of Other MWC Air Emissions, Joumal of the Air and Waste Management Association, 40(9):1324-1329, Sept.

Burton, B.K., 1990, letter from Burton, Institute of Resource Recovery, Washington, D.C., to F.L. Porter, U.S. Environmental Protection Agency, Oct. 19.

Johnston, M.G., 1991, Municipal Waste Combustors: Status Report on the Development of Proposed Standards for Units with Capacity Greater Than 250 Tons per Day, in Minutes of Meeting: January 29-31, 1991, National Air Pollution Control Techniques Advisory Committee, U.S. Environmental Protection Agency, Research Triangle Park, N.C., pp. 373-392.

Porter, F., 1991, comments following Municipal Waste Combustors - Status Report on the Development of Proposed Standards for Units with Capacity Greater Than 250 Tons per Day, by M.G. Johnston, in Minutes of Meeting: January 29-31, 1991, National Air Pollution Control Techniques Advisory Committee, U.S. Environmental Protection Agency, Research Triangle Park, N.C., p. 383.

Sussman, D.B., 1991, Testimony before the National Air Pollution Control Techniques Advisory Committee, in Minutes of Meeting: January 29-31, 1991, U.S. Environmental Protection Agency, Research Triangle Park, N.C., pp. 415-442. 

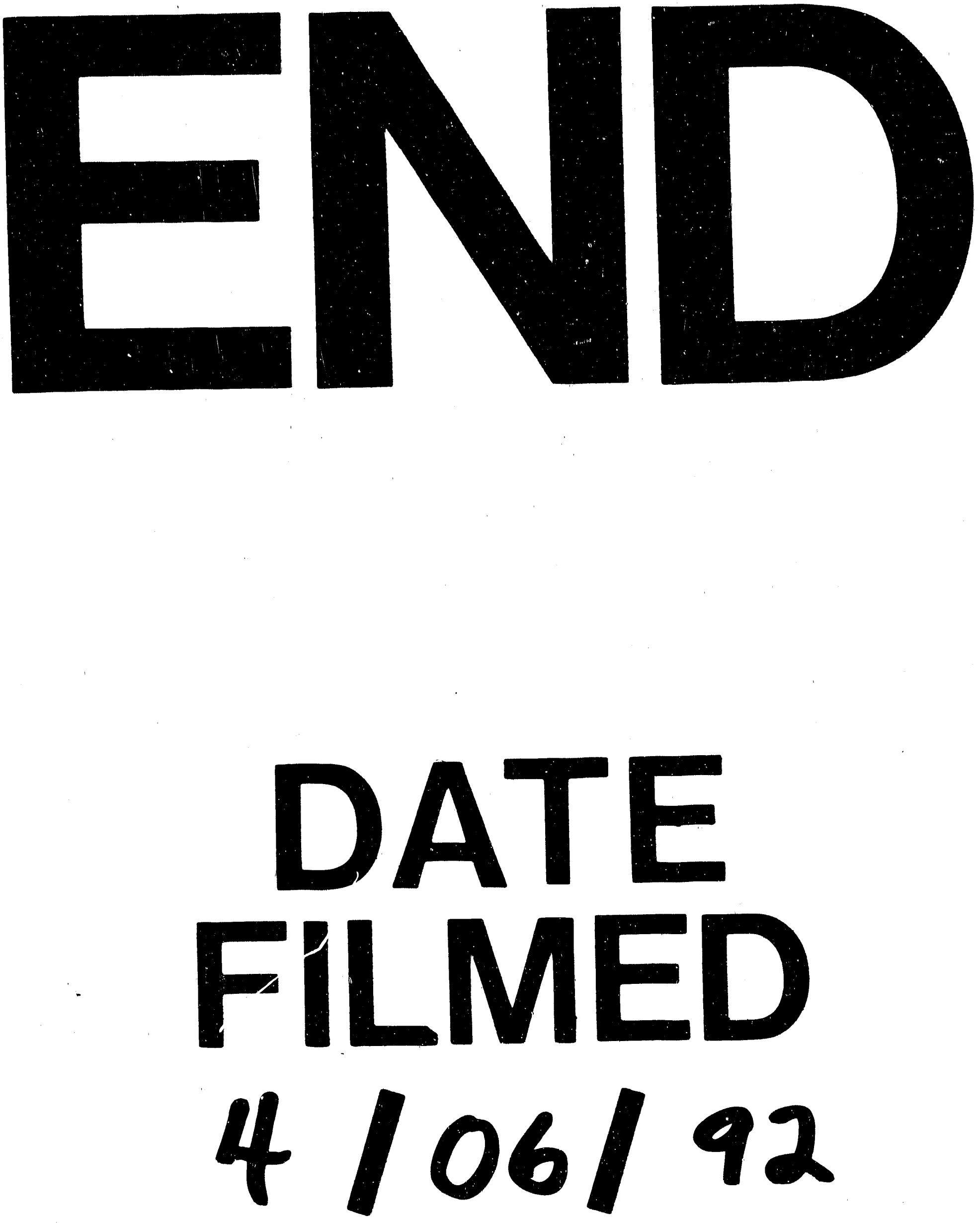

$\pm$ 
